\title{
TESTING GROUND BASED GEOPHYSICAL TECHNIQUES TO REFINE ELECTROMAGNETIC SURVEYS NORTH OF THE 300 AREA, HANFORD, WASHINGTON
}

Prepared for the U.S. Department of Energy Assistant Secretary for Environmental Management

Contractor for the U.S. Department of Energy

under Contract DE-AC06-08RL14788

CH2MIHILL

Plateau Remadiation Company

P.O. Box 1600

Richland, Washington 99352

Approved for Public Release;

Further Dissemination Unlimited 


\section{TESTING GROUND BASED GEOPHYSICAL TECHNIQUES TO REFINE ELECTROMAGNETIC SURVEYS NORTH OF THE 300 AREA, HANFORD, WASHINGTON}

\section{Date Published}

December 2010

Prepared for the U.S. Department of Energy

Assistant Secretary for Environmental Management

Contractor for the U.S. Department of Energy

under Contract DE-AC06-08RL14788

\section{CH2MHHILL}

Plateau Remediation Company

P.O. Box 1600

Richland, Washington
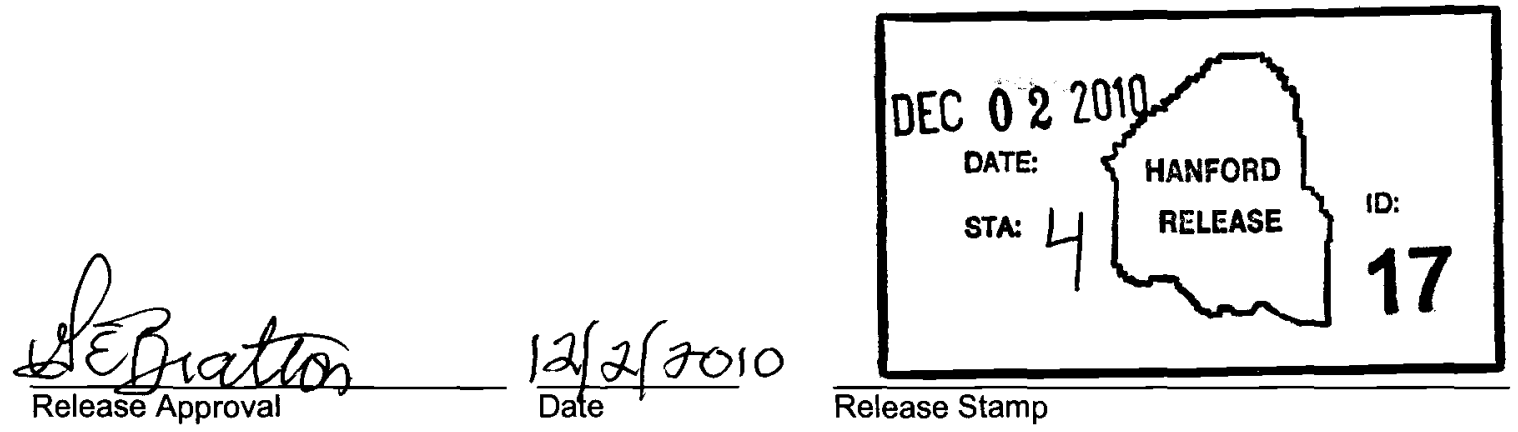

Approved for Public Release;

Further Dissemination Unlimited 


\section{TRADEMARK DISCLAIMER}

Reference herein to any specific commercial product, process, or service by trade name, trademark, manufacturer, or otherwise, does not necessarily constitute or imply its endorsement, recommendation, or favoring by the United States Government or any agency thereof or its contractors or subcontractors.

This report has been reproduced from the best available copy.

Total Pages: $\quad 63$ 


\section{Contents}

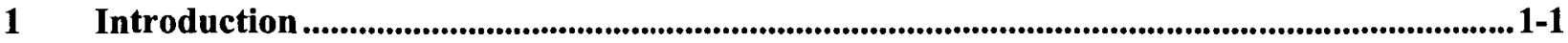

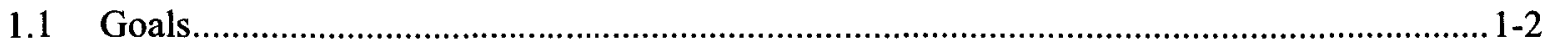

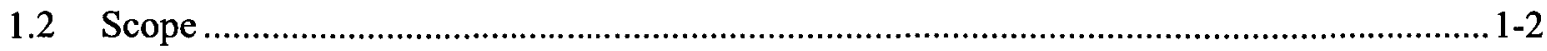

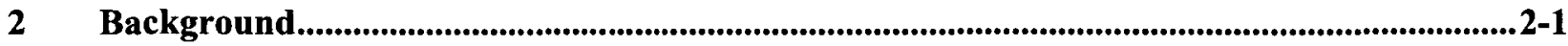

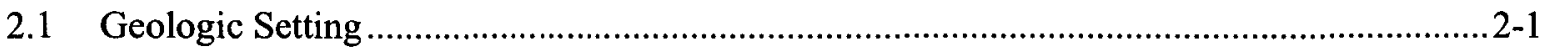

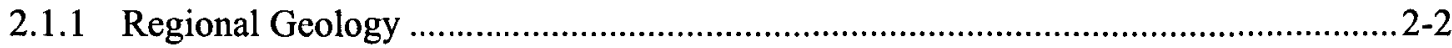

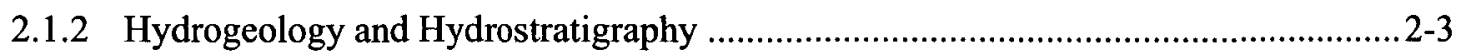

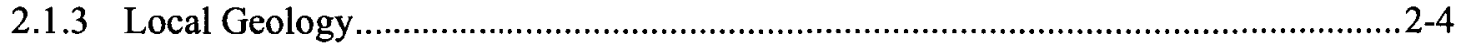

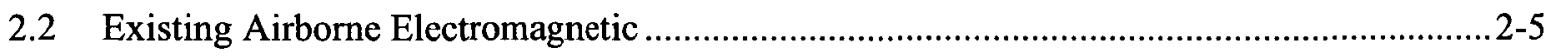

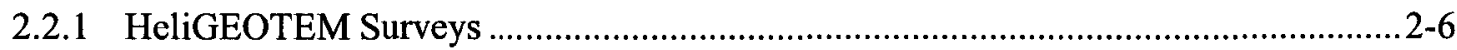

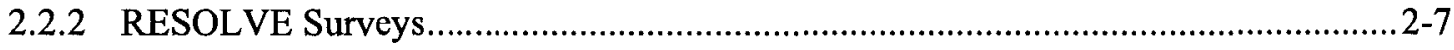

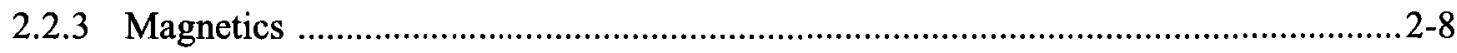

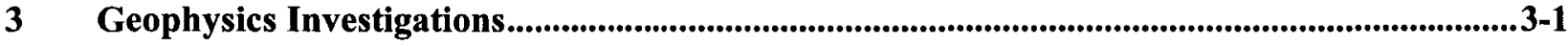

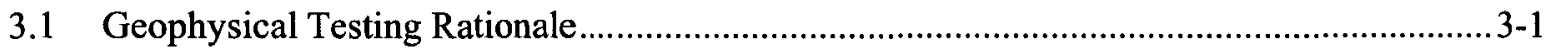

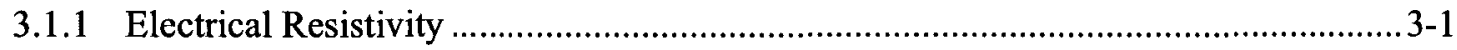

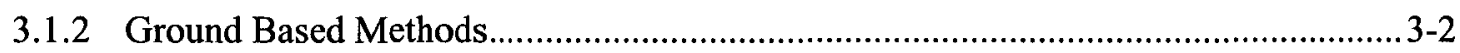

3.1.3 Test Profile Location............................................................................................ 3-2

3.2 Frequency Domain Electromagnetic Surveys (EM-34) ............................................... 3-5

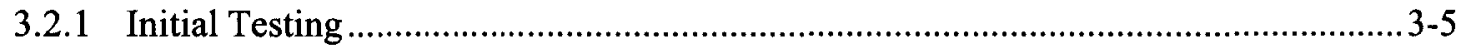

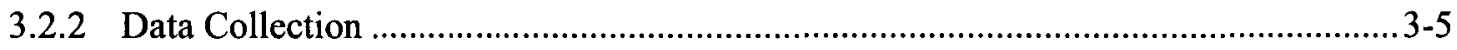

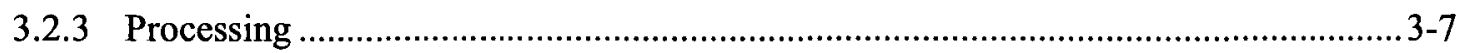

3.3 Two-Dimensional Direct Current Resistivity Profiling ...................................................... 3-8

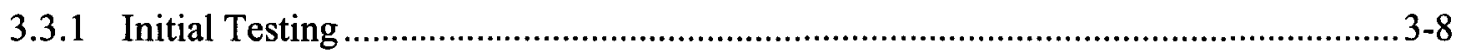

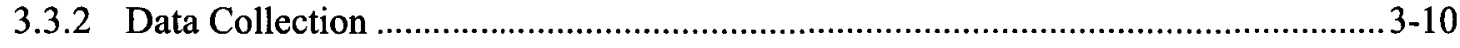

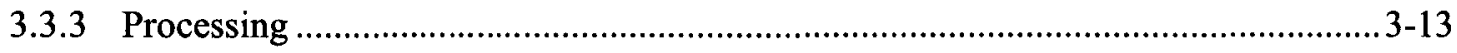

3.3.4 Constrained Model Inversion...........................................................................

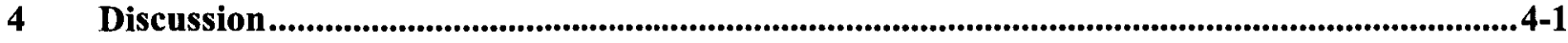

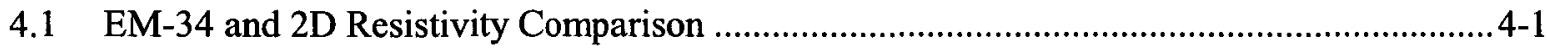

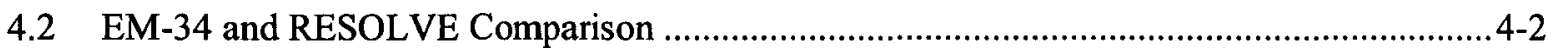

4.3 2D Resistivity and RESOLVE Comparison.......................................................................4-3

4.4 2D Resistivity and HeliGEOTEM Comparison .............................................................. 4-4

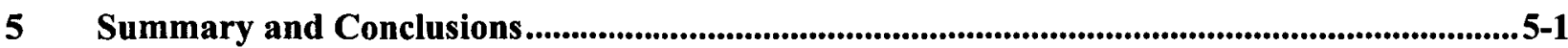

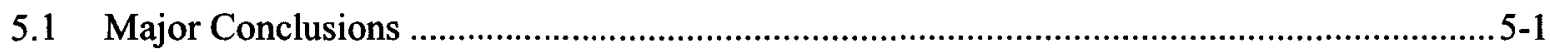

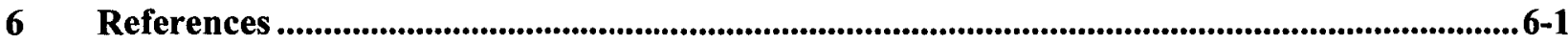




\section{Appendices}

\section{Figures}

Figure 1-1. Hanford Site and Location of Airborne Electromagnetic Surveys. $1-1$

Figure 2-1. Generalized Stratigraphy of the Hanford Site and the 200 East Area..... $. .2-1$

Figure 2-2. Water Table and Inferred Flow Directions in March 2008 (DOE/RL-2008-66) .................2-3

Figure 2-3. Geologic Cross-Section Adjacent to Ground Based Geophysical Test Site .........................2-4

Figure 2-4. Airborne Geophysical Survey Coverage, 200-PO-1 Groundwater Operable Unit ...............2-5

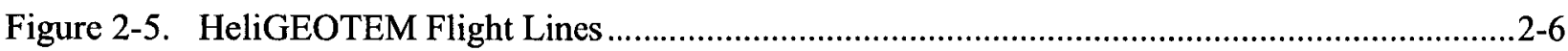

Figure 2-6. HeliGEOTEM Apparent Resistivity Depth Slices for Three Depth Zones...........................2-7

Figure 2-7. RESOLVE Flight Lines, 200-PO-1 Groundwater Operable Unit .......................................2-7

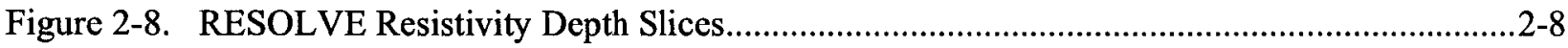

Figure 2-9. Airborne Magnetic Anomaly Maps.................................................................................. 2-9

Figure 3-1. Location of Geophysical Testing Profile..................................................................... $3-1$

Figure 3-2. RESOLVE Data Along Geophysical Test Profile ...............................................................3-3

Figure 3-3. HeliGEOTEM Data Adjacent to the Geophysical Test Profile ........................................... 3-4

Figure 3-4. AirBeo Inversion of HeliGEOTEM Profile J-J' .................................................................. 3-4

Figure 3-5. EM-34 Sensitivity to Nearby Power Line ..................................................................... 3-6

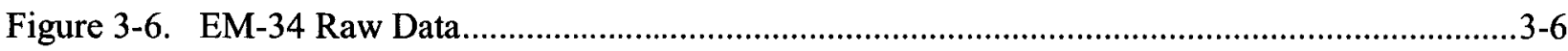

Figure 3-7. EM-34 Model Section Along Geophysical Test Profile...................................................... 3-7

Figure 3-8. Contact Resistance Tests ............................................................................................ 3-9

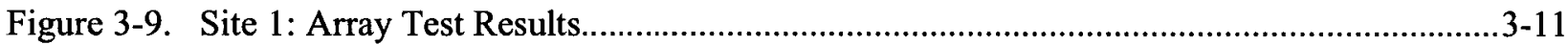

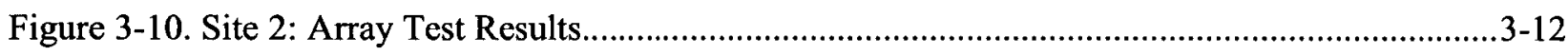

Figure 3-11. Comparison of Array Testing at North End of Profile Using RES2DINV ........................3-15

Figure 3-12. Comparison of Array Testing at North End of Profile Using EarthImager.........................3-16

Figure 3-13. Entire Production Survey RES2DINV and EarthImager Modeling Results .......................3-17

Figure 3-14. Constrained Model Inversion .................................................................................

Figure 4-1. Comparison of EM-34 and 2D Resistivity Models ........................................................ 4-1

Figure 4-2. Comparison of EM-34 and RESOLVE Models ...............................................................4-2

Figure 4-3. Comparison of 2D Resistivity and RESOLVE Data..........................................................4-4

Figure 4-4. Comparison of 2D Resistivity and HeliGEOTEM Model .................................................4-5

\section{Tables}

Table 3-1. Site 1 and Site 2 Data Loss and Noise

Table 3-2. North End and Production Survey Data Loss and Noise 


\section{Terms}

1D

2D

AEM

bgs

CHPRC

CRB

EM

ERI

FY

GPS

HGI

OU

RDI

RMI

RMS one-dimensional

two-dimensional

airborne electromagnetic

below ground surface

CH2M HILL Plateau Remediation Company

Columbia River Basalt

electromagnetic

electrical resistivity imaging

fiscal year

global positioning system

HydroGEOPHYSICS, Inc.

operable unit

resistivity-depth-image

residual magnetic intensity

root-mean-square 
SGW-47996, REV. 0 


\section{Introduction}

Airborne electromagnetic (AEM) surveys were flown during fiscal year (FY) 2008 within the 600 Area in an attempt to characterize the underlying subsurface and to aid in the closure and remediation design study goals for the 200-PO-1 Groundwater Operable Unit (OU) (Figure 1-1). The rationale for using the AEM surveys was that airborne surveys can cover large areas rapidly at relatively low costs with minimal cultural impact, and observed geo-electrical anomalies could be correlated with important subsurface geologic and hydrogeologic features. Initial interpretation of the AEM surveys indicated a tenuous correlation with the underlying geology, from which several anomalous zones likely associated with channels/erosional features incised into the Ringold units were identified near the River Corridor. Preliminary modeling resulted in a slightly improved correlation but revealed that more information was required to constrain the modeling (SGW-39674, Airborne Electromagnetic Survey Report, 200-PO-1 Groundwater Operable Unit, 600 Area, Hanford Site).

Both time-and frequency domain AEM surveys were collected with the densest coverage occurring adjacent to the Columbia River Corridor (Figure 1-1). Time domain surveys targeted deeper subsurface features (e.g., top-of-basalt) and were acquired using the HeliGEOTEM ${ }^{\circledR}$ system along north-south flight lines with a nominal $400 \mathrm{~m}(1,312 \mathrm{ft})$ spacing. The frequency domain RESOLVE system acquired electromagnetic $(E M)$ data along tighter spaced $(100 \mathrm{~m}[328 \mathrm{ft}]$ and $200 \mathrm{~m}[656 \mathrm{ft}])$ north-south profiles in the eastern fifth of the 200-PO-1 Groundwater OU (immediately adjacent to the River Corridor).

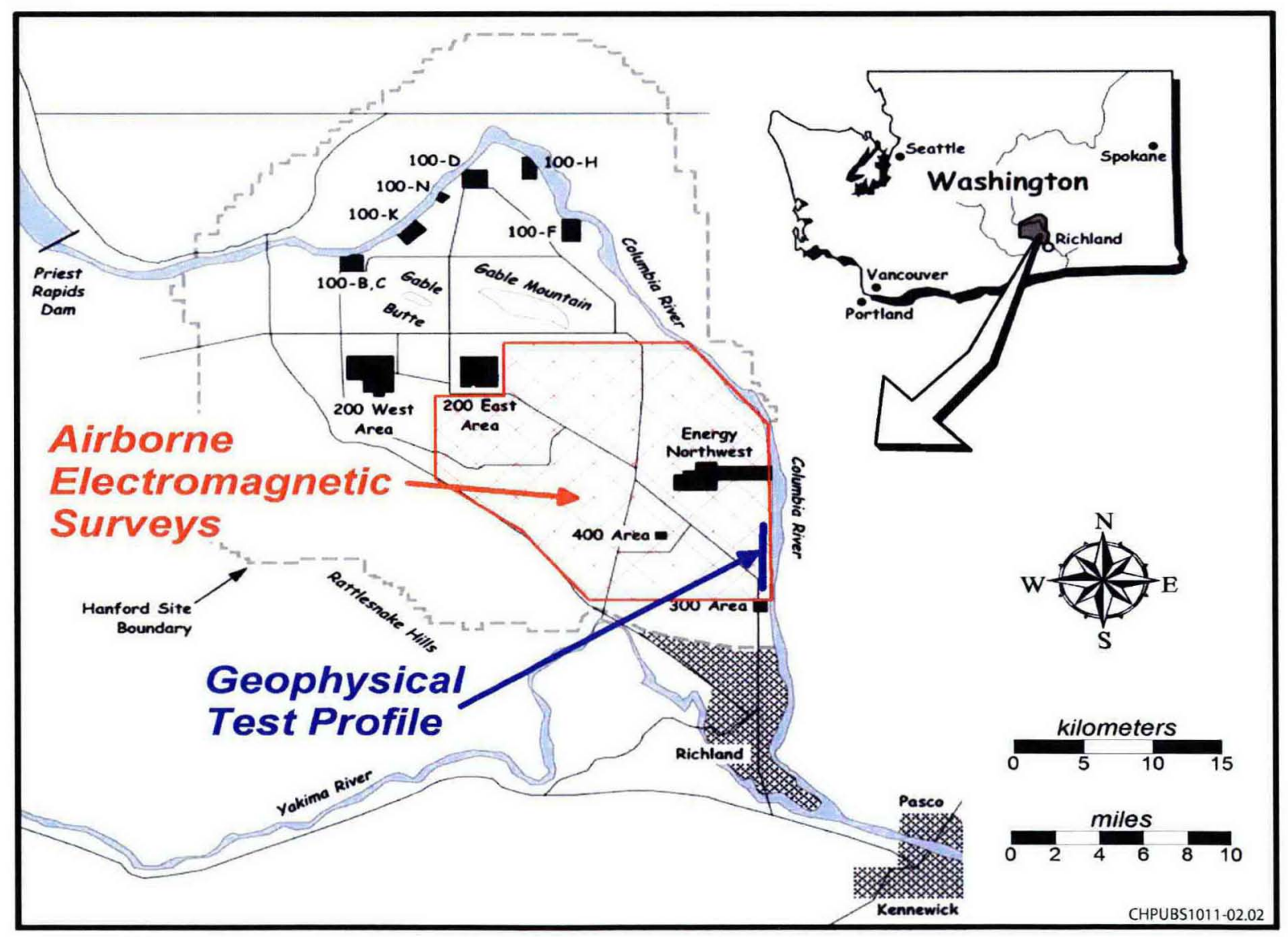

Figure 1-1. Hanford Site and Location of Airborne Electromagnetic Surveys

${ }^{\circledR}$ HeliGEOTEM is a trademark of Fugro Airborne Surveys Corp., Ottawa, Ontario, Canada. 
CH2M HILL Plateau Remediation Company (CHPRC) conducted ground based geophysical surveying along the test profile location shown in Figure 1-1. Ground based geophysical information was used to refine interpretations of existing AEM survey data. This effort aids in characterizing subsurface geologic features and ascertaining hydrogeologic conditions.

\subsection{Goals}

The overall goal of this study is to provide further quantification of the AEM survey results, using ground based geophysical methods, and to link results to the underlying geology and/or hydrogeology.

Specific goals of this project are as follows:

- Test ground based geophysical techniques for the efficacy in delineating underlying geology

- Use ground measurements to refine interpretations of AEM data

- Improve the calibration and correlation of AEM information

The potential benefits of this project are as follows:

- Develop a tool to map subsurface units at the Hanford Site in a rapid and cost effective manner

- Map groundwater pathways within the River Corridor

- Aid development of the conceptual site model

If anomalies observed in the AEM data can be correlated with subsurface geology, then the rapid scanning and non-intrusive capabilities provided by the airborne surveys can be used at the Hanford Site to screen for areas that warrant further investigation.

\subsection{Scope}

This work focused on conducting ground based geophysical surveys to correlate AEM data directly with subsurface conditions. Frequency domain EM surveying and two-dimensional (2D) resistivity profiling information were acquired along a $5.5 \mathrm{~km}(3.4 \mathrm{mi})$ profile that encompassed several AEM anomalies (see Figure 1-1). These surveys are used to help determine if geo-electrical features (or anomalies) observed in the AEM data correlate with traditionally acquired surface geophysical data and if observed geo-electrical features can be further correlated with the underlying geology. Ground based surveys were acquired in an area adjacent to existing AEM flight line coverage that has borehole control, low cultural interference, and accessibility with minimum disturbance to natural conditions. 


\section{Background}

This section explains the geological and EM data background for the Hanford Site.

\subsection{Geologic Setting}

The Hanford Site is located within the Columbia Plateau of Washington State and is underlain by basalt bedrock of the Columbia River Basalt Group bedrock, which lies near surface down to several hundred meters below ground surface (bgs). Gravel, sand, and clay deposits of the Ringold Formation overlay the basalt, and those deposits are in turn overlain by the thick (30 m [98 ft] to $120 \mathrm{~m}[394 \mathrm{ft}]$ ), unconfined, heterogeneous glacial-fluvial gravel, cobble, and sand deposits of the Cold Creek and Hanford formations. A generalized stratigraphy of the Hanford Site is shown in Figure 2-1.

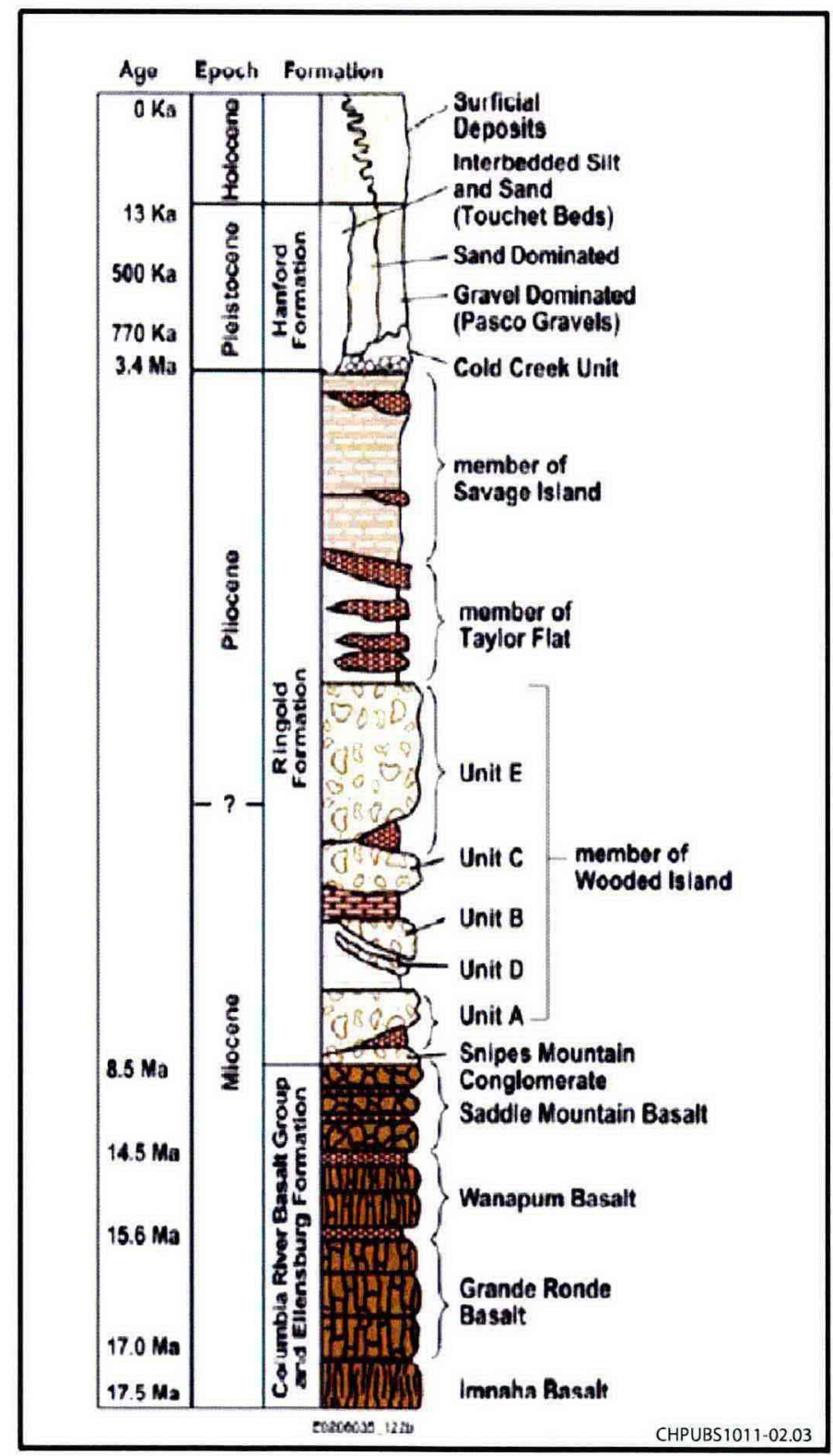

Figure 2-1. Generalized Stratigraphy of the Hanford Site and the 200 East Area 


\subsubsection{Regional Geology}

The youngest basalt flows of the Columbia River Basalt (CRB) group are the Elephant Mountain Formation, which is 10.5 million years old and ranges from $20 \mathrm{~m}(66 \mathrm{ft})$ to $30 \mathrm{~m}(98 \mathrm{ft})$ thick. The CRB group members have been folded and faulted to form Gable Mountain and Gable Butte. In addition, sub-surface anticlinal and synclinal structures, that may have controlled some of the flood flows and channel development, are present near Gable Mountain (PNNL-12261, Revised Hydrogeology for the Suprabasalt Aquifer System, 200-East Area and Vicinity, Hanford Site, Washington).

The Ringold formation is upper Miocene to Pliocene in age (10.5 to 3.9 million years ago) consisting of continental fluvial and lacustrine sediments deposited on the Elephant Mountain basalt by the ancestral Columbia and Clearwater-Salmon Rivers during late Miocene to mid-Pliocene time (BHI-00184, Miocene- to Pliocene-Aged Suprabasalt Sediments of the Hanford Site, South-Central Washington; PNNL-12261). These formations are generally unconsolidated to semi-consolidated and consist of clay, silt, fine- to coarse-grained sand, and variably cemented, granule to cobble gravel.

After deposition of the Ringold sediments, a period of regional incision occurred followed by soil development and depositions of windblown sediments during the late Pliocene to early Pleistocene. These deposits are currently termed the Cold Creek Unit and include sediments previously classified as the Plio-Pleistocene unit and pre-Missoula gravels.

Ice Age floods originating predominantly from the outflow of glacial Lake Missoula resulted in the deposition of cataclysmic flood deposits locally referred to as the Hanford Formation (DOE/RL-2002-39, Standardized Stratigraphic Nomenclature for Post-Ringold-Formation Sediments Within the Central Pasco Basin; PNNL-15237, Geology of the Integrated Disposal Facility Trench) between $1 \mathrm{Ma}$ to $12 \mathrm{Ka}$. The Hanford Formation can be divided into three dominant lithofacies consisting of gravel dominated, sand dominated, and interbedded sand and silt-dominated, all of which both vertically and laterally grade into one another.

The geologic structures formed by the basalt focused the flood energy, causing it to scour out the overlying Ringold sediments and, in some cases, eroded down to and possibly into basalt bedrock. These channels were later filled by the younger Pleistocene Hanford sands and gravels. In PNNL-12261, it is suggested that the Columbia River shifted its course to the north of Gable Mountain after the ancestral river channel became plugged with flood deposits. Erosion features associated with post-Ringold fluvial incision and Pleistocene cataclysmic flooding created a scoured and channeled surface that was later buried and is often difficult to map (PNNL-12261). Within this buried paleo-channel and scoured area, Ringold-age sediments have been reworked and/or removed and younger, pre-Missoula gravels or the Hanford formation cataclysmic flood deposits of sand and gravel lie directly on top-of-basalt. Based on PNNL-12261, the erosion seen across the 200 Area is believed to be the result of a series of erosional events that scoured out some areas and left remnant mounds of Ringold sediments. This is principally based on well log discrepancies.

These floods have both eroded channels in the substrate and deposited large quantities of poorly-sorted sands and gravels (PNNL-12261; PNNL-SA-53273, Hanford Site Vadose Zone Studies: An Overview). These lakes may have reached a depth of several hundred meters. The resulting sediments also formed desiccation cracks that were filled with finer grained sediments than the surrounding matrix.

These fine-grained sediments may act as vertical and horizontal clastic dikes that can control the movement of water and contaminants in the vadose zone and form localized confining layers such as in the lower Ringold Formation. In addition, channels cut in the basalt and Ringold formation that have been filled with sands and gravels may also control the movement of water and contaminants in the vadose zone. 


\subsubsection{Hydrogeology and Hydrostratigraphy}

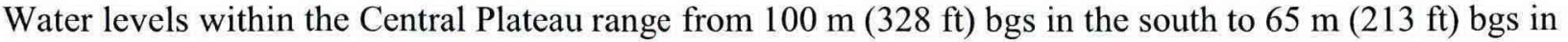

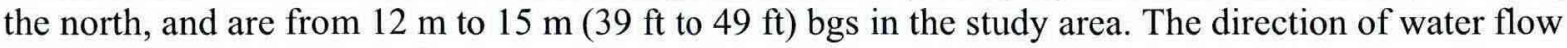
across the Hanford Site is from west to east. This is inferred from water table elevations shown in Figure 2-2 (PNNL-16346, Hanford Site Groundwater Monitoring for Fiscal Year 2006). In the area north of the 200 East Area, the groundwater generally has a shallow gradient and is moving north and west through the Gable Gap area via buried paleo-channels (PNNL-12261; DOE/RL-2008-66, Hanford Site Groundwater Monitoring for Fiscal Year 2008). Steeper groundwater gradients to the west and east are associated with lower permeability sand and gravel of the Ringold Formation at the water table, while the shallower groundwater gradients may be associated with higher permeable sand and gravel of the Hanford formation at the water table (DOE/RL-2008-66). The higher permeability may have a direct relation to how quickly contaminants could reach the Columbia River.

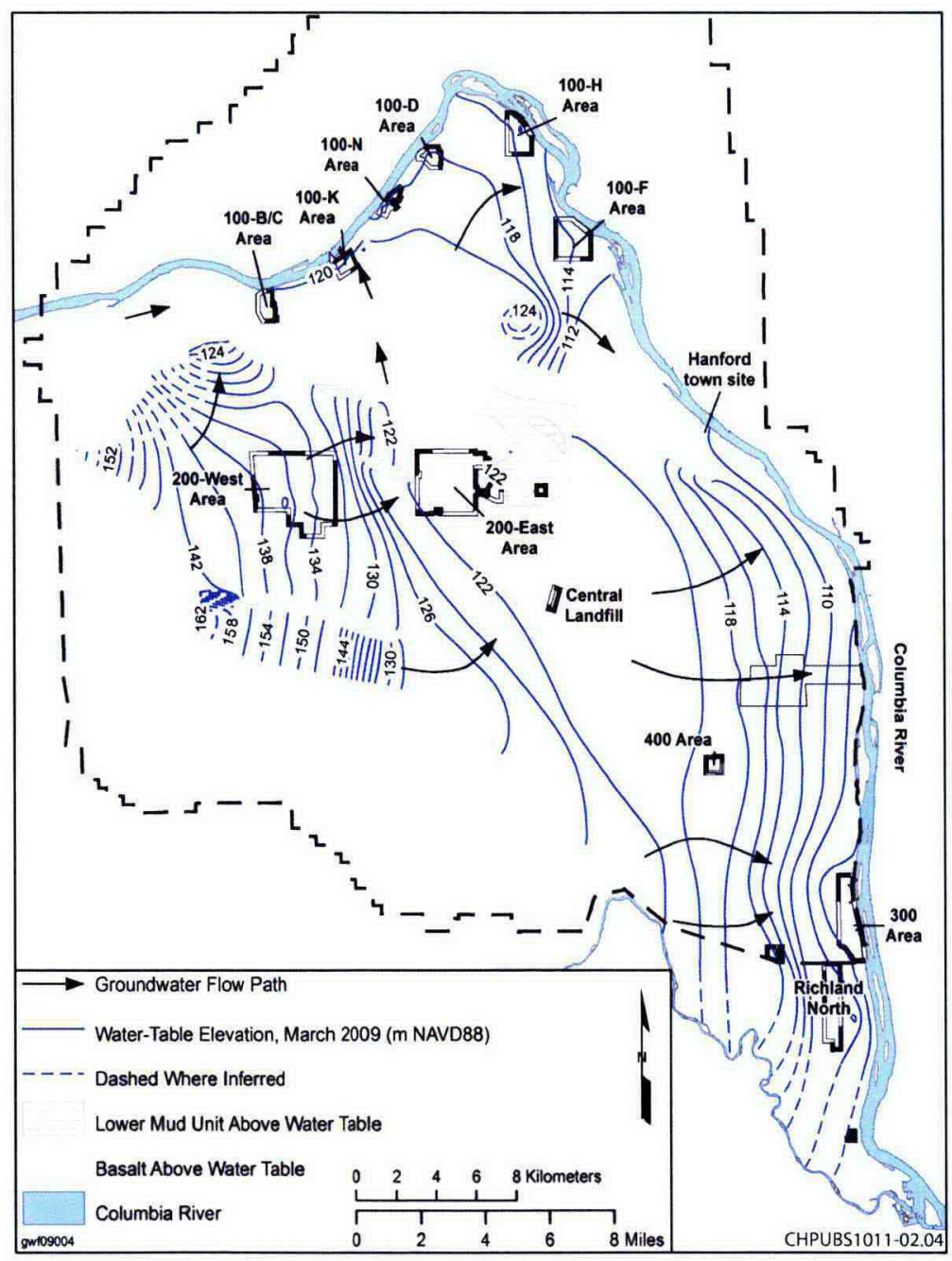

Figure 2-2. Water Table and Inferred Flow Directions in March 2008 (DOE/RL-2008-66) 
The shallowest unit is the Hanford formation. Sediments were deposited between $2.5 \mathrm{Ma}$ and $13 \mathrm{Ka}$ and are composed of relatively unconsolidated pebble-to-boulder gravel, fine-to-coarse-grained sand, and silt-to-clayey silt (PNNL-12261). The Hanford formation hydraulic conductivity values are the highest of all hydrogeologic units present and may not have the cementation characteristics of the Ringold Formation.

The Ringold Formation is composed of continental fluvial and lacustrine sediments deposited above the Elephant Mountain basalt by the ancestral Columbia and Clearwater-Salmon Rivers during late Miocene to mid-Pliocene time (PNNL-12261). The unit consists of intercalated layers of indurated to semi-indurated and/or pedogenically altered sediment including clay, silt, fine-to coarse-grained sand, and granule-to-cobble gravel. Within most of the Ringold Formation, there is a thick confining layer or lower mud composed of fluvial overbank, paleosol, and lacustrine silts and clay. This is between the Ringold Unit $A$ and Unit $C$ shown in Figure 2-1.

\subsubsection{Local Geology}

Local geologic structure near the geophysical test profile is shown in Figure 2-3 and is derived from the geologic profile (J-J') used for the 200-PO-1 investigation. Also shown are the well points used to construct the cross-section and driller's descriptions of the geologic units encountered. Gravels and sands of the Hanford formation range from $15 \mathrm{~m}(50 \mathrm{ft})$ to $23 \mathrm{~m}$ (75 ft) in thickness. Water head occurs within the Hanford units with a maximum saturated interval of about $15 \mathrm{~m}(49.2 \mathrm{ft})$ in thickness. Water head decreases about $3 \mathrm{~m}(9.8 \mathrm{ft})$ in elevation from north to south.

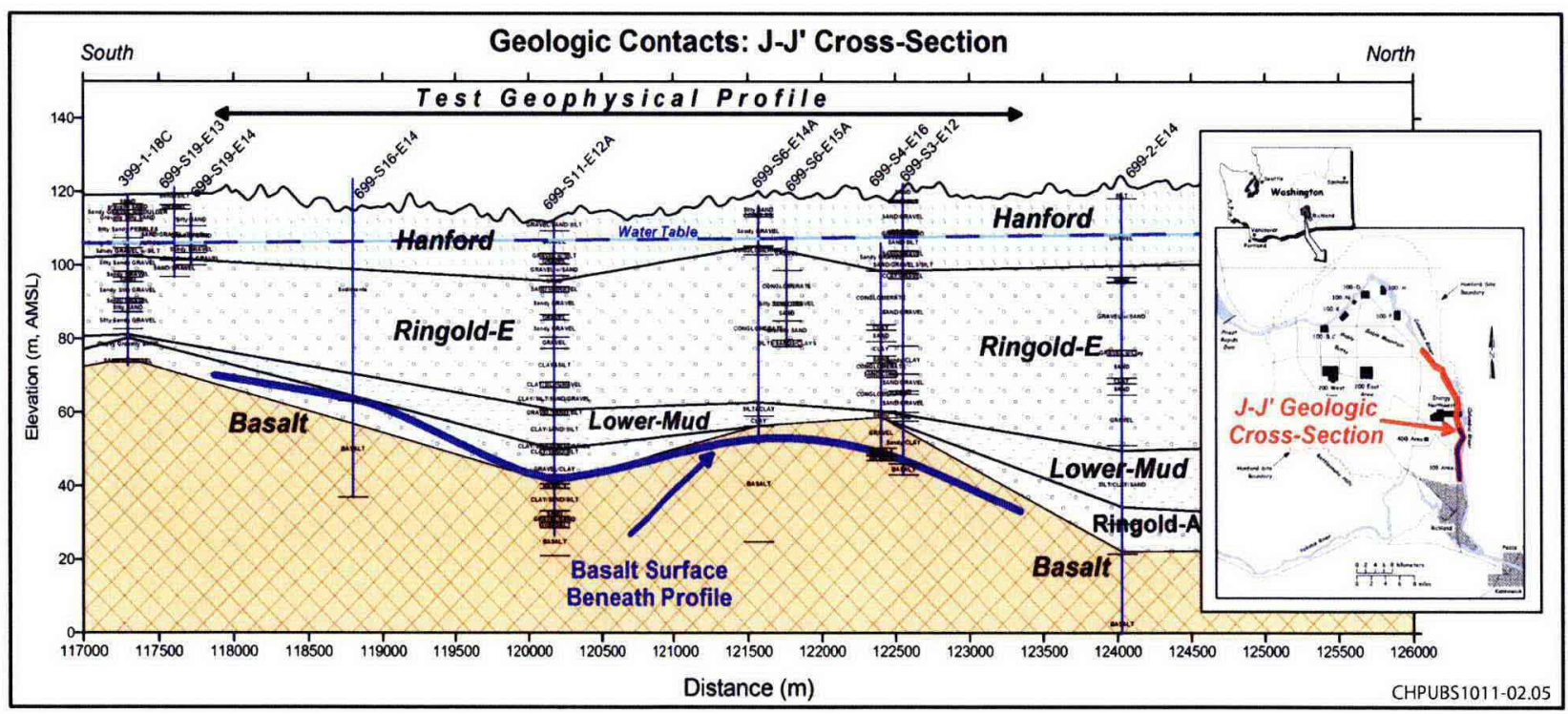

Figure 2-3. Geologic Cross-Section Adjacent to Ground Based Geophysical Test Site

The presence of the shallow water table should result in a general decrease in resistivity from unsaturated to saturated conditions. For the test profile, two geo-electrical layers should result within the Hanford sediments representing the unsaturated and saturated intervals.

Ringold units increase in thickness from about $30 \mathrm{~m}(99 \mathrm{ft})$ in the south to approximately $75 \mathrm{~m}(246 \mathrm{ft})$ in the north. The basalt surface descends in a stair step in the south with two local depressions centered at profile distance 120250 and 124000. The Ringold Lower Mud and A sub-units are interpreted to thin over the adjacent basalt highs. The Ringold Lower Mud achieves its greatest thickness of $25 \mathrm{~m}(82 \mathrm{ft})$ at the north end of the profile. 


\subsection{Existing Airborne Electromagnetic}

As part of the fiscal year (FY) 2008 phase I geophysical surveys, Fugro was contracted to collect AEM and magnetic data within the Far Field area of the 200-PO-1 Groundwater OU using a helicopter (Figure 2-4). The airborne surveys included Fugro's transient (or time domain) EM sounding HeliGEOTEM system, Fugro's multi-frequency EM sounding RESOLVE system, and a total-field magnetic survey using a cesium vapor magnetometer. RESOLVE surveys were only conducted in the eastern part of the 600 Area (Figure 2-4). The details of the methodology and initial results of these airborne surveys are published in SGW-39674, and a following vendor derived interpretation incorporated later in this report is published in SGW-47839, Interpretation of Airborne Electromagnetic and Magnetic Data in the 600 Area. Additional integration of preliminary interpretations was incorporated for SGW-42313, Geophysical Investigations: 200-PO-1 Groundwater Operable Unit. AEM and magnetic surveys measure changes in the geo-electrical and magnetic properties of the underlying soil and rock. Geo-electrical characteristics can generally be correlated to grain size, grain composition, and saturation for sedimentary materials, and to mineralogy, weathering, and clay-content for rock. Changes in the magnetic properties can be correlated to rock/sediment type and structural attitude and depend on the presence of magnetite and/or other ferro-magnetic minerals.

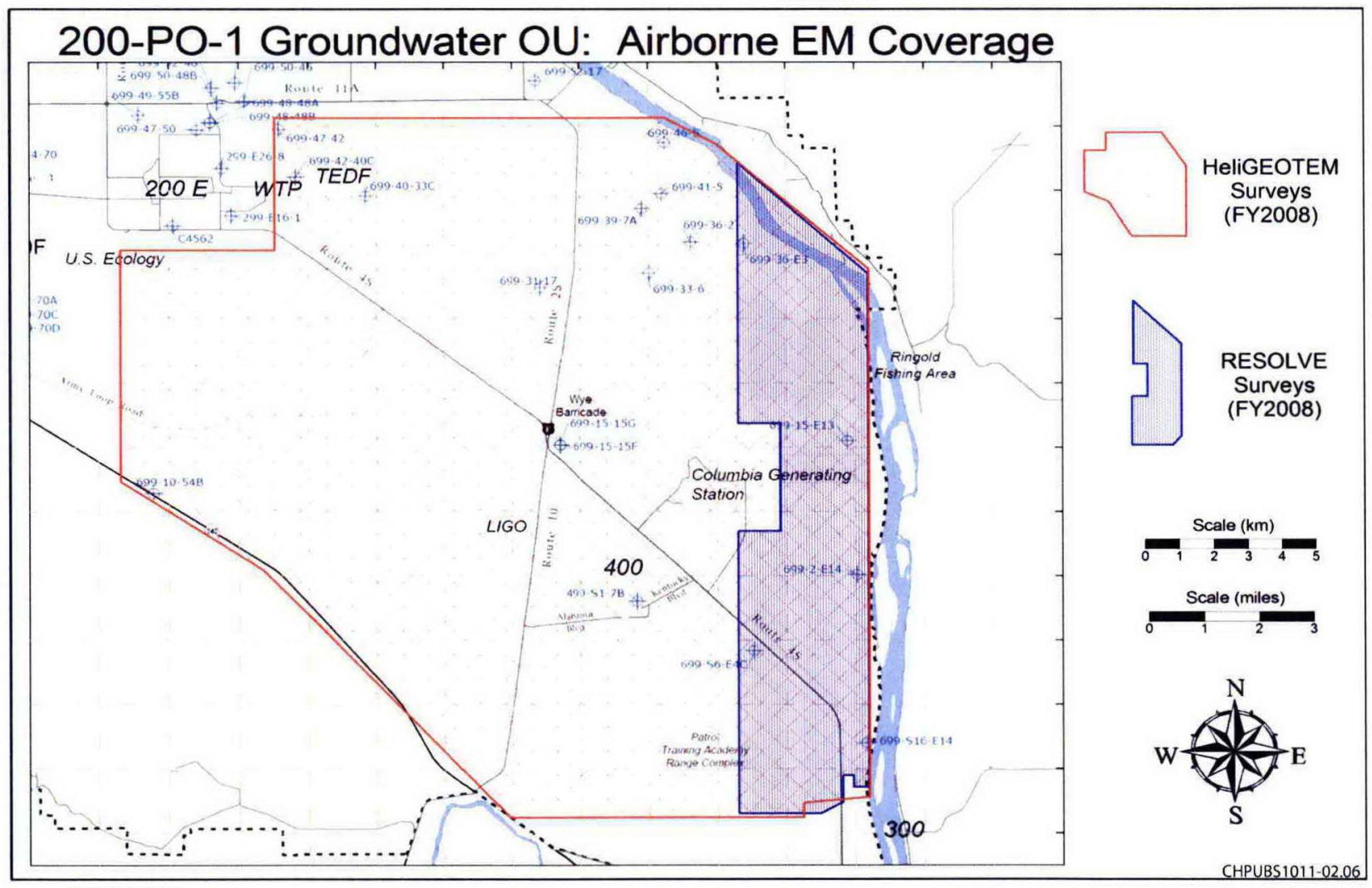

Figure 2-4. Airborne Geophysical Survey Coverage, 200-PO-1 Groundwater Operable Unit

EM surveys use a transmitter coil to induce an electrical current in the subsurface and a receiver coil to measure the strength of the secondary magnetic field generated by these currents. The strength of the secondary magnetic field is proportional to the electrical conductivity of the material through which the induce current is propagating. Two EM methods were used: time domain and frequency domain.

Time domain EM surveys measure the decay rate of the secondary magnetic field and correlate the decay rate to subsurface electrical structure. Frequency domain EM surveys also measure the strength of the 
secondary magnetic field but achieve different investigation depths by changing the frequency and coil configuration.

Magnetic surveys measure variations in the Earth's local magnetic field caused by changes in lithology, mineralogy, geologic structures, and manmade features. The magnetic anomaly results from the Earth's magnetic field inducing a secondary magnetic field, which in turn interacts and perturbs the local magnetic field. The magnetic anomaly is a complex signal with high-low anomaly pairs. Some geologic units (e.g., basalts) have a remnant magnetization where the Earth induced field locked in place when the unit cools and crystallizes.

\subsubsection{HeliGEOTEM Surveys}

Time domain HeliGEOTEM surveys were flown over the Hanford 600 Area portion of the 200-PO-1 Groundwater OU during June 19-20, 2008. A total of 55 south-to-north traverse lines were flown with a nominal spacing of $\sim 400 \mathrm{~m}$ (1,312 ft) between flight lines totaling $925 \mathrm{~km}$ ( $575 \mathrm{mi})$ for the complete survey (Figure 2-5). The HeliGEOTEM system employed a $154 \mathrm{~m}^{2}\left(505 \mathrm{ft}^{2}\right)$ area transmitter coil and a three-component receiver recording four samples per second over 20 channels (time gates). The receiver coil was maintained at a nominal height of $72 \mathrm{~m} \mathrm{(236} \mathrm{ft)} \mathrm{above} \mathrm{ground} \mathrm{level} \mathrm{with} \mathrm{the} \mathrm{transmittal} \mathrm{slung}$ $25 \mathrm{~m}(82 \mathrm{ft})$ bgs. Flight speed was 55 knots.

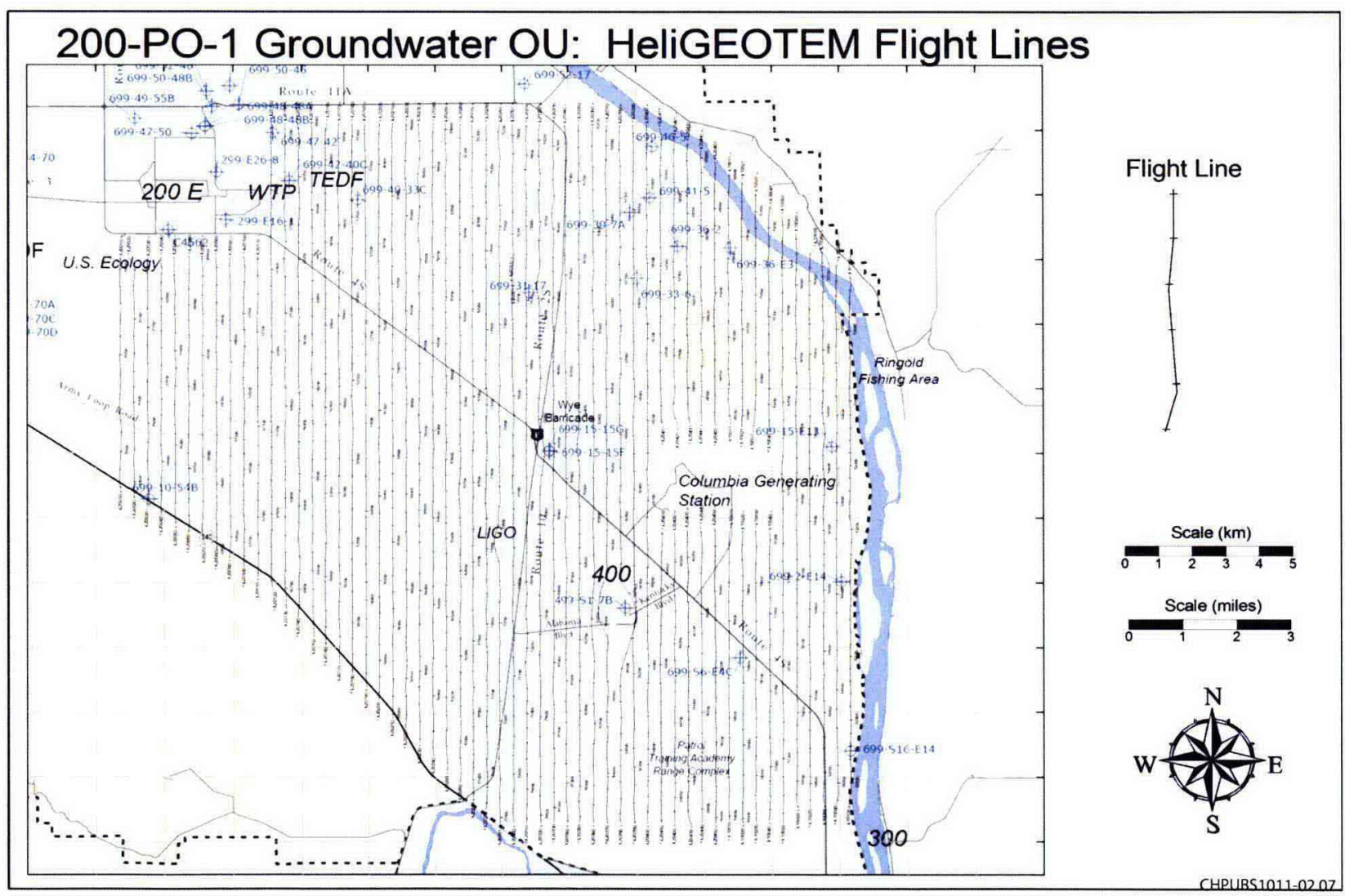

Figure 2-5. HeliGEOTEM Flight Lines

Initial processing provided by the contractor involved converting the flight line data into depth slices of electrical resistivity. A simple modeling algorithm was used to convert the EM time domain data into apparent depth and resistivity cross-sections, termed resistivity-depth-images (RDIs) by Fugro.

RDI sections were calculated from the B Field Z-coil response using an algorithm that converts the response in any measurement window (on- or off-time) into resistivity. Further details of the 
methodology, analysis, and initial results of these airborne surveys are published in SGW-39674.

Figure 2-6 shows results from three slices: shallow ( $40 \mathrm{~m}[131 \mathrm{ft}])$, middle $(\sim 100 \mathrm{~m}[328 \mathrm{ft}])$, and deep $(\sim 160 \mathrm{~m}[525 \mathrm{ft}])$ investigation depths.

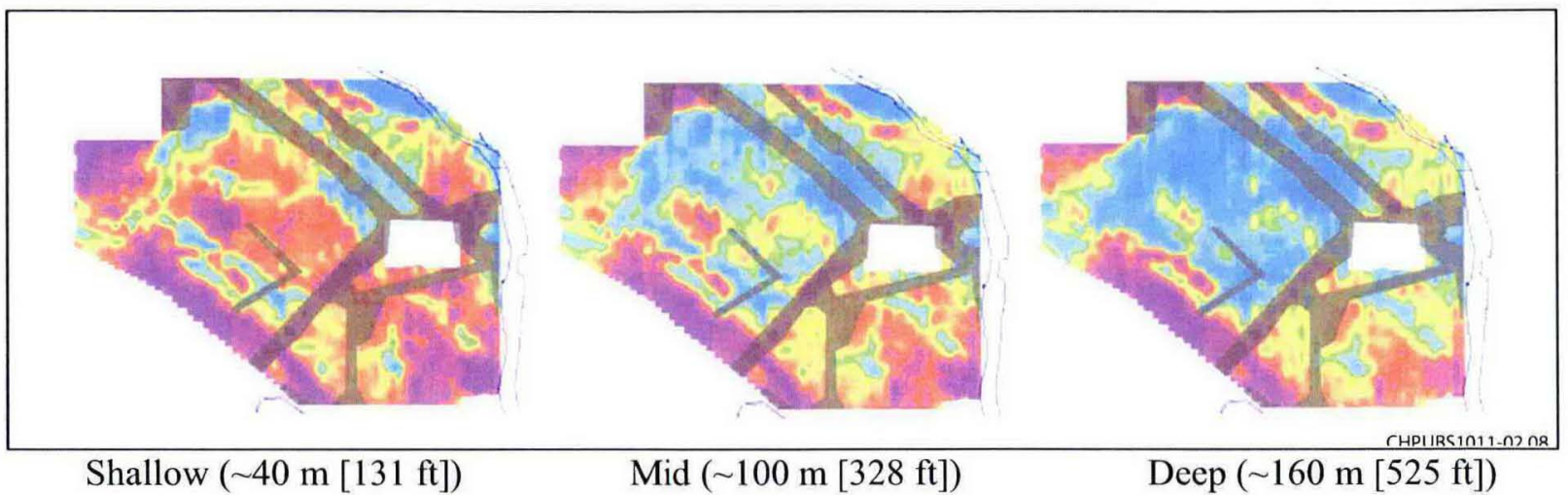

Note: Shaded regions represent zones of potential cultural interference, such as power lines and buildings. Red colors are more electrically resistive; blue colors are the more electrically conductive areas.

Figure 2-6. HeliGEOTEM Apparent Resistivity Depth Slices for Three Depth Zones

\subsubsection{RESOLVE Surveys}

The frequency domain RESOLVE system was flown over a smaller portion of the Hanford 600 Area adjacent to the Columbia River between June 29 and July 1, 2008. A total of 29 south-to-north traverse lines were flown with a nominal spacing of $\sim 200 \mathrm{~m}$ (656 ft) between flight lines, except for the seven easternmost lines where a line separation of $\sim 100 \mathrm{~m}$ (323 ft) was used (Figure 2-7). Survey coverage totaled approximately 412 line-km.

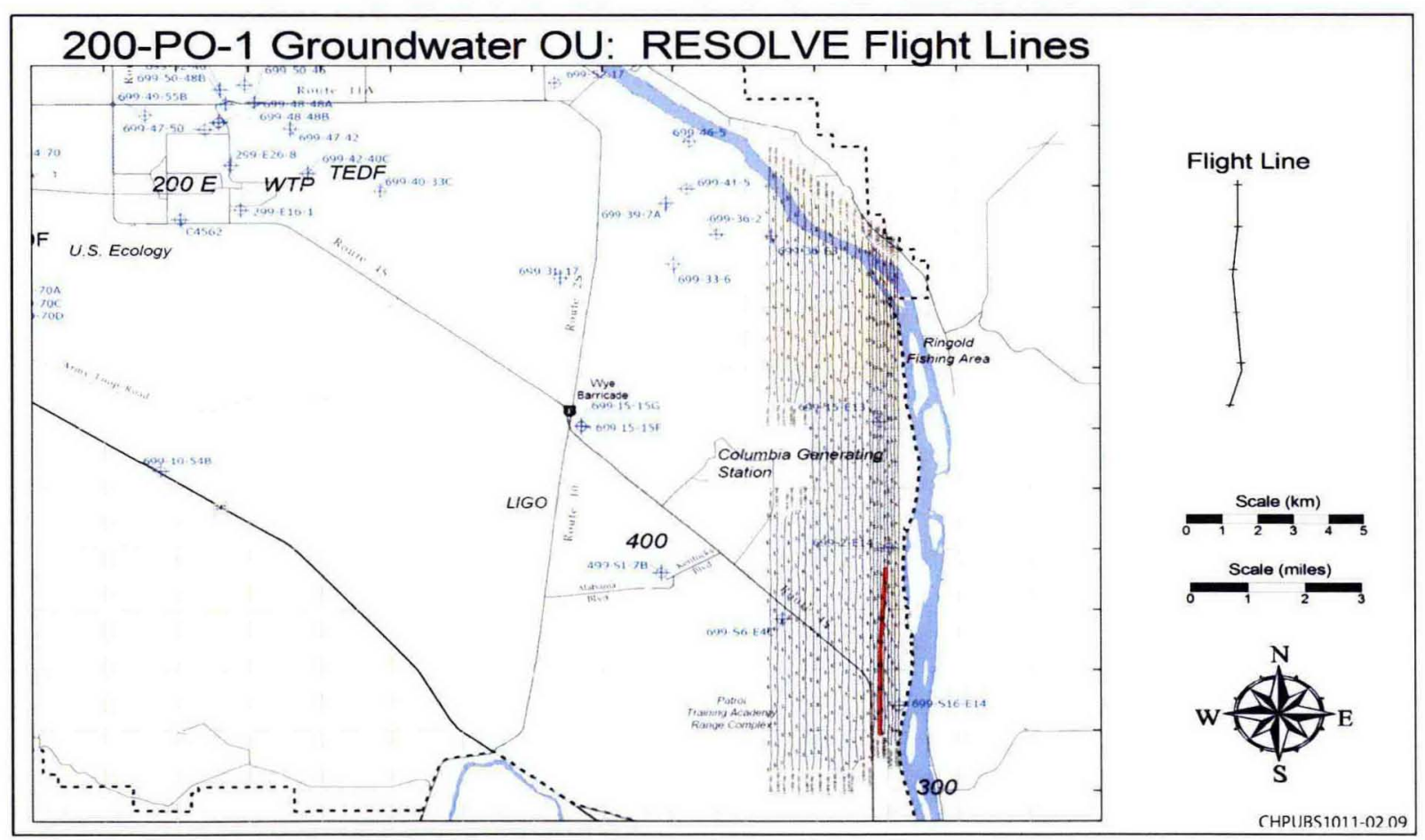

Figure 2-7. RESOLVE Flight Lines, 200-PO-1 Groundwater Operable Unit 
The RESOLVE system employed a symmetric dipole configuration operated at a nominal altitude of $30 \mathrm{~m}(98 \mathrm{ft})$ above ground level with a sample rate of 10 samples per second. Coil separation is $7.9 \mathrm{~m}$

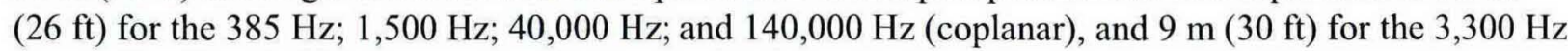
(coaxial) coil pair. The system records data on 14 channels: 6 quadrature channels, 6 in-phase channels, and 2 monitor channels.

Initial processing provided by the contractor involved converting the flight line data into depth slices of electrical resistivity. Apparent resistivities were calculated using both the in-phase and quadrature amplitudes using a pseudo-layer half-space model. The half-space model and depth of the in-phase current flow centroid were used to create apparent resistivity with depth sections (Sengpiel, 1988, "Approximate Inversion of Airborne EM Data from a Multi-Layered Ground"). Further details of the methodology, analysis, and initial results of these airborne surveys are published in SGW-39674.

Figure 2-8 shows results for the five depth slices and the digital terrain model measured during the RESOLVE survey.

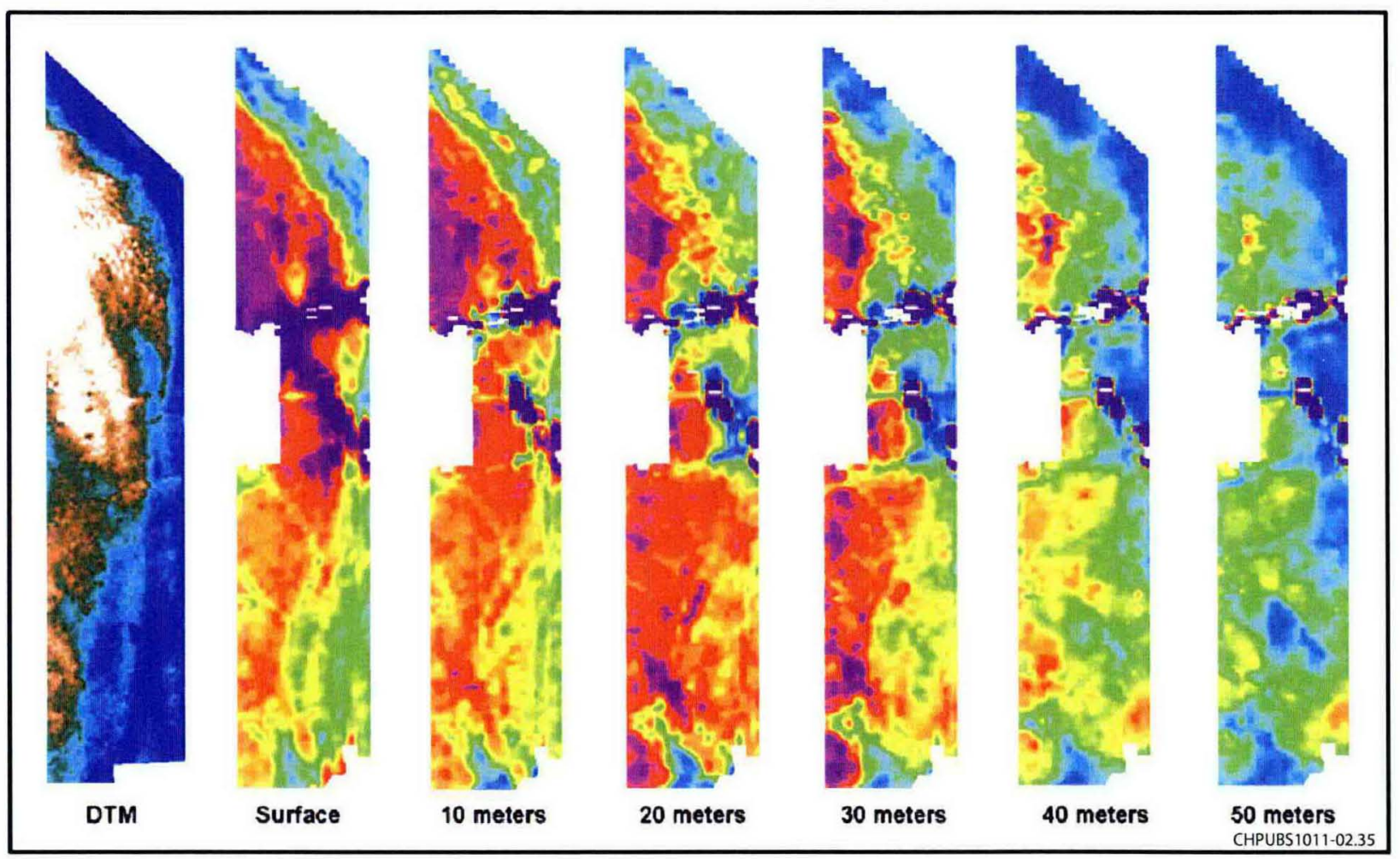

Note: Red colors are more electrically resistive; blue colors are more electrically conductive.

Figure 2-8. RESOLVE Resistivity Depth Slices

\subsubsection{Magnetics}

Total field magnetics information was acquired simultaneously with both of the AEM systems, with surveyed areas shown in Figure 2-4. A Scintrex Cesium-3 optically pumped cesium vapor magnetometer was used to measure the magnetic field at a sample rate of 10 readings per second. A second magnetometer was deployed as a base station to measure diurnal drift and recorded data at one sample per second. 
Initial processing converted the total field magnetic data into a residual magnetic intensity (RMI) by correcting for diurnal drift and subtracting a regional magnetic field calculated using the international geo-referenced magnetic field model. The RMI anomaly map should represent, in theory, localized perturbations in the Earth's magnetic field. Additional processing included calculating the first vertical derivative of the RMI in order to enhance the response of magnetic bodies within the upper $500 \mathrm{~m}$ $(1640 \mathrm{ft})$ of the subsurface. Further details of the methodology, analysis, and initial results of these airborne surveys are published in SGW-39674 and SGW-47839. The resulting magnetic anomaly maps for the residual magnetic intensity and first vertical derivative are shown in Figure 2-9.

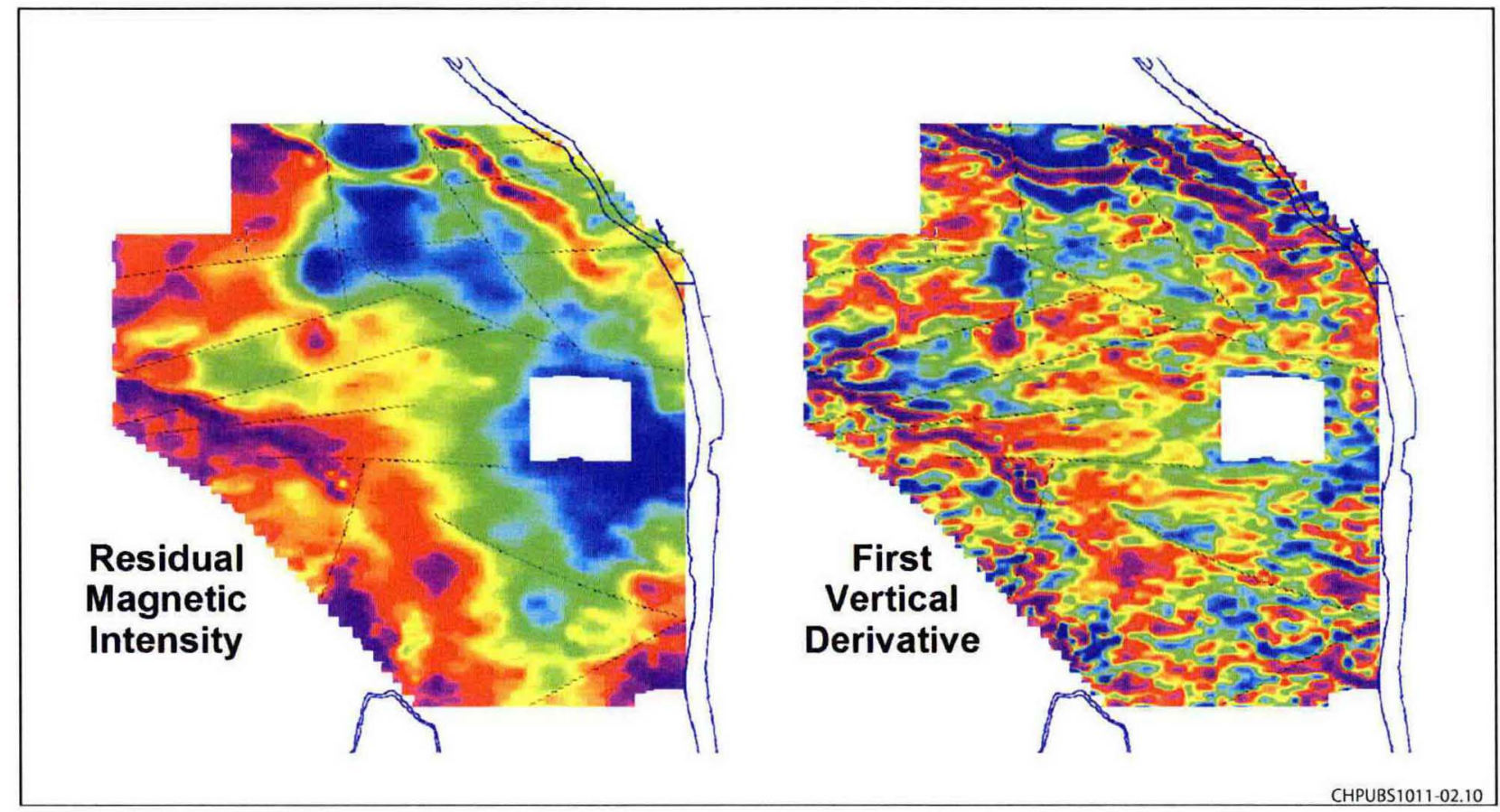

Figure 2-9. Airborne Magnetic Anomaly Maps 
SGW-47996, REV. 0 


\section{Geophysics Investigations}

This section describes the geophysics investigations including rationale, methodology, and processing of results.

\subsection{Geophysical Testing Rationale}

Ground based geophysical tests consisting of frequency domain EM surveying and 2D electrical resistivity profiling was conducted along a test profile shown in Figure 3-1. The purpose of the ground based testing was to determine how well geo-electrical features (or anomalies) observed with the AEM data correlates with traditionally acquired surface geophysical data, and whether or not these observed geo-electrical features can be correlated with the underlying geology. If the AEM features can be correlated with subsurface geology, then the rapid scanning and non-intrusive capabilities provided by the airborne surveys can be used at the Hanford Site to screen for areas that warrant further investigation.

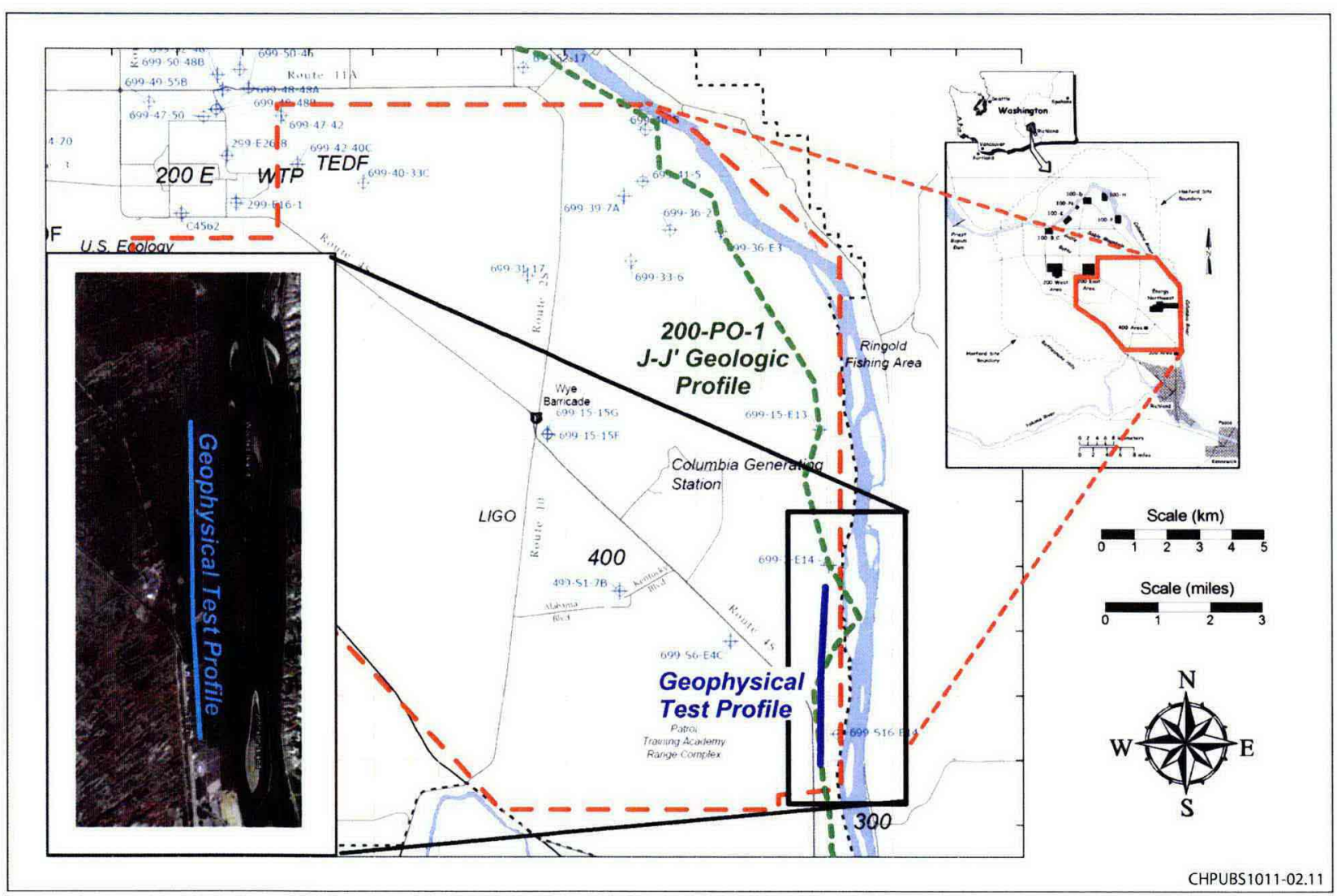

Figure 3-1. Location of Geophysical Testing Profile

\subsubsection{Electrical Resistivity}

Electrical resistivity is an intrinsic property of the earth that is controlled by the mineralogical composition of the matrix (sediment grain or rock type), the size and arrangement of individual grains or minerals, and the electrical properties of the pore-fluid (if present). In fresh water environments, coarser grain units such as sand and gravel zones tend to have a higher electrical resistivity than adjacent clay and silt intervals. In the presence of electrically conductive fluids, or interstitial components, the electrical resistivity will be decreased. 
At the Hanford Site, coarser grained gravels and sands of the Hanford formation are expected to have a higher electrical resistivity than adjacent finer grained sequences, and unsaturated sequences will have a greater electrical resistivity than their saturated equivalents. The electrical properties of the underlying Ringold Formation are poorly understood but should maintain similar relationships between finer- and coarser-grained intervals as observed within the Hanford formation. Basaltic units should have a relatively high resistivity except where extremely weathered or fractured (fractures filled with clay).

Because a broad and overlapping range of resistivities is likely for the Hanford sediment and rock (Keller, 1966, "Electrical Properties of Rocks and Minerals"), interpretation of the resistivity data will require constraint from lithologic data obtained from boreholes adjacent to the profiles. Further complicating the interpretation are the electrical effects of the pore-fluids (natural groundwater and contaminant), which may act to lower or increase the electrical resistivity. Resistivity surveys at the BC Cribs and Trenches Area (as well as other liquid waste disposal sites) document remnant ionic effects of the leachate, in this case nitrate laden waste (PNNL-17821, Electrical Resistivity Correlation to Vadose Zone Sediment and Pore-Water Composition for the BC Cribs and Trenches Area).

\subsubsection{Ground Based Methods}

Two ground based techniques, frequency domain EM and 2D electrical resistivity profiling, were chosen for the following reasons:

- EM profiling is relatively rapid methodology and if results can be directly compared with the AEM data, then anomalies observed from airborne surveys can be quickly verified using this technique.

- EM profiling has minimal cultural or ecological impact (does not require roads or trails to be emplaced).

- Ground based EM methods are adequately proven with extensive literature describing methodology and results. Versions of the EM profiling method have been successfully used to investigate Hanford waste disposal sites.

- The resistivity method provides a geo-electrical model that can be compared with the subsurface models estimated by the AEM surveys.

- Resistivity surveying is minimally invasive and requires only the shallow insertion (25 cm [10 in.]) of stainless steel electrodes in the ground and the deployment of cables to connect the electrodes.

- The resistivity method has been used for Hanford leak detection, tank farm, and disposal site investigations. Resistivity data have been correlated at the BC Cribs with well control (PNNL-17821).

\subsubsection{Test Profile Location}

The location for the test geophysical profile was selected based on the following criteria:

- Cultural free zone

- Accessibility

- Both AEM methods

- Anomalous testing features

Analysis of the HeliGEOTEM information indicated three areas where cultural interference is likely absent (or very minimal): in the western third of the survey area, in the northern eighth (along the river), and in the southeastern fifth (see Figure 2-6). The western third region is ruled out due to the absence of the RESOLVE surveys. Preliminary analyses and the latest vendor supplied interpretation (SGW-47839) 
suggest the presence of preferred groundwater flow routes trending towards the southeast from the 200 Area to just north of the 300 Area.

Examination of the southeast quarter of the AEM survey area provides the following information:

- Both AEM methods

- Relatively no cultural interference with one north-south oriented power line, apparently having little impact on the airborne surveys (not detected with $60 \mathrm{~Hz}$ noise monitor)

- Presence of access roads (reduce impact of surveys)

- Possible channel features consisting of coarser-grained Hanford formation sediments incised into the underlying Ringold

- Hanford, Ringold, and basalt units within investigation depths of both the AEM and ground based methods

- Possible correlation with Pacific Northwest National Laboratory efforts in the 300 Area

Figure 3-2 shows the RESOLVE geo-electrical cross-section along the geophysical test profile. This section was interpolated from bounding RESOLVE flight lines L10310, L10320, L10330, and L10340. Overlain on the section are geologic contacts derived for the J-J' geologic cross-section, which crosses near the geophysical test profile (see Figure 2-3 and Figure 3-1). A layered model is produced by the RESOLVE survey, with a general low-to-high-to-very-low relative change in resistivity with depth. Near surface material has modeled values of 60 to $150 \mathrm{ohm}-\mathrm{m}$, the intermediate zone from 100 to $200 \mathrm{ohm}-\mathrm{m}$, and the deepest zone below $70 \mathrm{ohm}-\mathrm{m}$. Follow on discussion with the vendor indicated that the resistivity estimate for the near surface material is likely in error due to tuning issues with the RESOLVE sensor. In this case, sediments with very high resistivities ( $>500 \mathrm{ohm}-\mathrm{m})$ are at the lower end of the electrical-conductivity scale used by RESOLVE.

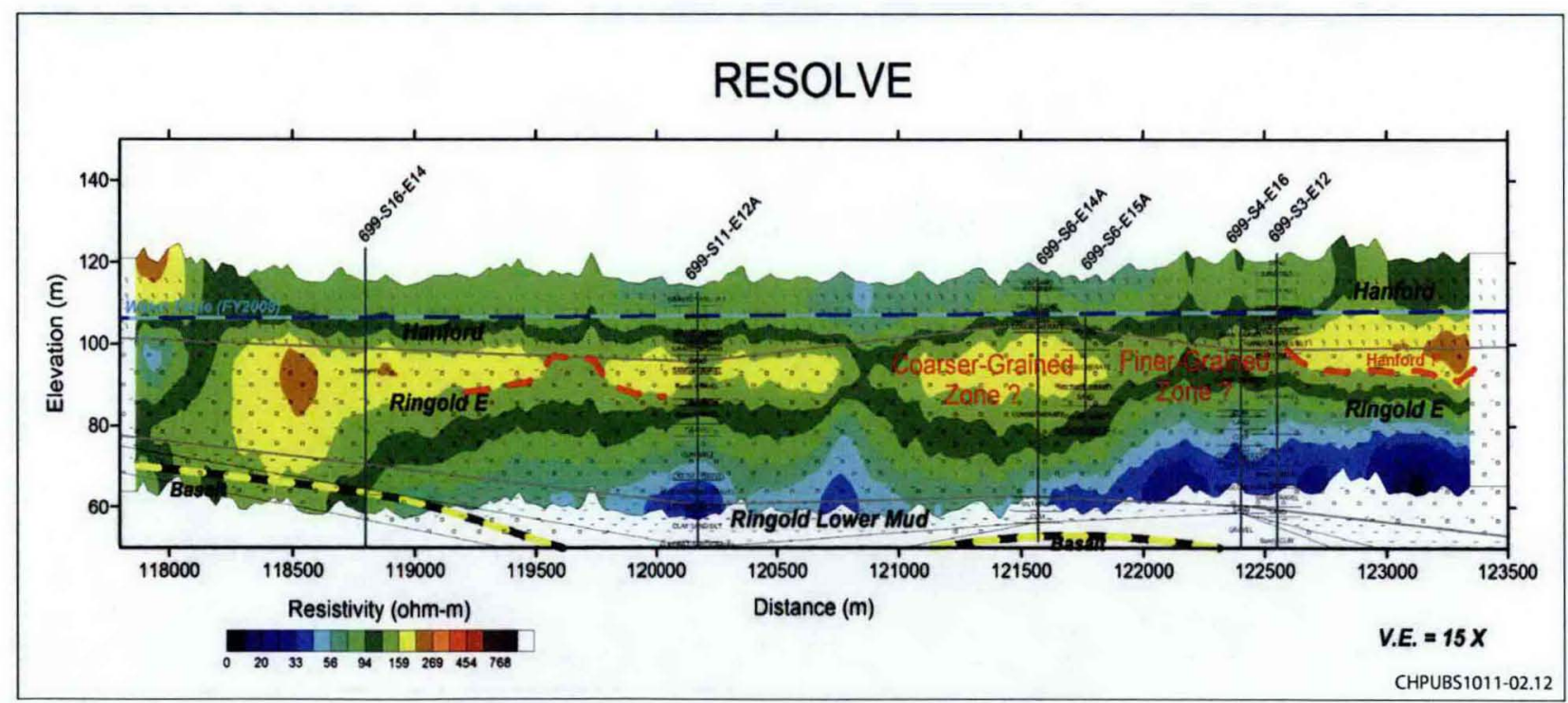

Figure 3-2. RESOLVE Data Along Geophysical Test Profile

The lateral changes in resistivity that occur near the Hanford-Ringold contact, and whether these changes correlate with fine-to-coarse grained fractions or indicate filled scours of coarser-grained Hanford 
sediment, are of interest. The zone of relatively low resistivity at depth likely correlates with the Lower Mud of the Ringold Formation (or with zones of increased silt/clay within the Ringold).

The initial geo-electrical cross-section computed for HeliGEOTEM Profile L10090 is shown in Figure 3-3. The section shows a decrease in resistivity to the north, from approximately $130 \mathrm{ohm}-\mathrm{m}$ on the south end to $\sim 45 \mathrm{ohm}-\mathrm{m}$ on the north, and a very gradual decrease in resistivity with depth. There is a very weak correspondence with the low resistivity at depth, though the HeliGEOTEM model estimate places this zone at a much greater depth than the RESOLVE model.

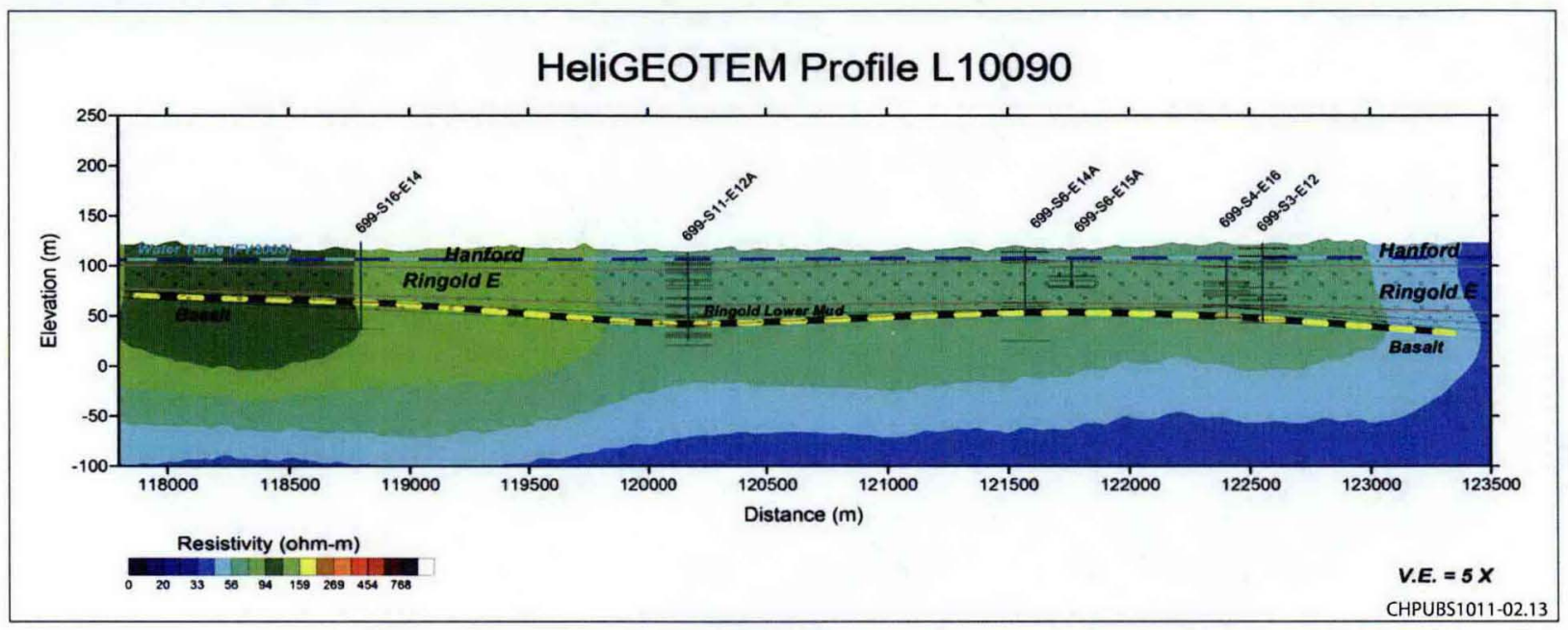

Figure 3-3. HeliGEOTEM Data Adjacent to the Geophysical Test Profile

Ongoing discussions with the vendor (Fugro) suggest that the HeliGEOTEM data require further processing (true, model-layer inversion) in order to place the vertical position of observed anomalies more accurately. Figure 3-4 is a geo-electric model of the HeliGEOTEM data along the J-J' geologic profile inverted using the AirBeo modeling (SGW-47839). Also shown on the figure is the approximate position of the geophysical test profile (see Figure 3-1). The HeliGEOTEM model data appear to respond to both the top-of-basalt (south end) and presence of Ringold Lower Mud (coordinates 8500 to 1300), though these relationships are poorly defined to the north. Further comparisons with the trial inverted HeliGEOTEM data are provided in Section 4 of this report (see Figure 4-4).

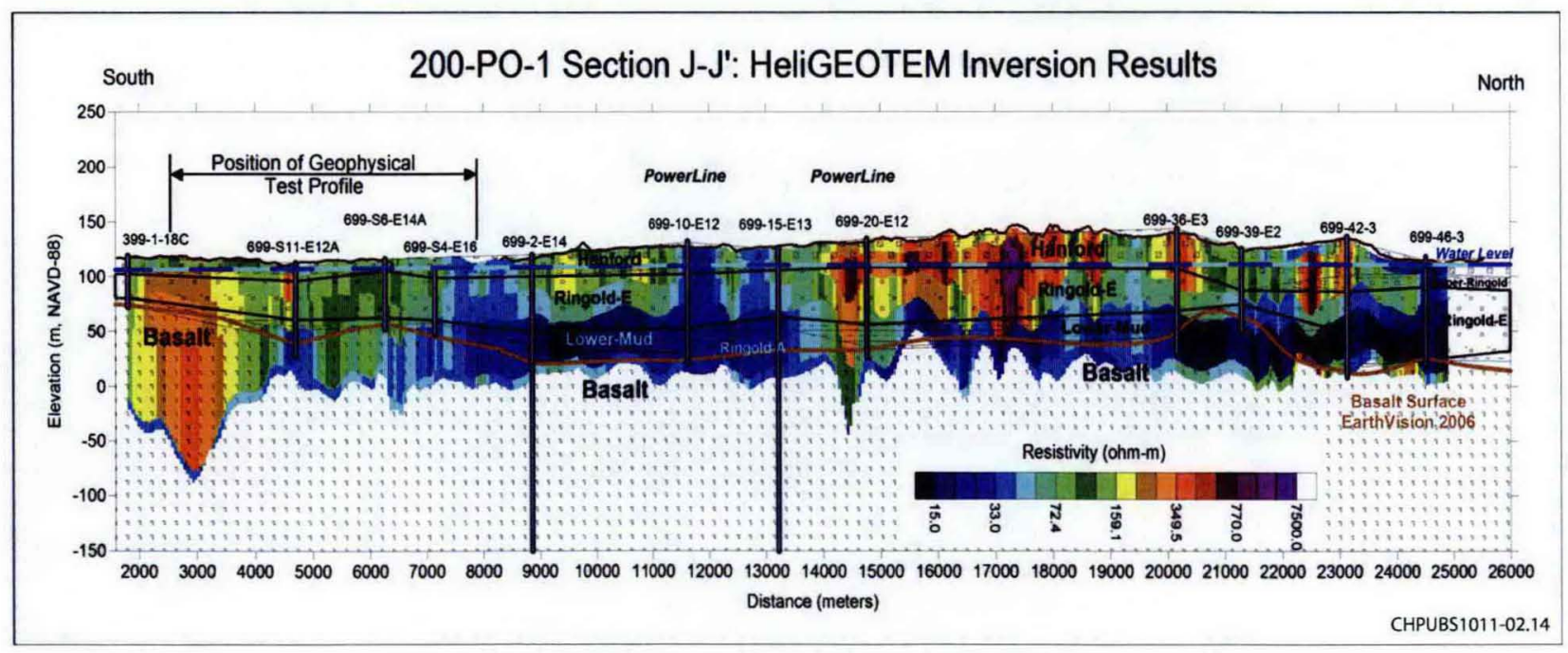

Figure 3-4. AirBeo Inversion of HeligEOTEM Profile J-J' 


\subsection{Frequency Domain Electromagnetic Surveys (EM-34)}

A Geonics EM-34 was used to measure the electrical conductivity of the near surface (Figure A-8 in Appendix A). A transmitter coil is used to induce an electrical current into the ground, and the receiver coil measures the strength of the secondary magnetic field generated by these currents.

The quadrature-phase component of the secondary magnetic field is used to measure the ground conductivity (Geonics, 1991, EM-34 Operating Manual). The electrical conductivity of the ground is almost linearly proportional to the strength of the quadrature-phase component and is given in units of milli-siemens per meter $(\mathrm{mS} / \mathrm{m})$. To convert from $\mathrm{mS} / \mathrm{m}$ (electrical conductivity) to ohm-m (electrical resistivity), divide the conductivity into 1,000 .

The coils can be oriented in either a vertical dipole or horizontal dipole configuration (Figure A-7 in Appendix A). For the vertical dipole case, the axes of the coils are oriented perpendicular to the ground surface; for the horizontal dipole, the axes are parallel to the ground surface. For both cases, the coils are maintained in a coplanar state. The vertical dipole orientation provides for a greater investigative depth and is less sensitive to near surface variations. For this study, EM-34 data were collected in both the horizontal and vertical dipole configurations at coil separations of $10 \mathrm{~m}(33 \mathrm{ft}), 20 \mathrm{~m}(67 \mathrm{ft})$, and $40 \mathrm{~m}$ (131 ft). More detailed information regarding the EM-34 is provided in Appendix A.

\subsubsection{Initial Testing}

Initial testing of the EM-34 focused on determining the influence of the power line located along the north-south access road from $100 \mathrm{~m}(328 \mathrm{ft})$ to $200 \mathrm{~m}(656 \mathrm{ft})$ east of the geophysical test profile. Data were recorded along a short profile, roughly perpendicular to the power line and near the center of the geophysical test profile (see Figure 3-1). Only the $40 \mathrm{~m}$ (131 ft) coil separation was used because this separation would be the most sensitive to external interference from the power line. Both vertical and horizontal co-planar dipoles were collected, and the measurement was made with the coil array oriented sub-parallel to the power line.

Figure 3-5 shows the resulting data plotted as a function of distance from the power line. Shown are the recorded readings (solid curves), reading range (error bars), and sensitivity scale used for each reading. As expected, the power line influences the readings as the point of measurement nears the power line. For the horizontal configuration, a stable reading could not be collected within $70 \mathrm{~m}(230 \mathrm{ft})$ of the power line (dashed lines indicate range of observed needle fluctuations on the measurement dial). In addition, the sensitivity scale had to be increased (instrument sensitivity decreased) in order to get a stable reading.

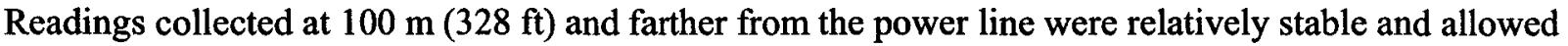
recording data using the appropriate sensitivity range setting (i.e., 30). Data collected along the geophysical test profile are likely to be free from power line interference because the line of profile is located from $120 \mathrm{~m}(394 \mathrm{ft})$ to $200 \mathrm{~m}(656 \mathrm{ft})$ west of the power line (see Figure 3-1).

\subsubsection{Data Collection}

Data were collected at nominal $100 \mathrm{~m}(328 \mathrm{ft})$ station spacing along the resistivity profile. Six coil configurations were recorded at each station and consisted of both horizontal and vertical co-planar dipole orientations at three coil separations: $10 \mathrm{~m}(33 \mathrm{ft}), 20 \mathrm{~m}(67 \mathrm{ft})$, and $40 \mathrm{~m}(131 \mathrm{ft})$. Results for the

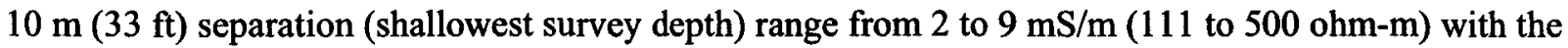
bulk of measurements between 2 to $3 \mathrm{mS} / \mathrm{m}$ (330 to $500 \mathrm{ohm}-\mathrm{m})$. For the $20 \mathrm{~m}(67 \mathrm{ft})$ data, a range of 3.5 to $9.5 \mathrm{mS} / \mathrm{m}$ was observed with nominal values in the 5 to $7 \mathrm{mS} / \mathrm{m}$ range (143 to $200 \mathrm{ohm}-\mathrm{m}$ ). At the $40 \mathrm{~m}$ (131 ft) coil separation, measured values range from 4 to $20 \mathrm{mS} / \mathrm{m}$ (50 to $250 \mathrm{ohm}-\mathrm{m})$ with the bulk of the measurements between 9 and $13 \mathrm{mS} / \mathrm{m}(\sim 75$ to $110 \mathrm{ohm}-\mathrm{m})$. The measured raw data are plotted in Figure 3-6. The vertical-dipole measurements at $40 \mathrm{~m}$ (131 ft) electrode separation 
("Vert $40 \mathrm{~m}$ " [131 ft]) show a general increase in electrical conductivity (decrease in resistivity) towards the north. This is likely a response to the increase in sediment thickness as the basalt surface descends towards the north (see Figure 2-3).

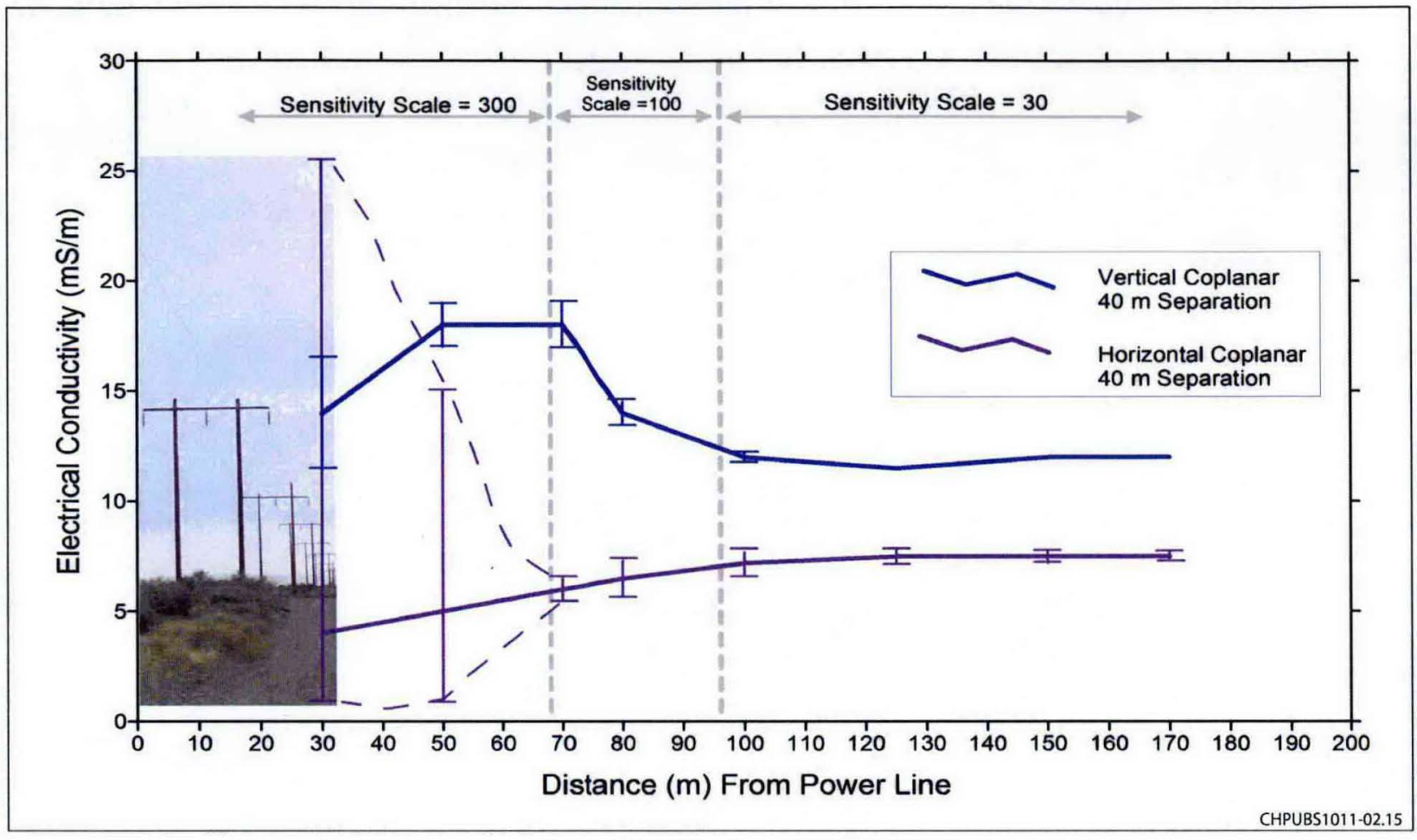

Figure 3-5. EM-34 Sensitivity to Nearby Power Line

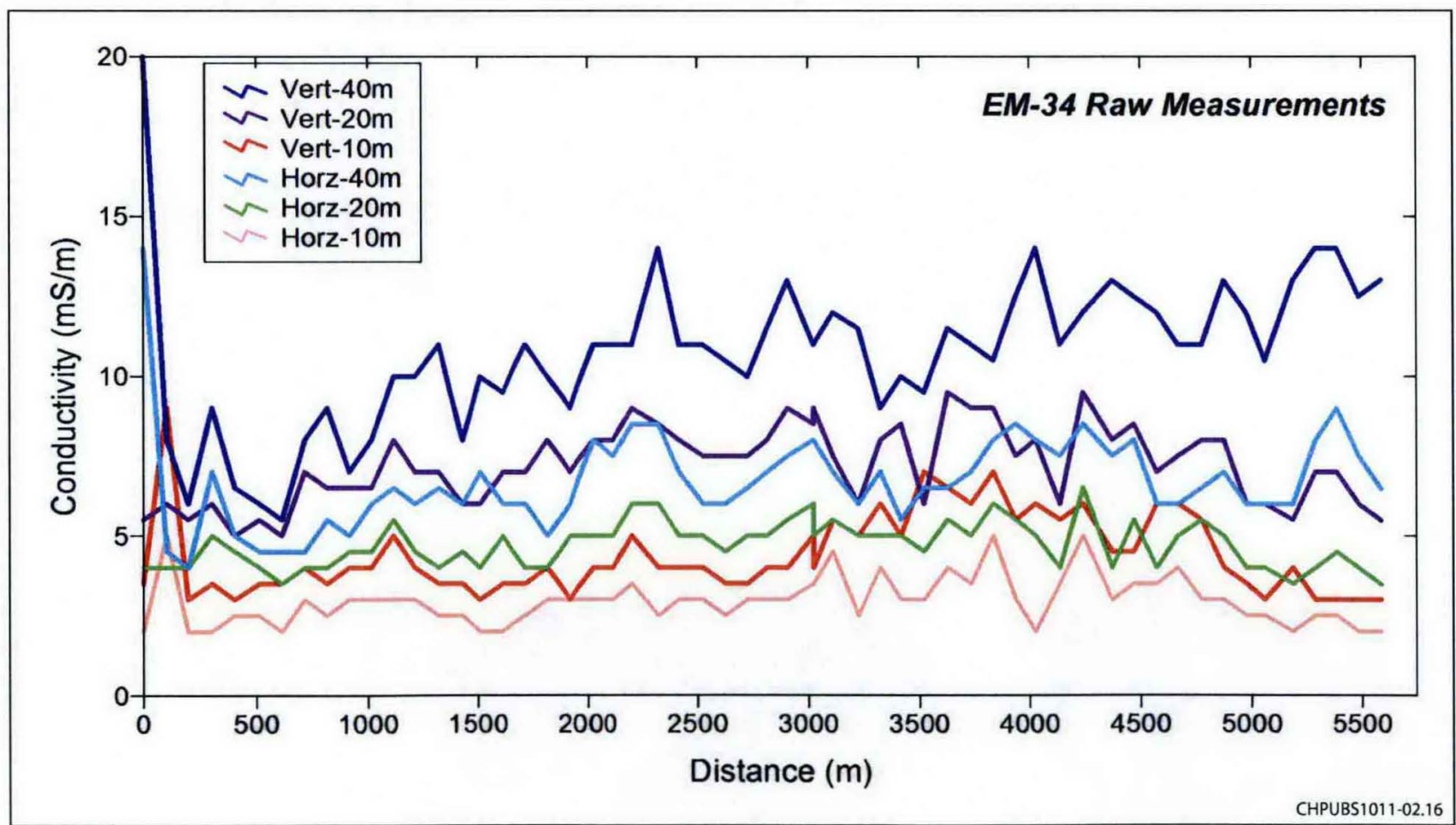

Figure 3-6. EM-34 Raw Data 


\subsubsection{Processing}

The six measurement configurations were converted into one-dimensional (1D) layered earth models using the FREQEM program (Loke, 2006, "1-D Frequency Domain EM Modeling”). The program employs the digital filter method, described by Koefoed et al., 1972, "Computation of Type Curves for Electromagnetic Depth Sounding with a Horizontal Transmitting Coil by Means of a Digital Linear Filter," and Guptasarma and Singh, 1997, "New Digital Linear Filters for Hankel J0 and J1 Transforms," to perform a damped, non-linear least-squares inversion on the EM-34 data (Lines and Treitel, 1984, "A Review of Least-Squares Inversion and its Application to Geophysical Problems"). An initial (or trial) model is iteratively updated (both layer thickness and electrical-conductivity) to reduce the difference between the measured and calculated data. Three-layer geo-electric model solutions proved to be the best fit for the EM-34 data, and all inversions used the same starting model. An example plot of the inversion for station 4500 is shown in Figure A-9 (Appendix A). Model layers are shown as green boxes, measured data as blue crosses, and modeled values as red crosses. Modeling predicts a high resistivity

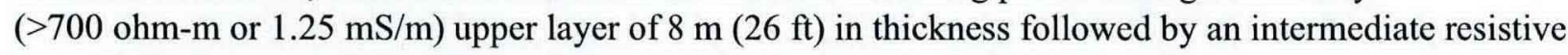
layer $(160 \mathrm{ohm}-\mathrm{m})$ and floored by a low resistivity layer at depth $(<60 \mathrm{ohm}-\mathrm{m})$.

The 1D models were collated and used to construct a geo-electrical cross-section shown in Figure 3-7. Zones of higher resistivity are shown as red colors and lower resistivity as blue. Also shown are the geologic contacts defined for the J-J' geologic cross-section (Figure 3-1). The EM-34 data show a subtle decrease in resistivity across the water table where vadose sediments generally have resistivities greater than $400 \mathrm{ohm}-\mathrm{m}$, and saturated sediments of the Hanford formation range from 200 to $400 \mathrm{ohm}-\mathrm{m}$. An exception occurs near the north end of the profile where a zone of 400 to $450 \mathrm{ohm}-\mathrm{m}$ is modeled below the water table.

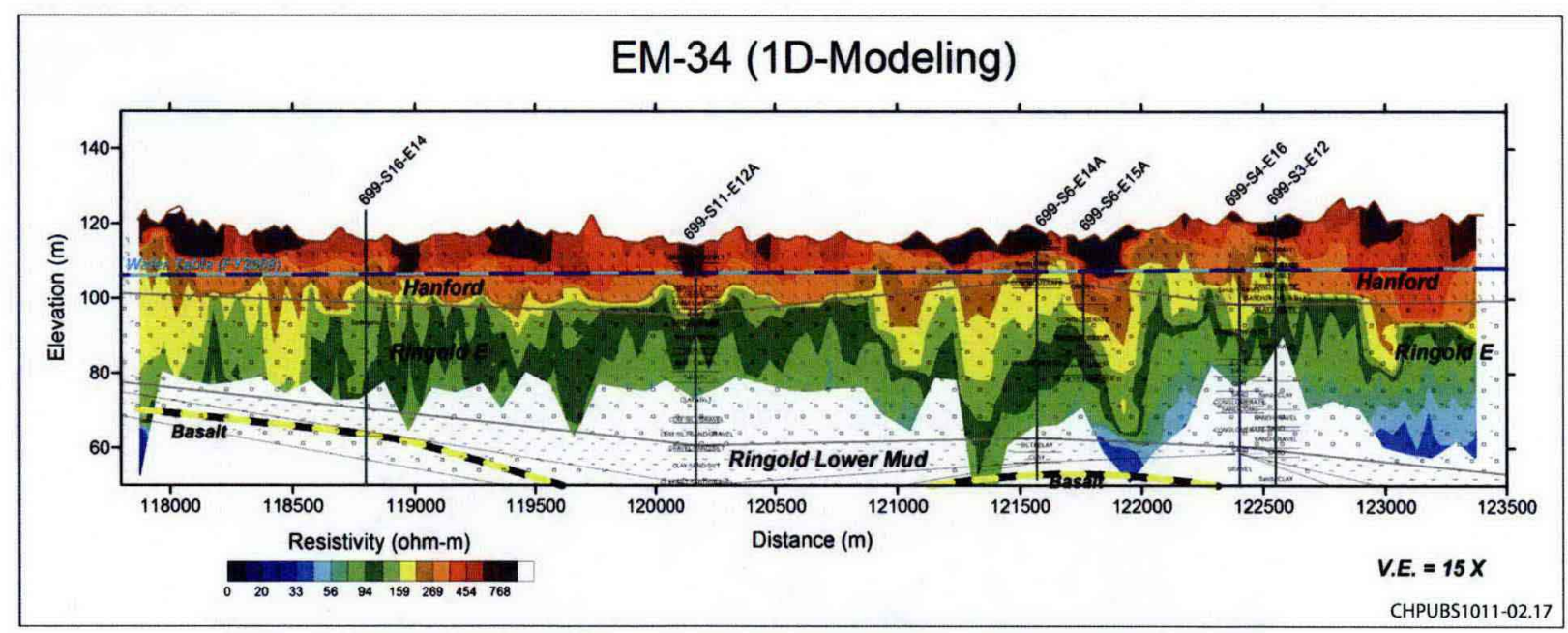

Figure 3-7. EM-34 Model Section Along Geophysical Test Profile

The Hanford-Ringold contact appears to correlate with a change in resistivity, from consistently above $250 \mathrm{ohm}-\mathrm{m}$ for the Hanford units to generally below $160 \mathrm{ohm}-\mathrm{m}$ for the Ringold units. This is not a change in saturation conditions because the Hanford-Ringold contact is below the water table. Notable exceptions are observed near the south end of the profile where more resistive material (160 to $250 \mathrm{ohm}-\mathrm{m}$ ) is modeled in the upper part of the Ringold, and between profile coordinates 121000 and 122000 where a thicker zone of 160 to $250 \mathrm{ohm}-\mathrm{m}$ is modeled for the Ringold. This latter zone is possibly more indurated (driller's logs indicate the presence of conglomerates) or dominated by more coarse-grained units (the two wells immediately to the north indicate the presence of clayey intervals at shallower depths). 


\subsection{Two-Dimensional Direct Current Resistivity Profiling}

2D electrical resistivity imaging (2D-ERI) measures both horizontal and vertical variations in the geo-electrical character of the subsurface. The resistivity method depends on different lithologies or sediment types having different electrical properties. The data are modeled using a tomographic inversion procedure and displayed as cross-sectional slices through the earth. Data were collected using the SuperSting R8 systems (Advanced Geosciences, Inc., 2001, SuperSting R8 IP 8-Channel Memory Earth Resistivity and IP Meter Instrument Manual)with either the smart electrode cables (by CHPRC) or the switch box (by the contractor) (see Figure A-4 in Appendix A). Further description of the 2D-ERI method and instrumentation used is provided in Appendix A.

The measured electrical resistivity data are converted into an electrical resistivity cross-section using a tomographic inversion algorithm (Loke, 2010, "Rapid 2D Resistivity \& IP Inversion Using the Least-Squares Method"). During the inversion, the subsurface is divided into a number of blocks (block model), and a smoothness-constrained least-squares approach is used to estimate the value of resistivity for each block. An iterative procedure of calculating the model response, least-squares comparison with the measured data, and adjustment of the block resistivity values is used until the model response begins to converge with the measured data.

\subsubsection{Initial Testing}

Array type and feasibility testing were conducted at two locations along the geophysical test profile using CHPRC's SuperSting R8 system with a 42 electrode array constructed from two overlapping spreads, each of 28 electrodes with an overlap of 14 electrodes. The first test location was at the south end of the proposed geophysical test profile, and the second location was near the middle. Goals of the initial testing were to determine whether resistivity information could be collected in this region and what array types will provide sufficient information in a cost effective manner. Test profiles employed the Inverse Schlumberger, Dipole-Dipole, Pole-Dipole, and Pole-Pole array types using $6 \mathrm{~m}$ (20 ft) electrode spacing (Figure A-2 in Appendix A).

Contact resistance tests (electrode-to-electrode resistance measurement) were conducted to determine whether the predominantly sand units at the surface would prove to be an impediment to resistivity surveys. Results are shown in Figure 3-8 by survey location, array test sequence, profile position, and measured resistance. Initial testing at the first location (Schlumberger and Dipole-Dipole arrays) was conducted in natural soils, and both surveys yielded undesirably high-contact resistances $(>2,500 \mathrm{ohm})$. Electrode positions were watered for subsequent surveys, and the resulting contact resistances were maintained below $2,500 \mathrm{ohm}$. Thus, with watering of electrode positions, conditions along the geophysical test profile should be conducive to collecting resistivity information.

Test data were converted into geo-electrical models using the RES2DINV software code of Loke (2010), with results for both test sites presented in Figure 3-9 and Figure 3-10. The test data required editing prior to modeling remove "bad" points due to the presence of a faulty electrode, intermittent electrode-ground coupling problems, and poor signal to noise. Poor signal noise results from either the system being unable to generate sufficient electrical current or from array type (i.e., subsurface combinations that yield low potential differences [insensitivity]). Data were edited in profile form and by the root-mean-square (RMS) residual error as provided by the RES2DINV software where noise spikes or data drop-outs are identified and deleted (see Appendix A). 


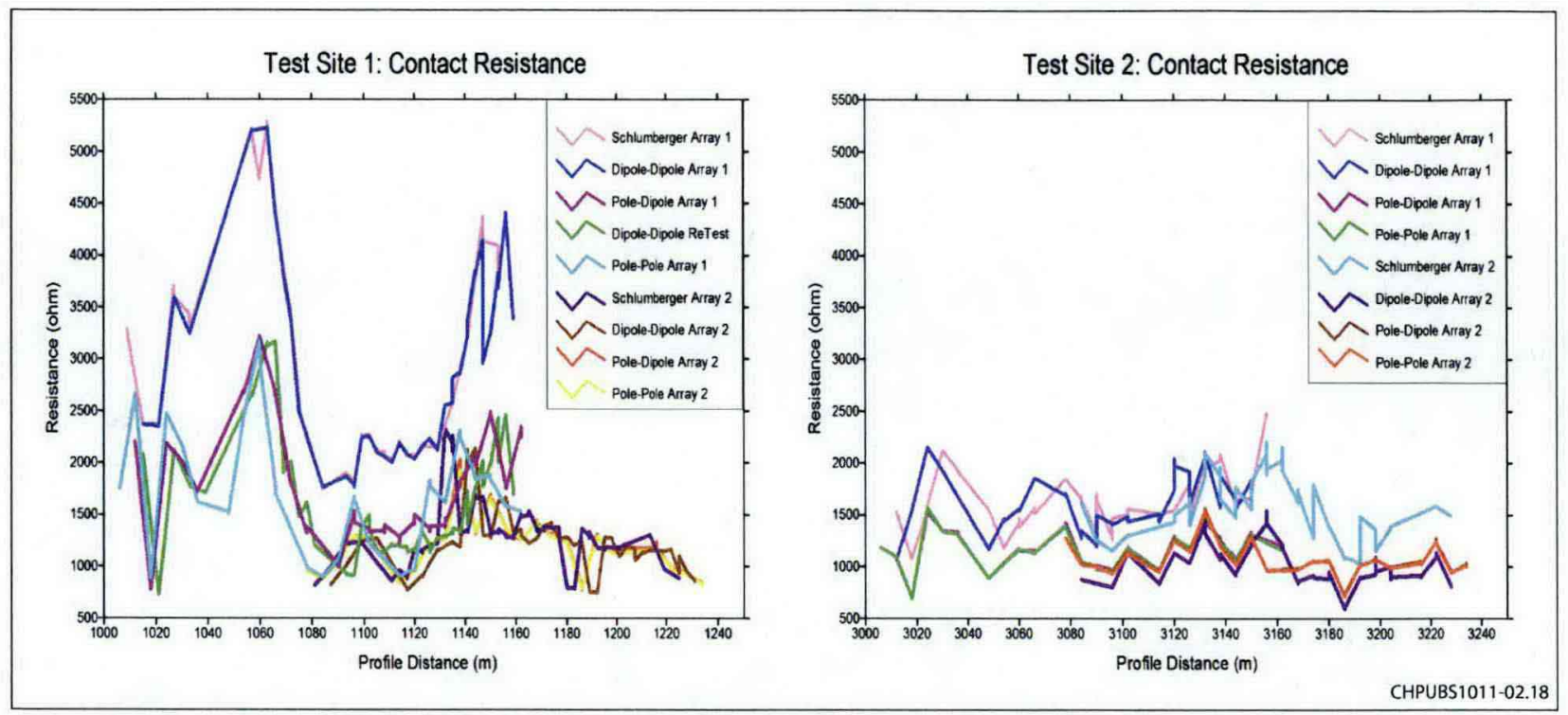

Figure 3-8. Contact Resistance Tests

Table 3-1 lists the total number of points acquired per array type (i.e., Acq Pts), the number of points used for the modeling (Mod Pts), and the percentage lost due to the editing. In general, system and ground conditions required removing from one-third to one-half of the data in order to construct reasonable geo-electrical models of the subsurface. The highest percent of information lost was for the Dipole-Dipole and Pole-Dipole array types, where the data loss is most likely the result of low-signal strength.

The Schlumberger and Pole-Pole surveys were marginally better performers (in terms of data non-loss), particularly for the second test site where both the Dipole-Dipole and Pole-Dipole test required removal of over half the measurement points.

Table 3-1. Site 1 and Site 2 Data Loss and Noise

\begin{tabular}{lcccccc}
\hline \multicolumn{1}{c}{ Array Type } & Acq Pts & Mod Pts & \% Loss & Acq Pts & Mod Pts & \% Loss \\
\hline Sclumberger & 215 & 136 & 36.7 & 198 & 123 & 37.9 \\
Dipole-Dipole & 399 & 210 & 47.4 & 355 & 159 & 55.2 \\
Pole-Dipole & 592 & 302 & 49.0 & 548 & 238 & 55.6 \\
Pole-Pole & 331 & 190 & 42.6 & 315 & 184 & 41.6 \\
\hline
\end{tabular}

Modeling results shown in Figure 3-9 and Figure 3-10 depict a near surface zone of high to very high

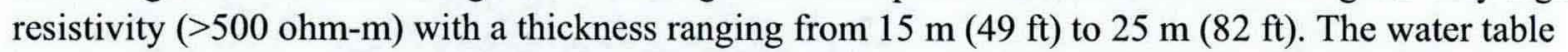
occurs at an average elevation of $105 \mathrm{~m}(344 \mathrm{ft})$ for Site 1 and $107 \mathrm{~m}(351 \mathrm{ft})$ for Site 2, which is near the change from high-to-low resistivity. Below the water table, the resistivity models indicate a range of values from $<20 \mathrm{ohm}-\mathrm{m}$ to $>300$ to $500 \mathrm{ohm}-\mathrm{m}$. 
The Dipole-Dipole and Pole-Dipole surveys consistently modeled zones of extremely low resistivity $(<20 \mathrm{ohm}-\mathrm{m})$ below the water table, and these zones are potential artifacts resulting from data noise and incomplete editing. In this case, the measurement data are extremely noisy, resulting in some judgment in what data to leave or remove. Schlumberger and Pole-Pole arrays showed better consistency in measured value below the water table.

Array testing indicates the feasibility of collecting resistivity data and the potential for mapping geo-electrical changes below the water table. Of these, the Pole-Pole array type has generally good noise characteristics and sufficient depth of investigation. The Schlumberger array type also has good noise characteristics but has the shallowest investigation depth of all four array types.

\subsubsection{Data Collection}

HydroGEOPHYSICS, Inc. (HGI) was contracted to collect the production data using the Pole-Pole array type. The scope of work included collecting Pole-Pole data along the geophysical test profile plus conducting further array tests at one end of the profile in order to verify the results. The SuperSting R8 (Figure A-4 in Appendix A) owned by HGI has been modified to have increased power over that of the standard R8 system (as owned by CHPRC); thus, noise issues encountered during the array testing were likely to be minimized. Over six days, $5.5 \mathrm{~km}(3.4 \mathrm{mi})$ of profiling was collected which included installing the remote electrodes and collecting the global positioning system (GPS) survey data.

The production survey used an electrode spacing of $6 \mathrm{~m}(20 \mathrm{ft})$ and 84 electrodes, giving a total unit electrode array length of $498 \mathrm{~m}(1,634 \mathrm{ft})$. The electrode array was rolled (leap-frogged) along the profile in increments of 42 electrodes ( $252 \mathrm{~m}$ [ $827 \mathrm{ft}]$ ), with a total of 21 overlapping spreads of 84 electrodes recorded during the survey. Total profile length was $5,538 \mathrm{~m}(18,169 \mathrm{ft}$ ). Pole-Pole (Figure A-2 in Appendix A) data were collected with an " $A$ " spacing (distance between current and potential electrodes

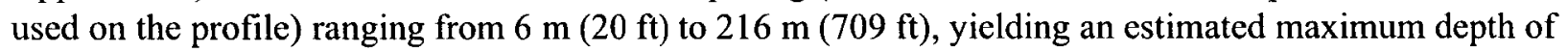
investigation of approximately $80 \mathrm{~m}(262 \mathrm{ft})$.

Data for the fifth roll-along array (profile positions 1,158 to 1,506 m) were corrupted after collection and after the electrodes had been moved down the profile. Multiple attempts were made to restore the corrupted data from the binary file (including having the instrument manufacturer try), but all attempts were unsuccessful. As a result, approximately $250 \mathrm{~m}(820 \mathrm{ft})$ of horizontal coverage was lost, and subsequent plots have this portion of the modeled image blanked out to reflect the absence of data.

Schlumberger and Pole-Dipole array types were collected at the north end of the geophysical test profile to help judge consistency in model results. These surveys used an electrode spacing of $3 \mathrm{~m}(9.8 \mathrm{ft})$ and 84 electrodes.

Stainless steel electrodes of $25 \mathrm{~cm}$ (10 in.) in length were used, and the ground surface around the electrode position was watered to improve soil-electrode coupling (reduce contact resistance).

Remote electrodes required by the Pole-Pole and Pole-Dipole surveys were installed offset from the north and south ends of the profile. The remote-receiver electrode was located approximately $1,300 \mathrm{~m} \mathrm{(4,265 \textrm {ft } )}$ northwest of the north end of the profile, and the remote-transmitter electrode was located about approximately $1,200 \mathrm{~m}(3,937 \mathrm{ft})$ southeast of the south end of the profile. Both remote electrodes are more than 5 times the maximum " $A$ " spacing used (216 m [709 ft]). 

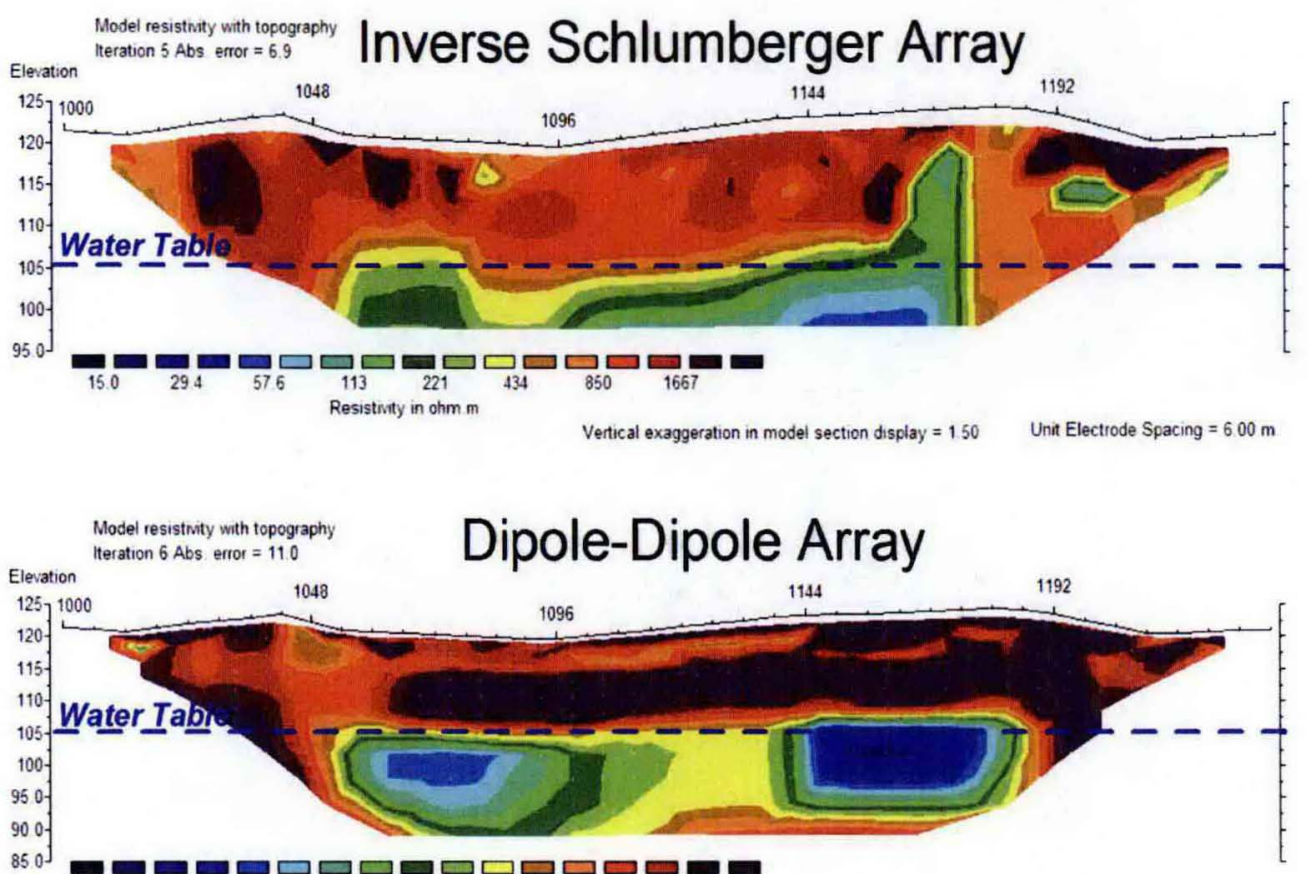

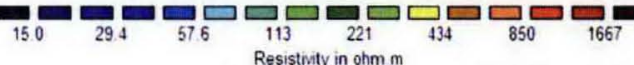

Vertical exaggeration in model section display $=116 \quad$ Unit Electrode Spacing $=6.00 \mathrm{~m}$

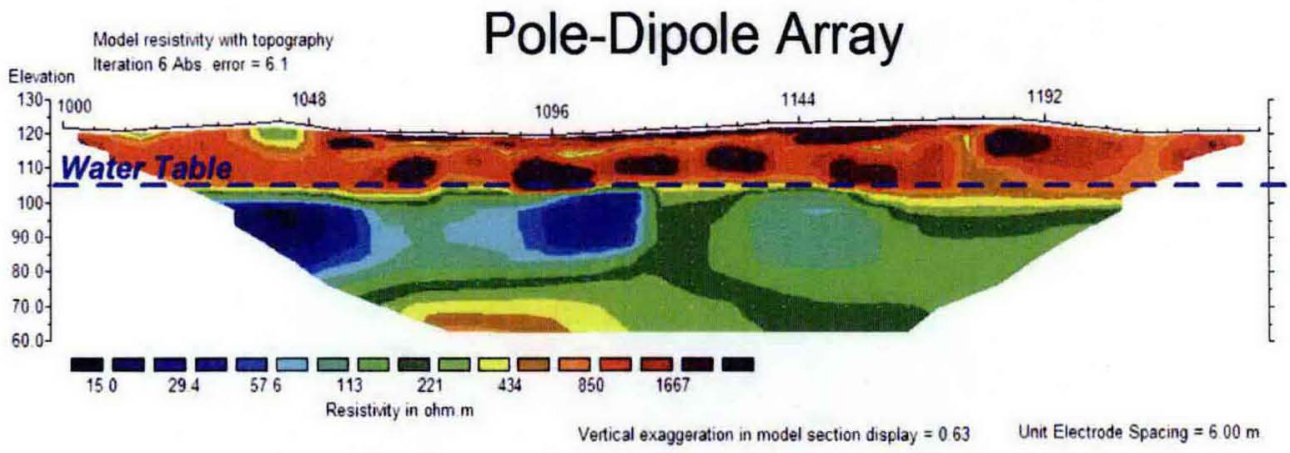

Model resistivity with topography Iteration 5 Abs enror $=26$

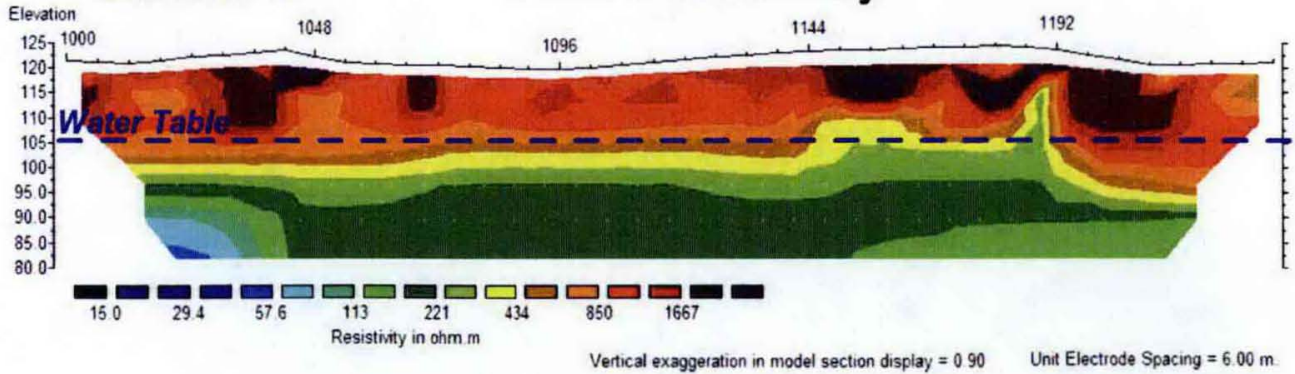

CHPUBS1011-02.19

Figure 3-9. Site 1: Array Test Results 

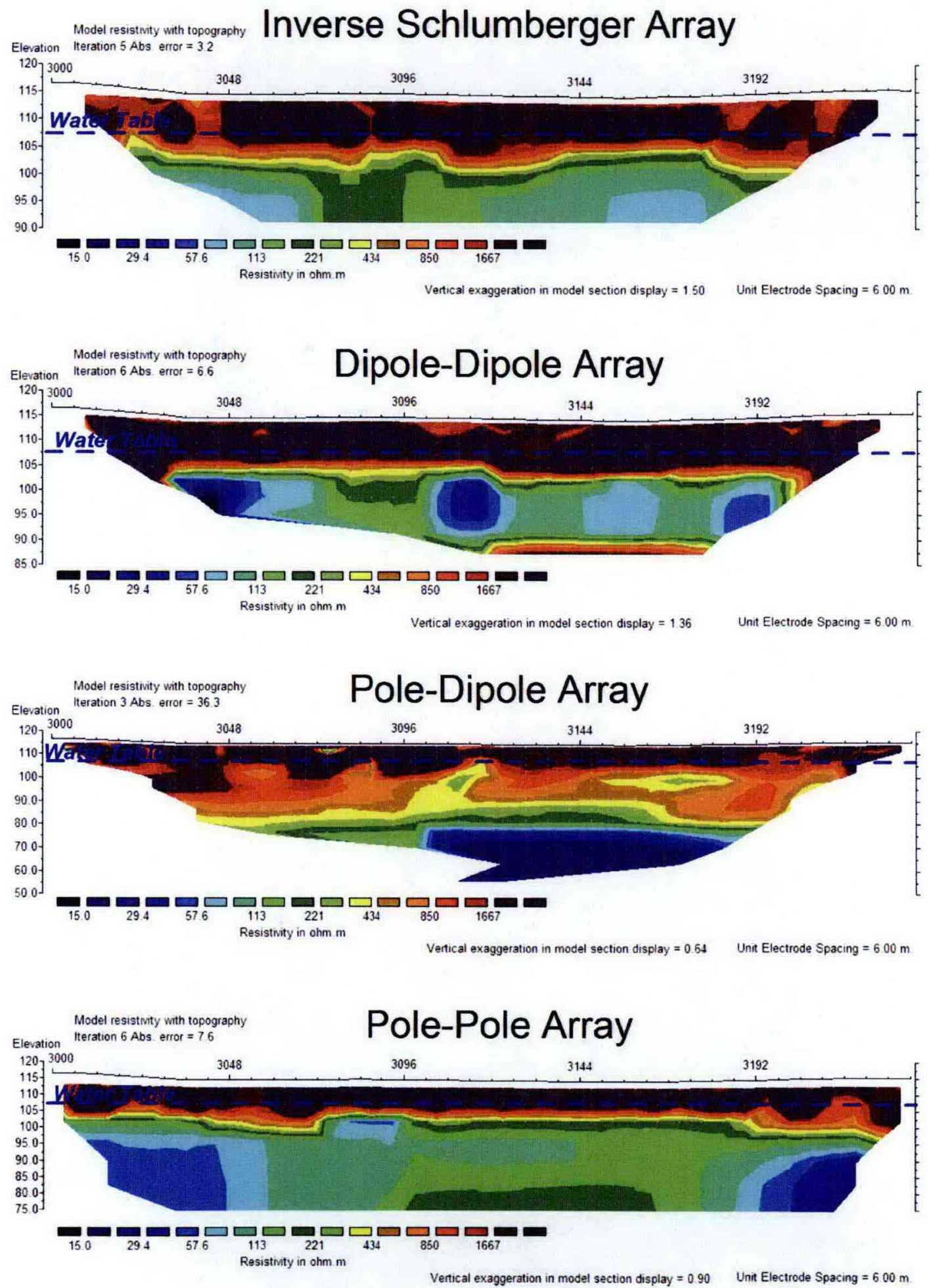

CHPUBS1011-02.20

Figure 3-10. Site 2: Array Test Results 
Positional data were acquired using a Leica 1200 RTK Survey Grade GPS. Wooden stakes were placed at nominal $100 \mathrm{~m}(328 \mathrm{ft})$ intervals with the electrode number recorded at each stake.

\subsubsection{Processing}

Both the EarthImager (v.2.40, available at: www.agiusa.com) and RES2DINV commercially available software codes were used to convert the raw resistivity data into cross-sectional geo-electrical models. Both programs employ the damped least squares method (Lines and Treitel, 1984) with smoothness constraint to perform a non-linear inversion of the measured data (see Appendix A for more discussion). The programs use a basic iterative process of estimating a subsurface model of resistivity (subsurface divided into rectangular blocks), computing a theoretical response to this model (model points), comparing the model and measured data points (error statistics), determining a model perturbation vector from the error statistics, and applying the perturbation vector information to generate a new subsurface model. These steps are repeated until the solution begins to converge (subsequent iterations result in only small changes in the error statistic and can result in artifacts).

The processing steps were as follows:

- Compile data into input file.

- Add topography and geometry information.

- Edit for noisy or unrealistic points (see Table 3-2).

- Invert (use several tests using range of modeling parameters).

- Examine errors between measured and modeled data (further editing).

- Output modeled values for gridding and contouring using Surfer.

Prior to modeling, the test data required editing to remove "bad" points due to the presence of intermittent electrode-ground coupling problems and poor signal due to noise. Poor signal noise results from either the system being unable to generate sufficient electrical current or from array type (i.e., subsurface combinations that yield low potential differences [insensitivity]). Data were edited both in profile form and by the RMS residual error (see Appendix A). In addition, data were screened for high repeat error ( $>5$ percent) and for occurrences of abnormally low injection current $(<5 \mathrm{~mA})$. Profile form editing allows removing obvious noise spikes, or data drop-outs are identified and deleted (see Figure A-5). Summary results for the number of data points removed and the information loss are provided in Table 3-2.

Table 3-2. North End and Production Survey Data Loss and Noise

\begin{tabular}{lccc}
\hline \multicolumn{4}{c}{ North End } \\
\hline \multicolumn{1}{c}{ Array Type } & Acquisition Points & Model Points & Percent Loss \\
\hline Schlumberger & 1,601 & 1,441 & 10 \\
Pole-Dipole & 1,828 & 1,316 & 28 \\
\hline & Production Survey $(\mathbf{5 . 5} \mathbf{~ k m})$ & 7 \\
\hline Pole-Pole & 27,164 & 25,250 & \\
\hline
\end{tabular}

Initial modeling was conducted for the data collected at the north end of the profile in order to determine appropriate inversion parameters and to judge how the different array types affect the estimate for the subsurface resistivity. Default inversion settings provided by the RES2DINV and EarthImager programs were used with a maximum iteration limit set of seven. Both the Pole-Pole and Schlumberger data ran through the full seven iterations, though the inversion began converging in the last three 
iterations. The Pole-Dipole data only required four iterations to converge (changes in subsequent models were small).

Model results from the RES2DINV and EarthImager programs (output has variable color scales) are shown in Figure 3-11 and Figure 3-12, along with the position of the water table (about $107 \mathrm{~m} \mathrm{[351} \mathrm{ft]} \mathrm{in}$ elevation). The modeled electric structure is similar for all three array types and images a near surface zone of high resistivity $(>500 \mathrm{ohm}-\mathrm{m})$ that overlies a thick zone of lower resistivity. The water table bisects the upper resistive zone on all three models in Figure 3-11 and Figure 3-12, separating a thinner zone of extremely high resistivity $(>1,000 \mathrm{ohm}-\mathrm{m})$ from the underlying and less resistive material (400 to $800 \mathrm{ohm}-\mathrm{m}$ ).

RES2DINV and EarthImager were both used to model the production survey data. Trial inversion runs were conducted with the parameters varied to determine what set of model parameters produce the best results. The vertical to horizontal flatness filter ratio was varied between 1.0 (no preference) to 0.3 (weight horizontal features more). Layer thickness parameter was tested for 10 percent and 25 percent increases with depth, with the initial layer thickness varying from one-half to one electrode spacing. Both the smooth model and robust (blocky) inversions were tested. Final parameters were no flatness preference (1.0), layer thickness increase with depth of 10 percent, and robust inversion with 5 percent data constraint (model data errors of more than 5 percent have a greatly reduced impact on final model), and the effects of end blocks were reduced using the severe setting.

Results for the entire production survey from the EarthImager and RES2DINV are shown in Figure 3-13. A range of model parameters was tried for the respective programs, and the data are unconstrained by the configuration of underlying geology. The color scale is different than that shown for the north end of the profile (Figure 3-11), and the water table is shown as a yellow and blue dashed line. Also shown is the data gap resulting from the corrupted file for the fifth roll-along spread $250 \mathrm{~m}(820 \mathrm{ft})$ data gap, marked by a "No Data" label. The likely position of the underlying basalt is labeled near the south end of the profile.

Both algorithms model an upper zone of high resistivity that varies from $15 \mathrm{~m}(49 \mathrm{ft})$ to $30 \mathrm{~m}(98 \mathrm{ft})$ in thickness and likely corresponds with Hanford Site sands and gravels (Figure 3-13). The water table bisects this zone separating a thinner zone of extremely high resistivity $(>1,000 \mathrm{ohm}-\mathrm{m})$ from the underlying and less resistive material (400 to $800 \mathrm{ohm}-\mathrm{m})$.

The program model solutions diverge below the water table with the EarthImager model estimating significantly lower resistivities than the RES2DINV model. For example, the basalt on the south end of the profile is estimated by RES2DINV to have resistivities in the 160 to $350 \mathrm{ohm}-\mathrm{m}$ range by RES2DINV, whereas EarthImager modeled it as 80 to $100 \mathrm{ohm}-\mathrm{m}$.

Both models image a zone of increased resistivity at depth with a rise in elevation between coordinates 120000 to 122000 . The overall shape of this zone is similar to the basalt surface (Figure 2-3) but is modeled about $20 \mathrm{~m}$ to $30 \mathrm{~m}$ ( $66 \mathrm{ft}$ to $98 \mathrm{ft}$ ) lower in elevation. Both of these models were created with a smooth model solution where discreet changes in resistivity (e.g., sediment-basalt boundary) are approximated with a resistivity gradient. In the next section, the RES2DINV program option to use a sharp boundary based on known layers is examined. 

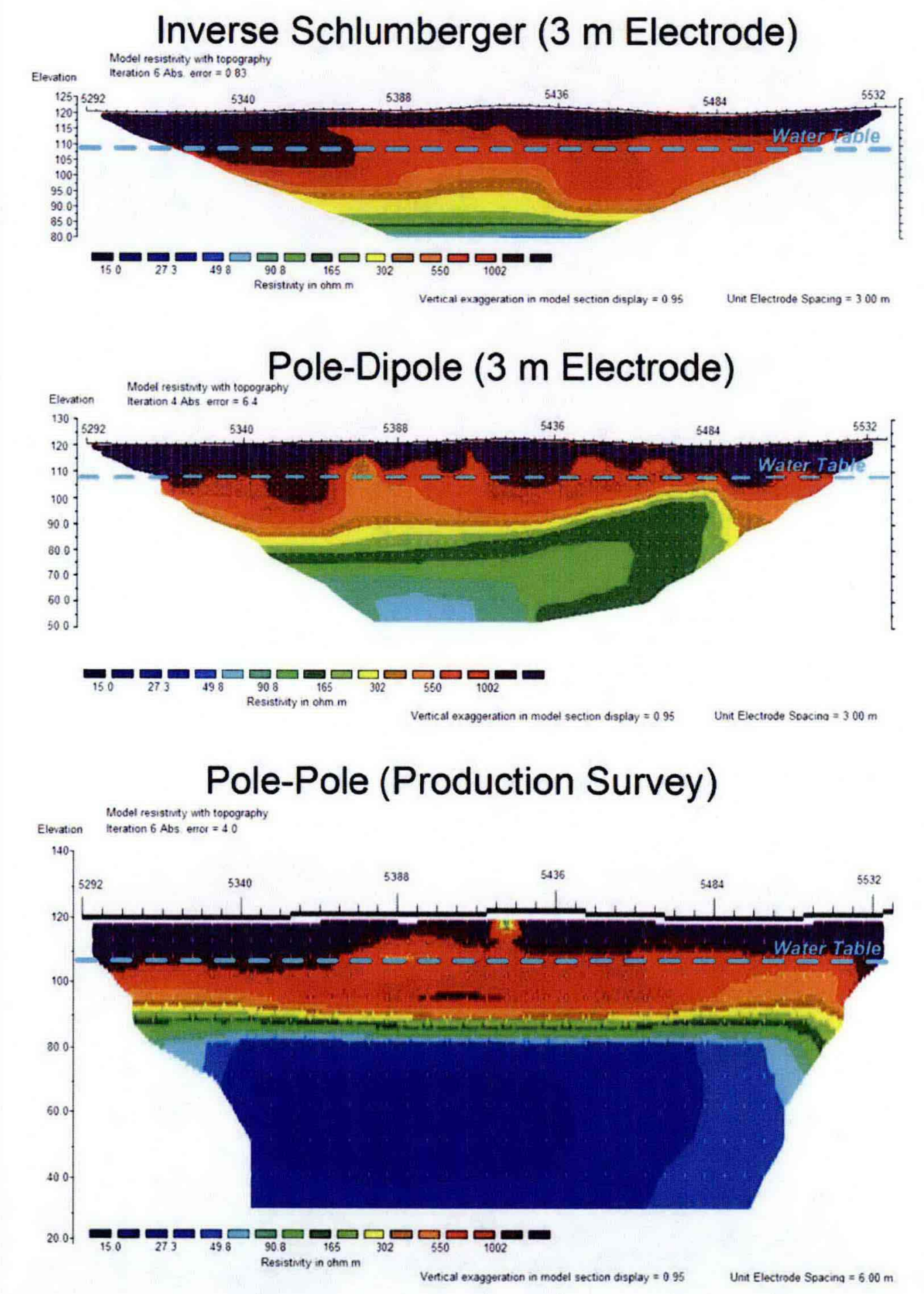

CHPUBS1011-02.21

Figure 3-11. Comparison of Array Testing at North End of Profile Using RES2DINV 


\section{Inverse Schlumberger ( $3 \mathrm{~m}$ Electrode)}

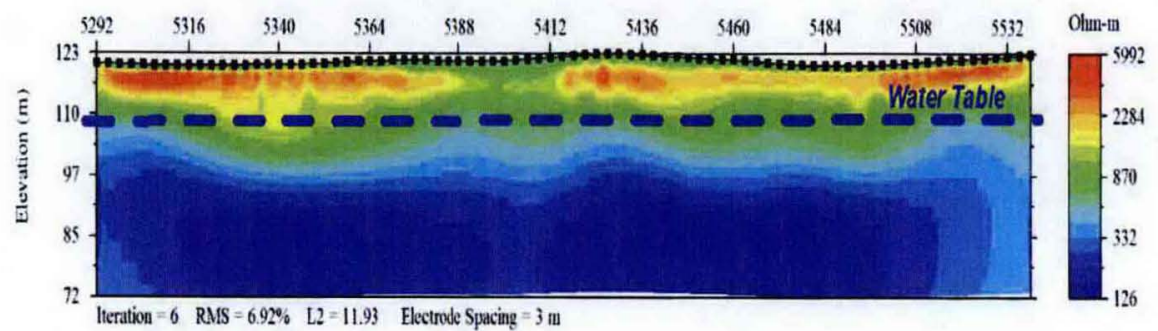

\section{Pole-Dipole ( $3 \mathrm{~m}$ Electrode)}

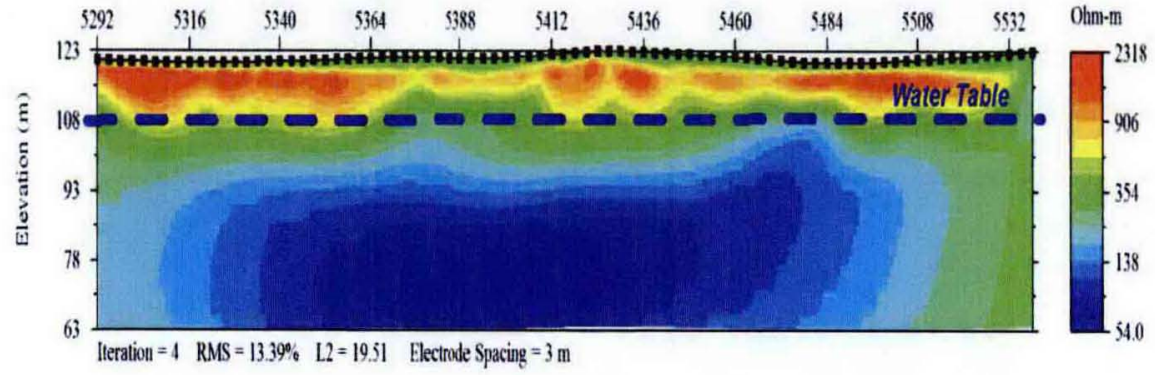

\section{Pole-Pole (Production Survey)}

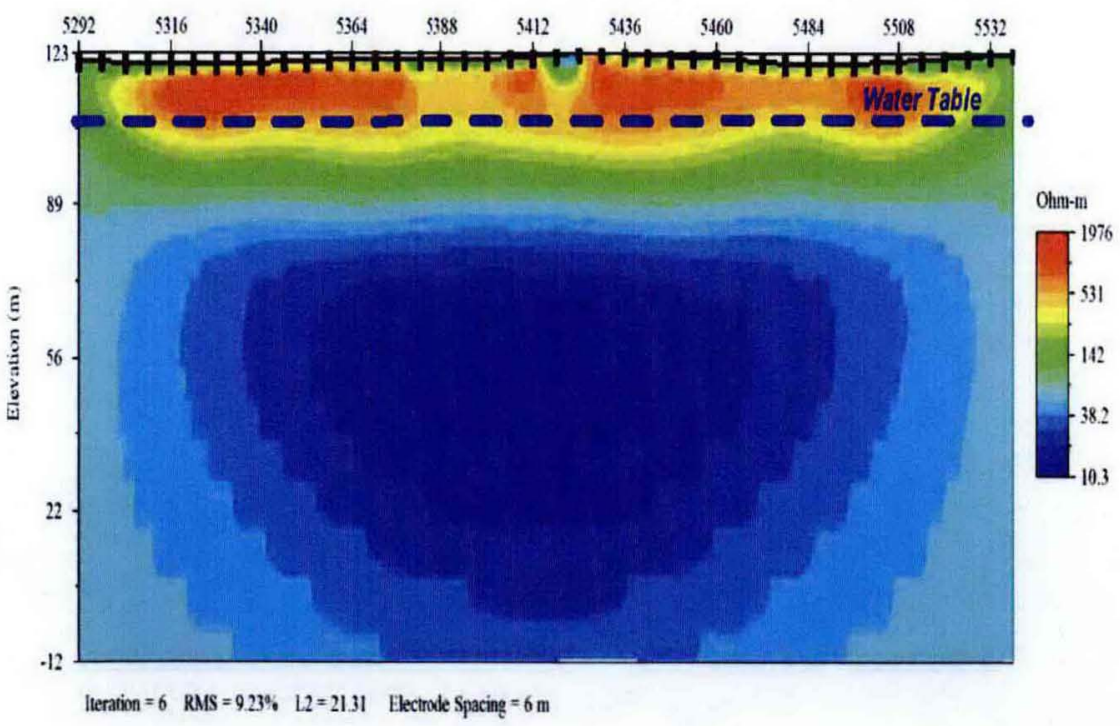

CHPUBS1011-02.22

Figure 3-12. Comparison of Array Testing at North End of Profile Using Earthlmager 


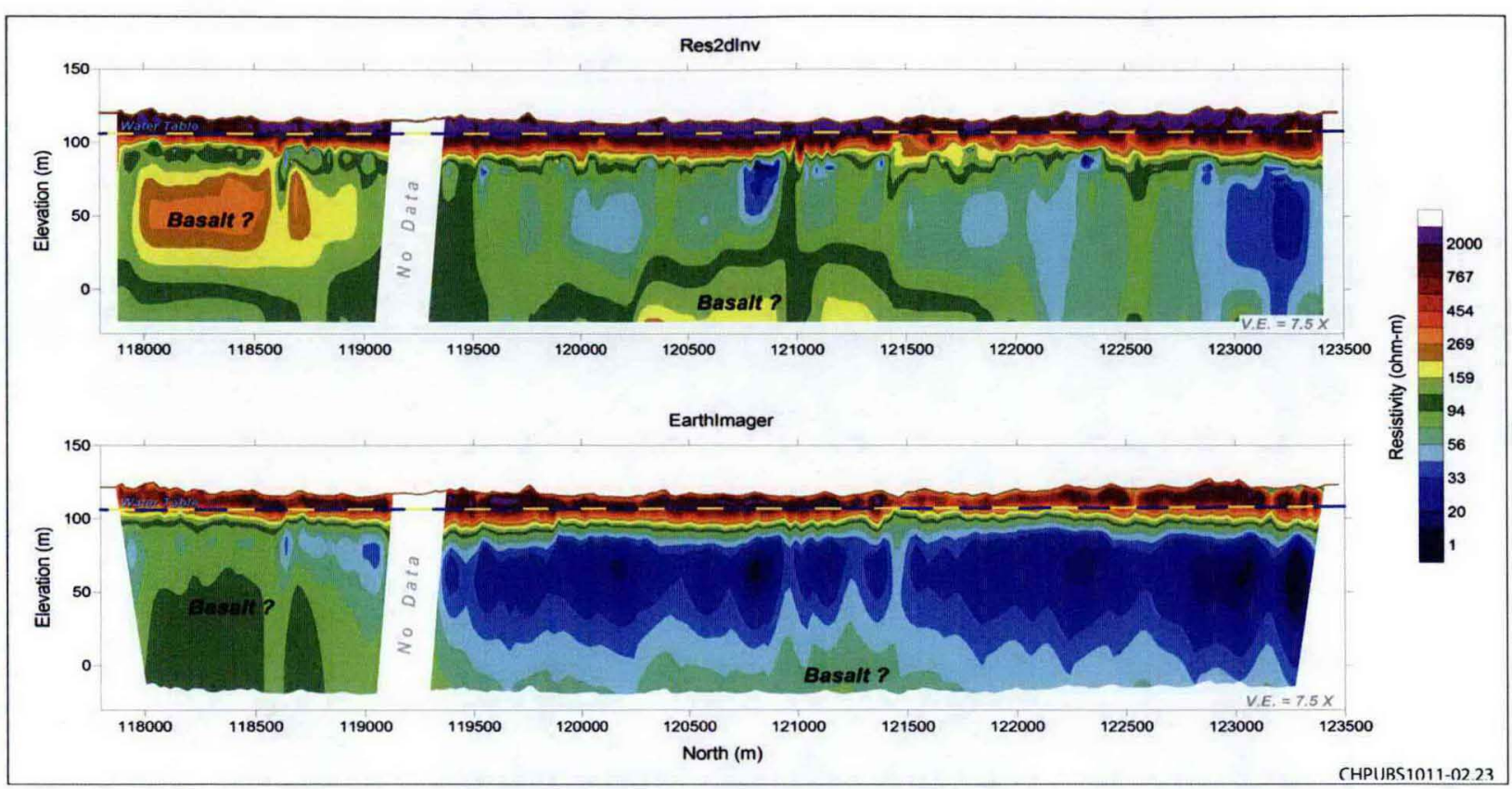

Figure 3-13. Entire Production Survey RES2DINV and Earthlmager Modeling Results

\subsubsection{Constrained Model Inversion}

RES2DINV offers an option to constrain the inversion using known contact boundaries as a means for providing a more accurate estimate of the layer resistivities. Modeling using this option allows for a sharp (or rapid) change in resistivity across this boundary so that material of disparate resistivities (e.g., basalt versus silts-sands) can be modeled. Resistivity data were inverted using only the water table and basalt surface as layer constraints because these boundaries remain fixed throughout the inversion. Estimates of the water table and basalt surface depths along the resistivity profile were extracted from the 2008 water table map (DOE/RL-2008-66) and the 2006 basalt surface map (Thorne et al., 2006). Using the geologic interfaces described for the J-J' profile may prove to be in error as the J-J' only crosses the southern half of the resistivity profile (J-J' trends east-northeast to a well point located along the Columbia River). There is no well control directly on the profile.

Constrained inversion results are shown in Figure 3-14. The constrained inversion attempted to model the Ringold-Basalt interface as a general low-to-high change in resistivity. Best results are in the southern km of the profile where more resistive basalt ( 180 to $340 \mathrm{ohm}-\mathrm{m}$ ) is overlain by presumably Ringold material of lower resistivity (100 to $150 \mathrm{ohm}-\mathrm{m})$.

Several zones of very low resistivity $(<40 \mathrm{ohm}-\mathrm{m})$ are modeled immediately above the basalt surface. The first occurs within the local basalt topographic low near profile coordinate 120250 , and the rest is on the northward slope of the basalt from coordinate 121500 and north. It is possible that these low resistivity zones are a response to the presence of the Ringold Lower Mud. On the north end, the thick zone of low resistivity may be a cumulative effect from clayey zones within the Ringold.

Of importance is the intra-Ringold change from high resistivity ( $>150 \mathrm{ohm}-\mathrm{m})$ to lower resistivity $(<100 \mathrm{ohm}-\mathrm{m})$ which may indicate a change from coarser- to finer-grained units. Clay intervals described on the driller's logs for Wells 699-S11-E12A, 699-S6-E15A, 699-S4-E16, and 699-S3-E12 are evidence of this change. In all cases, the first mention of clay occurs either at or immediately below the transition to lower resistivities. 


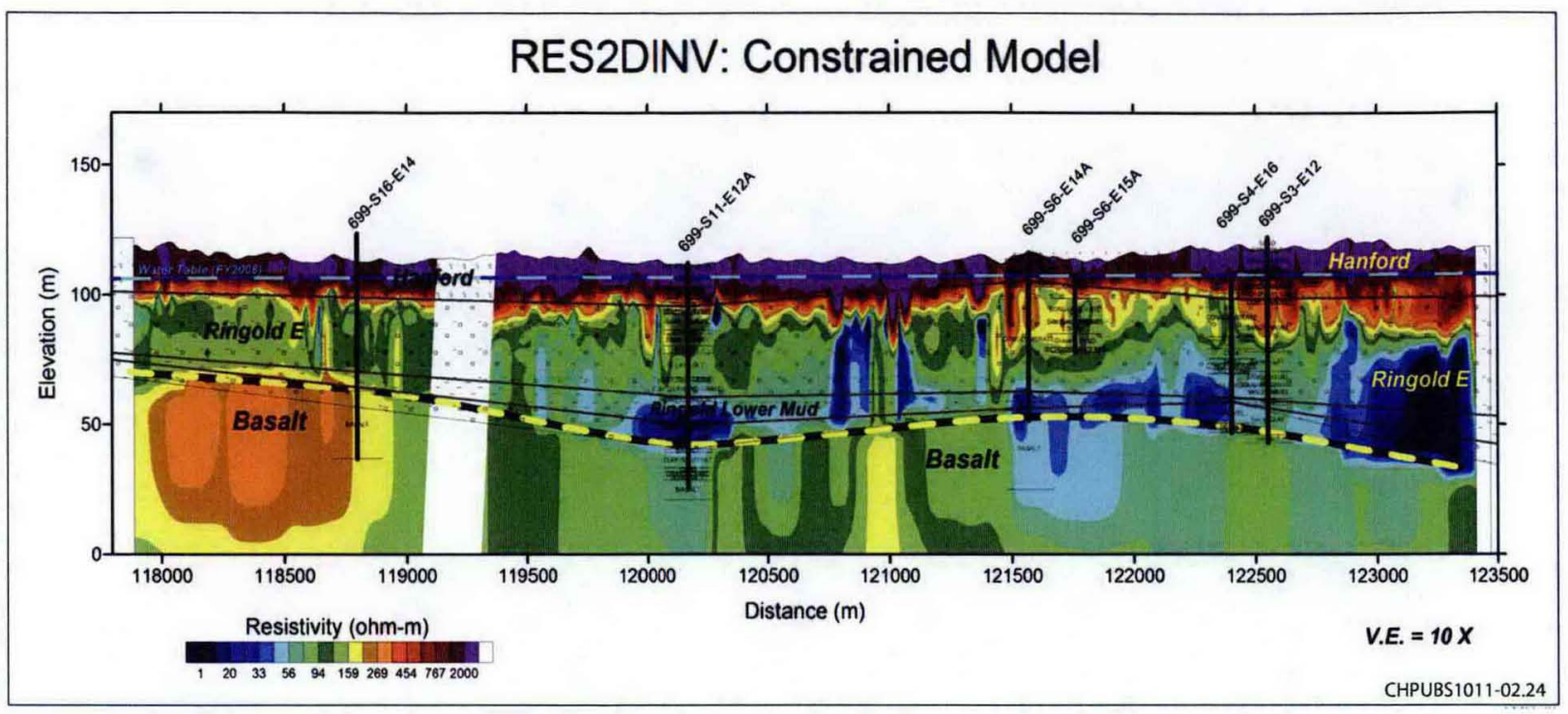

Figure 3-14. Constrained Model Inversion 


\section{Discussion}

EM terrain-conductivity surveying (EM-34) and 2D resistivity profiling were conducted along the test profile shown in Figure 3-1 in order to help refine the interpretation of AEM data collected in the areas shown in Figure 2-4.

In the following sections, the similarities and differences between the various models generated from the data are discussed.

\subsection{EM-34 and 2D Resistivity Comparison}

Geo-electrical sections are shown in Figure 4-1 for the modeled EM-34 and 2D resistivity data. Both models are shown in units of resistivity and are scaled and color-contoured the same. Geologic information from the J-J' cross-section and the drillers' descriptions for wells near the profile are shown.

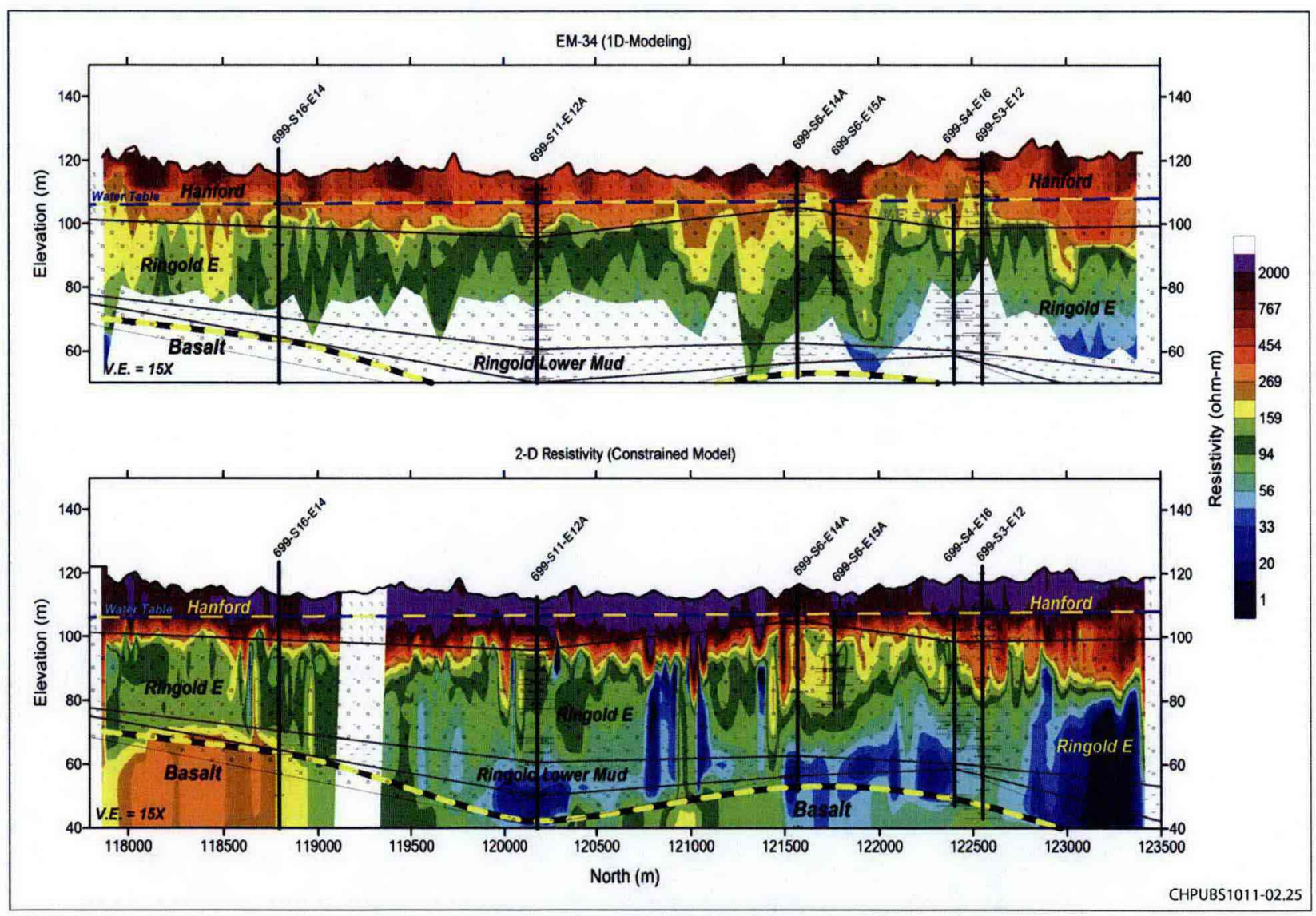

Figure 4-1. Comparison of EM-34 and 2D Resistivity Models

The EM-34 model does not estimate as high of resistivity for near surface vadose zone sediments as the $2 \mathrm{D}$ resistivity survey ( $>1,200 \mathrm{ohm}-\mathrm{m}$ for $2 \mathrm{D}$ resistivity and 350 to $1,000 \mathrm{ohm}-\mathrm{m}$ for EM-34). This is most likely due to tuning issues as very high resistivities approach zero on the electrical-conductivity scale. Both models, however, indicate a decrease in resistivity across the water table suggesting that the change from vadose to saturated conditions can be mapped (at least within Hanford).

The likely Hanford-Ringold contact is mapped as high-to-low change in resistivity from greater than $200 \mathrm{ohm}-\mathrm{m}$ (Hanford) to less than $150 \mathrm{ohm}$ (Ringold) on average. Estimates of intra-Ringold resistivities are similar for both surveys and range from 70 to $270 \mathrm{ohm}-\mathrm{m}$. 
Despite the EM-34 model's more limited investigation depth, the EM-34 model does image low resistivity on the north end of the profile. Lowest modeled values range from 30 to $40 \mathrm{ohm}-\mathrm{m}$. This appears to coincide with the $2 \mathrm{D}$ resistivity model and likely corresponds either to the Ringold Lower Mud or to clayey intervals within the Ringold. The resistivity model, however, estimates much lower resistivity $(<30 \mathrm{ohm}-\mathrm{m})$ for this zone, and the difference is most likely attributed to the shallower investigation depth of the EM-34 (here the low resistivity zones are not fully sampled).

A possible facies change within the Ringold from finer- to coarser-grained intervals is mapped as a relative thickening of the resistive zone between coordinates 121000 to 122000 . An alternate interpretation is that actual Hanford sediments have been filled into a channel incised into the top-of-Ringold. Coarser-grained sediments are indicated by the driller's descriptions for Well 699-S6-E14A and Well 699-S6-E15A.

\subsection{EM-34 and RESOLVE Comparison}

Results for the EM-34 modeling are compared with the AEM RESOLVE survey in Figure 4-2. The red and black dashed line is a $100 \mathrm{ohm}-\mathrm{m}$ contour based on the RESOLVE model and is used as a visual guide when correlating features. Both geo-electrical sections show a similar gross change from more resistive to more conductive at depth that is either an intra-Ringold change (RESOLVE) or the Hanford-Ringold contact (EM-34). It is possible that the RESOLVE model is not correctly located in the vertical sense.

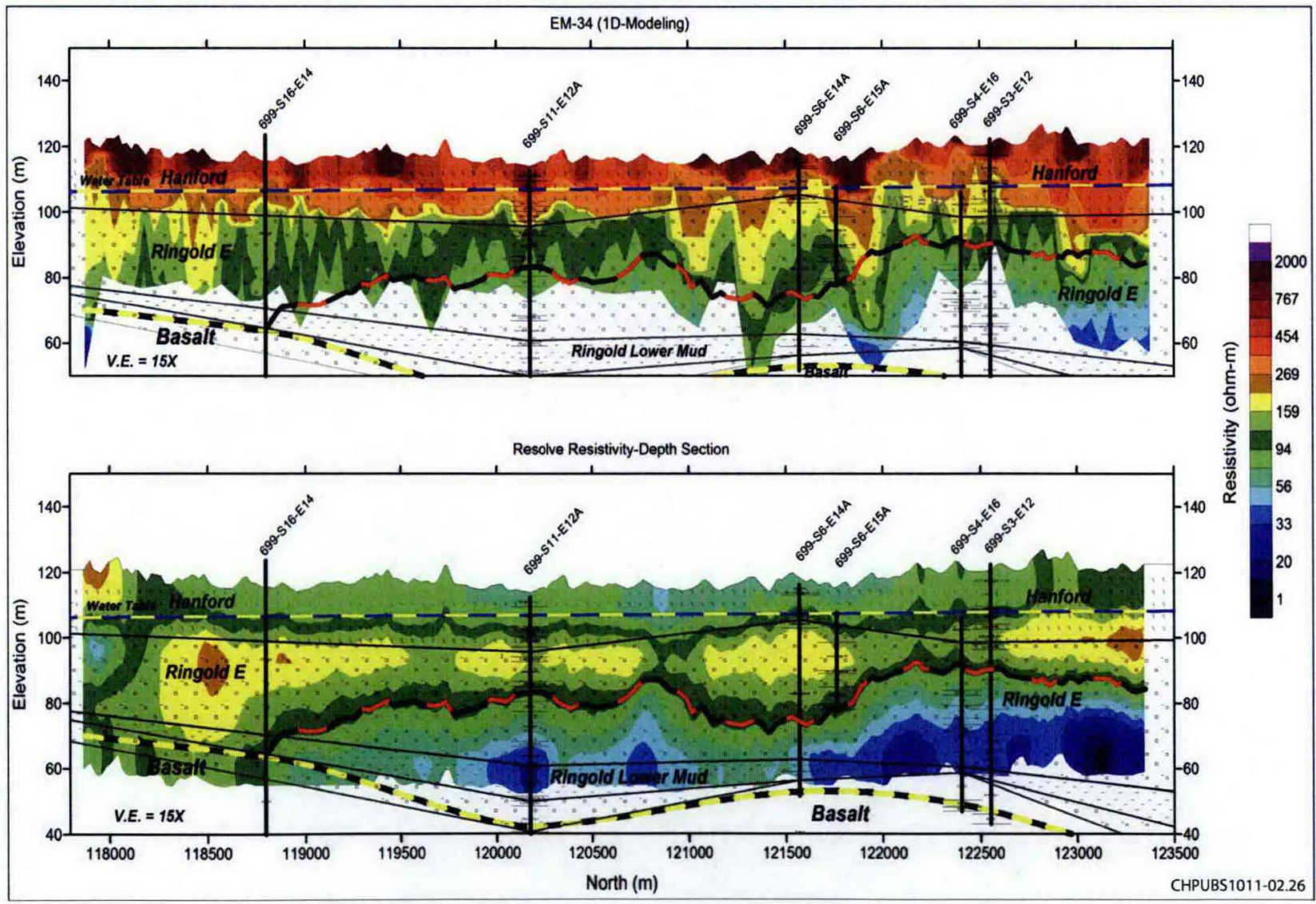

Figure 4-2. Comparison of EM-34 and RESOLVE Models 
The RESOLVE data map a more uniform and consistent zone of intermediate resistivity (125 to $250 \mathrm{ohm}-\mathrm{m}$ ) within the upper part of the Ringold than what is indicated in the EM-34 data. Primary differences likely arise from limitations of the 1D modeling used for the EM-34 data to generate the geo-electric section. The EM-34 was also not able to investigate to the same depth extent as the RESOLVE data.

A relative intra-Ringold thickening of a zone of higher resistivity is modeled by both methods between profile coordinates 121000 and 122000 . This high resistivity zone is likely comprised of a more coarse-grained facies within the Ringold.

Both techniques model a zone of low resistivity at depth on the north end of the profile. The greater investigation depth afforded by the RESOLVE survey allows for better detail of this zone.

The AEM survey has likely failed to model the more electrically resistive vadose sediments. The ground based EM data has better detail on the likely change in geo-electric character across the water table, generally indicating higher $(>400 \mathrm{ohm}-\mathrm{m})$ values above and lower $(<270 \mathrm{ohm}-\mathrm{m})$ values below. Such a change in resistivity is consistent with a change from vadose to saturated conditions.

Original interpretations of the RESOLVE data argued for an inverse relationship with lower resistivity material within the vadose zone and increased resistivity within the saturated interval. Analyses of the EM-34 and 2D resistivity data, and discussions with the vendor (Fugro), indicate that the RESOLVE system is not correctly measuring the near surface material. This is most likely due to the very high resistivity $(>1,000 \mathrm{ohm}-\mathrm{m})$ of the vadose sediments which correlates to very low electrical conductivity, and the RESOLVE EM system is not sensitive to the resulting small scale changes in conductivity. At depth, increase in saturation and the presence of finer-grained sediments provide conditions where the RESOLVE data work better. The EM-34 was operating at the lower end of its sensitivity range, recording raw values down to 1 to $2 \mathrm{mS} / \mathrm{m}$ (500 to $1,000 \mathrm{ohm}-\mathrm{m})$ for the near surface material.

\subsection{D Resistivity and RESOLVE Comparison}

Results for the 2D resistivity modeling are compared with the AEM RESOLVE survey in Figure 4-3. The red and black dashed line is a $100 \mathrm{ohm}-\mathrm{m}$ contour based on the RESOLVE model and is used as a visual guide when correlating features. Also shown on Figure 4-3 are the geologic contacts developed for the 200-PO-1 J-J' geologic cross-section (see Figure 2-3 and Figure 3-1 for additional details and location). The water table (DOE/RL-2008-66) and basalt surface (Thorne et al., 2006) are also plotted, as are driller's descriptions from wells adjacent to the profile.

Both geo-electrical sections in Figure 4-3 show a similar gross change from more resistive to more conductive at depth that is either an intra-Ringold change (RESOLVE) or the Hanford-Ringold contact (2D resistivity). Primary differences likely arise from limitations of EM methods to correctly imaging zones of higher resistivity. Both surveys estimate a similar range in resistivity for the Ringold sediments, however the RESOLVE data model a change from relatively higher $(>150 \mathrm{ohm}-\mathrm{m})$ to lower $(<100 \mathrm{ohm}-\mathrm{m})$ at a depth lower than the $2 \mathrm{D}$ resistivity data.

Zones of very low resistivity $(<40 \mathrm{ohm}-\mathrm{m})$ are modeled at depth by both methods, and these zones likely correlate with the Ringold Lower Mud or with clayey intervals within the Ringold. One low resistivity zone is centered within a topographic depression in the basalt surface (near profile coordinate 120250).

A relative thickening of the zone of increased resistivity modeled in the upper part of the Ringold by the RESOLVE survey has a corresponding increase in the $2 \mathrm{D}$ resistivity data. One possible interpretation is a change from finer- to coarser-grained sediment within the Ringold as evidenced by the driller's 
descriptions. Another possibility is that this more resistive zone corresponds to Hanford sediments that are infilling a channel incised into the upper part of the Ringold.

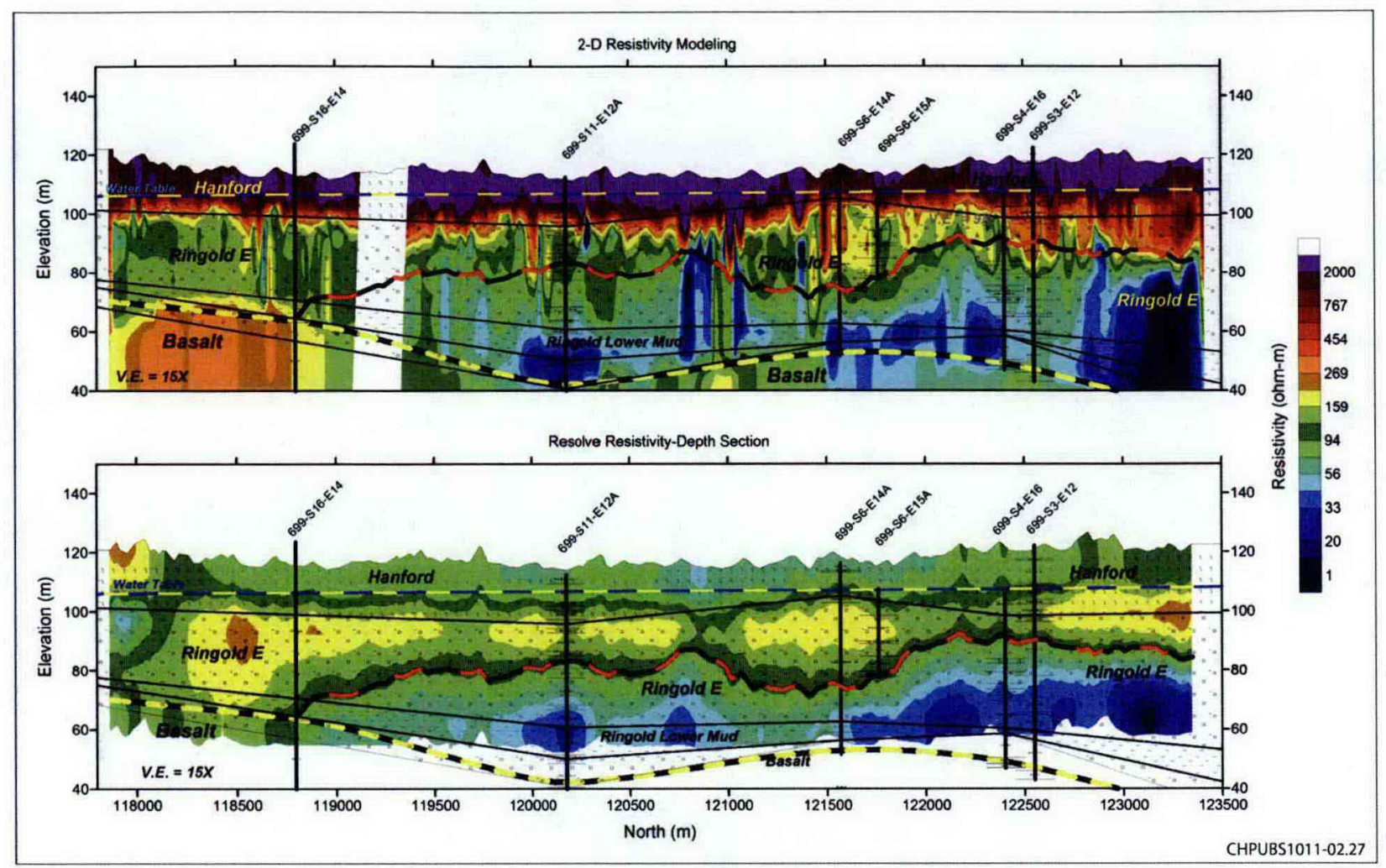

Figure 4-3. Comparison of 2D Resistivity and RESOLVE Data

The RESOLVE model could not distinguish the vadose zone sediments nor the decrease in resistivity associated with the change from vadose to saturated conditions. This is most likely due to the near surface sediments having very high resistivities $(>1,500 \mathrm{ohm}-\mathrm{m})$ which corresponds to very low electrical conductivities below the sensitivity range of the RESOLVE system.

\subsection{D Resistivity and HeliGEOTEM Comparison}

The HeliGEOTEM and 2D resistivity geo-electrical models are compared in Figure 4-4.

The HeliGEOTEM model is taken directly from SGW-42313 and re-colored and contoured based on the current resistivity color scale. Also shown are the geologic contacts developed for the 200-PO-1 J-J' geologic cross-section (see Figure 2-3 and Figure 3-1 for additional details and location). The water table (DOE/RL-2008-66) and basalt surface (Thorne et al., 2006) are also plotted, as are driller's descriptions from wells adjacent to the profile.

HeliGEOTEM has the poorest resolution of all four methods and requires modeling (inversion) prior to comparison with the underlying geology. North of the geophysical test profile (see Figure 3-4), the HeliGEOTEM data model a zone of very low resistivity that appears to correlate with the Ringold Lower Mud. Within the bounds of the test profile, the Ringold Lower Mud is likely modeled with a zone of very low resistivity $(<40 \mathrm{ohm}-\mathrm{m})$ near coordinate 120250 . This low resistivity zone appears to coincide with a topographic depression in the basalt's surface. 


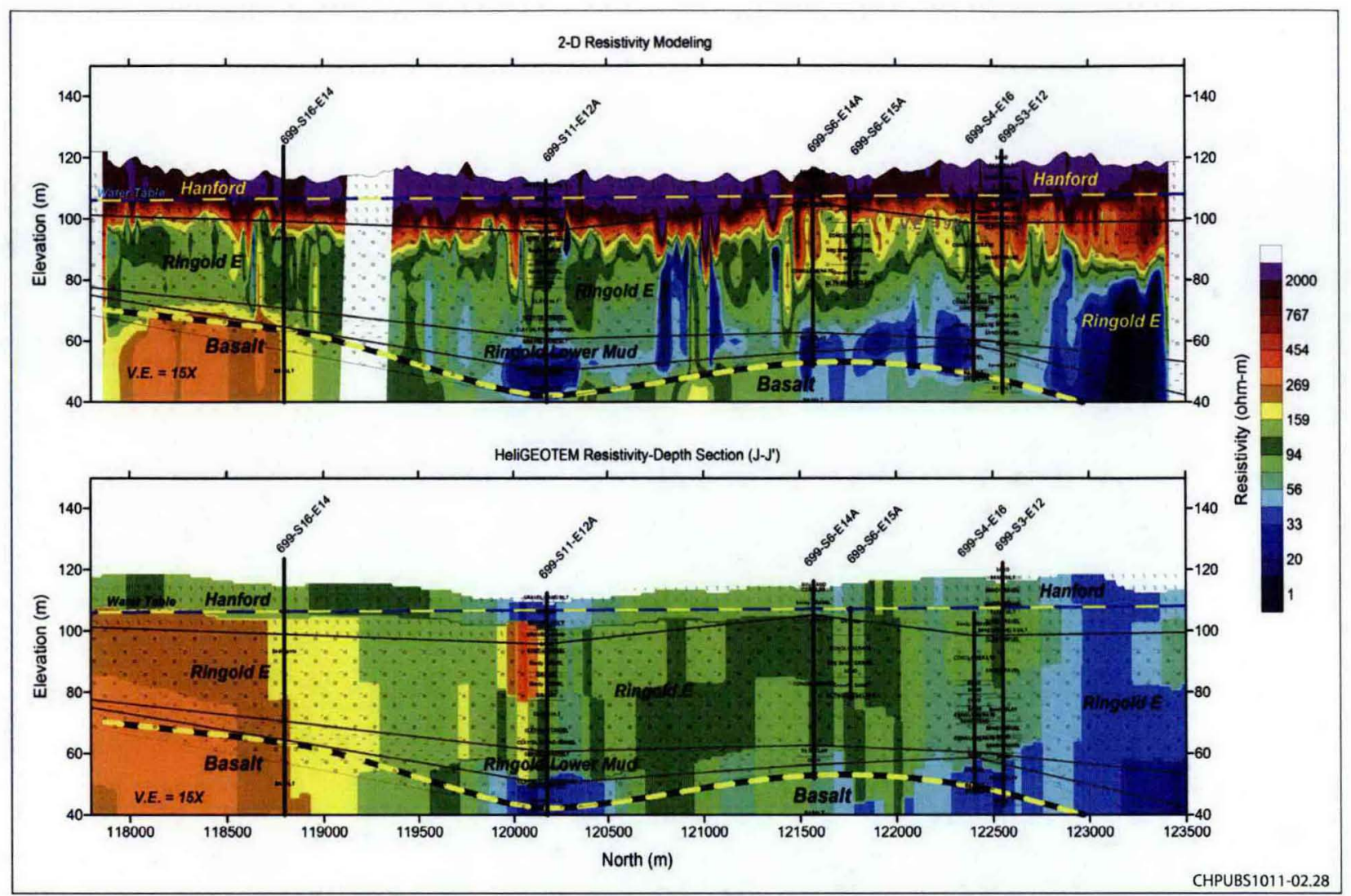

Figure 4-4. Comparison of 2D Resistivity and HeliGEOTEM Model

Both surveys indicate higher resistivities $(>250 \mathrm{ohm}-\mathrm{m})$ in a zone that correlates with the underlying basalt. The relatively poor resolution afforded by the HeliGEOTEM results in its model smearing the Ringold-basalt contact. 
SGW-47996, REV. 0 


\section{Summary and Conclusions}

Ground based geophysical data were successfully acquired and used to provide estimates of the underlying geo-electrical structure of the Hanford, Ringold, and Columbia River geologic units. Both frequency domain EM (EM-34) and 2D direct current electrical resistivity data were acquired, and results of both ground based surveys were compared with AEM data.

\subsection{Major Conclusions}

The following conclusions were based on the EM-34 Surveys:

- The shallowest investigation depth of methods was deployed in this study, which requires inverting raw data to the layered model prior to interpretation.

- The Hanford-Ringold contact appeared to be mapped as a change from higher resistivity $(>200 \mathrm{ohm}-\mathrm{m})$ to predominantly lower resistivities $(<130 \mathrm{ohm}-\mathrm{m})$.

- A zone of very low resistivity $(<45 \mathrm{ohm}-\mathrm{m})$ was partially detected at a depth that may correlate with the Ringold Lower Mud, or at least clayey intervals within the Ringold.

- A possible Ringold facies change to coarser-grained intervals is mapped as a relative thickening in a resistive zone (coordinates 121000 to 122000 ). An alternate interpretation is that these are actually Hanford sediments that have been filled into a channel incised into the top-of-Ringold.

The following conclusions were based on 2D resistivity:

- 2D resistivity has an investigation depth of $80 \mathrm{~m} \mathrm{(262} \mathrm{ft)} \mathrm{to} 120 \mathrm{~m}(394 \mathrm{ft})$ for the electrode geometry used, and the depth of investigation can be increased at expense of vertical and horizontal resolution.

- This was the slowest survey of all four methods and required approximately six days to acquire $5.5 \mathrm{~km}$ of profile data.

- The change from unsaturated to saturated conditions was successfully mapped (modeled with and without using layer constraints). Vadose units are generally greater than $1,000 \mathrm{ohm}-\mathrm{m}$ in the survey area, whereas saturated units are in a broader, but generally lower resistivity range of 300 to 1,500 .

- Hanford-Ringold contact is most likely represented from a change from higher resistivity (Hanford, $>250 \mathrm{ohm}-\mathrm{m}$ ) to lower resistivity (Ringold is generally less than $150 \mathrm{ohm}-\mathrm{m}$ in resistivity).

- A possible Ringold facies change to coarser-grained intervals is mapped as a relative thickening in a resistive zone (coordinates 121000 to 122000 ). An alternate interpretation is that actual Hanford sediments have been filled into a channel incised into the top-of-Ringold.

- Zones of very low resistivity ( $<40 \mathrm{ohm}-\mathrm{m})$ are mapped within the Ringold and likely correspond to the Ringold Lower Mud or clayey intervals within the Ringold. One low resistivity zone is within a local topographic depression on the basalt surface (near profile coordinate 120250).

- Top-of-basalt is imaged as a general increase in resistivity across the Ringold-Basalt contact, with best results occurring near the south end of the profile where the basalt is shallowest. 
The following conclusions were based on both the EM-34 and 2D resistivity surveys:

- Both methods show a general decrease in resistivity with depth that corresponds to the change from unsaturated to saturated conditions. The EM-34 system likely underestimates the unsaturated values.

- A resistivity change from higher $(>200 \mathrm{ohm}-\mathrm{m})$ to lower $(<150 \mathrm{ohm}-\mathrm{m})$ is modeled across the entire profile by both methods, and this change likely corresponds to the Hanford-Ringold contact.

- An intra-Ringold zone of increased resistivity (profile coordinates 121000 to 122000 ) is imaged by both techniques. This zone may be either Hanford units incised into the Ringold or an intra-Ringold facies change from fine- to coarse-grained sediments.

- A zone of low resistivity at depth near the north end of the geophysical survey is modeled by both methods and may correlate with clayey units or the Ringold Lower Mud.

The following conclusions were based on EM-34 - RESOLVE:

- RESOLVE survey does not correctly image the near surface, vadose zone sediments. This is most likely due to these sediments having very high resistivities $(>1,500 \mathrm{ohm}-\mathrm{m})$ which corresponds to very low electrical conductivities and below the sensitivity range of the RESOLVE system. The EM-34 does detect a decrease in resistivity from vadose to saturated conditions, but likely underestimates the resistivity of the vadose units.

- Both surveys estimate a similar range in resistivity for the likely Ringold Units. The RESOLVE model, however, places the change from relatively higher $(>150 \mathrm{ohm}-\mathrm{m})$ to lower $(<100 \mathrm{ohm}-\mathrm{m})$ resistivity at a lower elevation than the EM-34.

- A zone of very low resistivity at depth near the north end of the profile is partially detected by the EM-34 and more fully imaged by the deeper penetrating RESOLVE system. This zone likely correlates with clayey units or the Ringold Lower Mud.

The following conclusions were based on 2D resistivity-RESOLVE:

- Both surveys estimate a similar range in resistivity for the likely Ringold Units. In the southern two-thirds of the profile, the RESOLVE model places the change from relatively higher $(>150 \mathrm{ohm}-\mathrm{m})$ to lower $(<100 \mathrm{ohm}-\mathrm{m})$ resistivity at a lower elevation than does the $2 \mathrm{D}$ resistivity model.

- Zones of very low resistivity are modeled at depth by both methods. These zones likely correlate with clayey units or the Ringold Lower Mud.

The following conclusions were based on 2D resistivity - HeliGEOTEM:

- HeliGEOTEM has the poorest resolution and requires modeling (inversion) prior to comparison with the underlying geology. North of the geophysical test profile, the HeliGEOTEM data model has a zone of very low resistivity that appears to correlate with the Ringold Lower Mud.

- Within the test profile, the Ringold Lower Mud is likely modeled with a zone of very low resistivity ( $<40 \mathrm{ohm}-\mathrm{m}$ ) near coordinate 120250 . This low resistivity zone appears to coincide with a topographic depression in the basalt's surface.

- Both surveys indicate higher resistivities $(>250 \mathrm{ohm}-\mathrm{m})$ in a zone that correlates with the underlying basalt. The coarser-resolution provided by the HeliGEOTEM has smeared this zone. 


\section{References}

Advanced Geosciences, Inc., 2001, SuperSting R8 IP 8-Channel Memory Earth Resistivity and IP Meter Instrument Manual, Advanced Geosciences, Inc., Austin, Texas. Available at: http://www.agisusa.com/supersting.shtml.

BHI-00184, 1995, Miocene- to Pliocene-Aged Suprabasalt Sediments of the Hanford Site, South-Central Washington, Rev. 00, Bechtel Hanford, Inc., Richland, Washington.

DOE/RL-2002-39, 2002, Standardized Stratigraphic Nomenclature for Post-Ringold-Formation Sediments Within the Central Pasco Basin, Rev. 0, U.S. Department of Energy, Richland Operations Office, Richland, Wasington.

DOE/RL-2008-66, 2009, Hanford Site Groundwater Monitoring for Fiscal Year 2008, Rev. 0, U.S. Department of Energy, Richland Operations Office, Richland, Washington. Available at: http://www2.hanford.gov/arpir/?content=findpage\&AKey=0905131281. http://www2.hanford.gov/arpir/?content=findpage\&AKey $=0905131282$.

Geonics, 1991, EM-34 Operating Manual, Geonics Ltd., Mississauga, Ontario, Canada.

Guptasarma, D. and B. Singh, 1997, "New Digital Linear Filters for Hankel J0 and J1 Transforms," Geophysical Prospecting 45(5):745-762.

Keller, G.R., 1966, "Electrical Properties of Rocks and Minerals," in Handbook of Physical Constants, rev. ed. Geological Society of America Memoir 97, pp. 553-577.

Koefoed, O., D.P. Ghosh, and G.J. Polman, 1972, "Computation of Type Curves for Electromagnetic Depth Sounding with a Horizontal Transmitting Coil by Means of a Digital Linear Filter," Geophysical Prospecting 20(2):406-420.

Lines, L.R. and S. Treitel, 1984, “A Review of Least-Squares Inversion and its Application to Geophysical Problems,” Geophysical Prospecting 32(2):159-186.

Loke, M.H., 2006, “1-D Frequency Domain EM Modeling,” FreqEM Software Manual, PugSoft, Inc., Penang, Malaysia.

Loke, M.H., 2010, "Rapid 2D Resistivity \& IP Inversion Using the Least-Squares Method," RES2DINV Version 3.59 Software Manual, GEOTOMO Software, Penang, Malaysia.

PNNL-12261, 2000, Revised Hydrogeology for the Suprabasalt Aquifer System, 200-East Area and Vicinity, Hanford Site, Washington, Pacific Northwest National Laboratory, Richland, Washington. Available at: http://www5.hanford.gov/arpir/?content=findpage\&AKey=0906180659.

PNNL-14753, 2006, Groundwater Data Package for Hanford Assessments, Rev. 1, Pacific Northwest National Laboratory, Richland, Washington. Available at: http://www.pnl.gov/main/publications/external/technical_reports/PNNL-14753Rev1.pdf.

PNNL-15237, 2005, Geology of the Integrated Disposal Facility Trench, Pacific Northwest National Laboratory, Richland, Washington. Available at: http://www5.hanford.gov/arpir/?content=findpage\&AKey=DA451550. 
PNNL-16346, 2007, Hanford Site Groundwater Monitoring for Fiscal Year 2006, Pacific Northwest National Laboratory, Richland, Washington. Available at:

http://www.pnl.gov/main/publications/external/technical_reports/PNNL-16346.pdf.

PNNL-17821, 2008, Electrical Resistivity Correlation to Vadose Zone Sediment and Pore-Water Composition for the BC Cribs and Trenches Area, Pacific Northwest National Laboratory, Richland, Washington.

PNNL-SA-53273, 2007, Hanford Site Vadose Zone Studies: An Overview, Pacific Northwest National Laboratory, Richland, Washington. Available at: http://ifchanford.pnl.gov/pdfs/53286 gee.pdf.

Sengpiel, K.P., 1988, “Approximate Inversion of Airborne EM Data from a Multi-Layered Ground,” Geophysical Prospecting 36:446-459.

SGW-39674, 2009, Airborne Electromagnetic Survey Report, 200-PO-1 Groundwater Operable Unit, 600 Area, Hanford Site, Rev. 0, CH2M HILL Plateau Remediation Company, Richland, Washington.

SGW-42313, 2009, Geophysical Investigations: 200-PO-1 Groundwater Operable Unit, Rev. 0, CH2M HILL Plateau Remediation Company, Richland, Washington.

SGW-47839, 2010, Interpretation of Airborne Electromagnetic and Magnetic Data in the 600 Area, Rev. 0, CH2M HILL Plateau Remediation Company, Richland, Washington. 
SGW-47996, REV. 0

\section{Appendix A}

Geophysical Methods 
SGW-47996, REV. 0

A-ii 
SGW-47996, REV. 0

\section{Terms}

2D

ASTM

DC

EM

ERI

VES two-dimensional

American Society for Testing and Materials

direct current

electromagnetic

electrical resistivity imaging

vertical electrical sounding 
SGW-47996, REV. 0

A-iv 


\section{A1 Geophysical Methods}

Geophysical methods used in this investigation consisted of electromagnetic (EM) terrain-conductivity surveying and two-dimensional (2D) electrical resistivity imaging (ERI). In order to meet data quality and project objectives, the following guidelines developed by the American Society for Testing and Materials (ASTM) were used in the construction and implementation of the geophysical surveys: ASTM D6431-99, Standard Guide for Using the Direct Current Resistivity Method for Subsurface Investigation, for 2D-ERI profiling and ASTM D6639-01, Standard Guide for Using the Frequency Domain Electromagnetic Method for Subsurface Investigations, for the EM surveys.

\section{A2 Electrical Resistivity}

Electrical resistivity is an intrinsic property of the earth that is controlled by the mineralogical composition of the matrix (sediment grain or rock type), the size and arrangement of individual grains or minerals, and the electrical properties of the pore-fluid (if present). Electrical resistivity is expressed in units of ohm-m. In freshwater environments, coarser grain units such as sand and gravel zones tend to have a higher electrical resistivity than adjacent clay and silt intervals. In the presence of electrically conductive fluids, or interstitial components, the electrical resistivity will be decreased.

In Archie, 1942, "The Electrical Resistivity Log as an Aid in Determining Some Reservoir Characteristics," the following empirical relationship between resistivity and granular sediment properties was determined:

$$
\mathrm{R}_{\mathrm{b}}=\frac{\mathrm{FR}_{\mathrm{w}}}{\mathrm{S}_{\mathrm{w}}^{\mathrm{n}}}
$$

where:

$R_{b}=$ resistivity of the formation (bulk or measured resistivity)

$R_{w}=$ resistivity of the pore water

$\mathrm{S}_{\mathrm{w}}$ = water saturation index (percent pore space occupied by water, 0 to 1 )

$\mathrm{n}$ = empirical constant, commonly taken to be 2 (Hilchie, 1989, Advanced Well Log Interpretation)

$\mathrm{F}$ = formation resistivity factor, which is described by the following

$$
\mathrm{F}=\mathrm{a} / \Phi^{\mathrm{m}}
$$

where:

$\phi=$ porosity (and a and $\mathrm{m}$ empirical constants depend on the pore geometry and cementation properties of the sediment)

Thus, changes in resistivity for a particular sediment type can be due to change in either saturation or fluid-electrical properties. For example, decreasing the saturation from fully saturated $\left(S_{w}=1\right)$ to partial saturation $\left(S_{w}<1\right)$ will increase the measured resistivity. Increasing the total dissolved solids of the pore-fluid will likely decrease the electrical resistivity of the pore-fluid and decrease the measured electrical resistivity. 


\section{A3 Two-Dimensional Resistivity Surveying}

2D-ERI (Loke and Barker, 1996, "Rapid Least-Squares Inversion of Apparent Resistivity Pseudosections by a Quasi-Newton Method") is used to measure subsurface changes in resistivity associated with either changes in rock or sediment type, changes in saturation, or changes in pore-fluid electrical properties.

\section{A3.1 General Description}

The 2D-ERI method is normally acquired using a multi-electrode system that uses various electrode combinations (electrode arrays) to inject direct current (DC) electrical current and measure voltages (Figure A-1). Two electrodes $(\mathrm{C} 1, \mathrm{C} 2)$ are used for injecting the electric current, and two different electrodes (P1, P2) are used for measuring the voltage (potential difference). The measured voltage is a factor of the resistance of the earth material and the geometric factor defined by electrode array (e.g., Pole-Pole, Schlumberger, and Dipole-Dipole). Electrical resistivity is then calculated using the measured voltage, the electric current strength, and a geometric factor for the electrode array. The calculated resistivity value is actually an apparent resistivity because it includes the resistances of all the material that the electrical current passes through. A modeling procedure is then used to convert the measured apparent resistivity data into earth-layer resistivity sections.

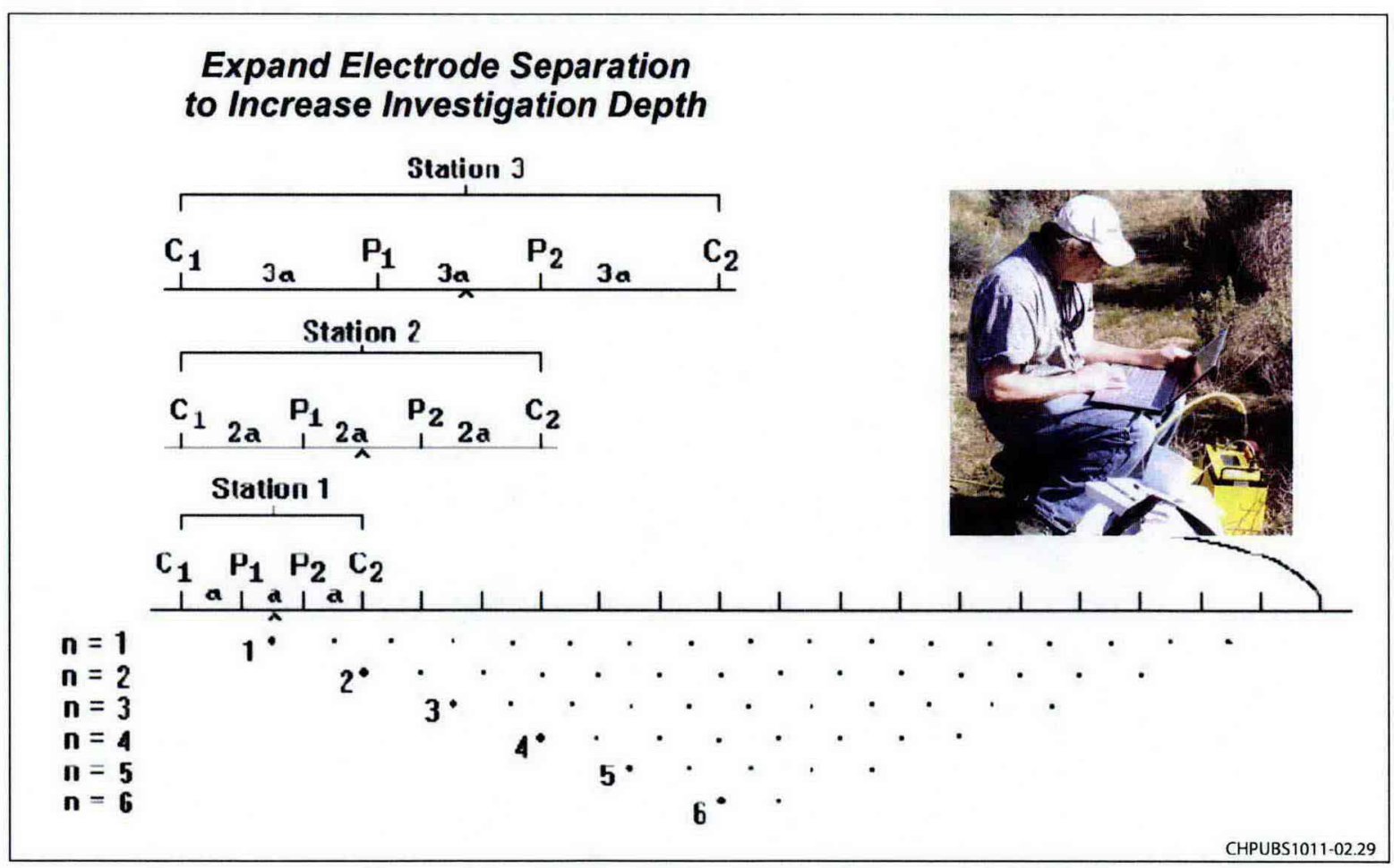

Figure A-1. Two-Dimensional Resistivity Equipment Layout

The electrodes used to measure the voltage difference are arranged in various geometries called arrays, and the calculated apparent resistivity value is interpreted to represent a depth point at the center of an individual array (Figure A-2). Depth of measurement is related to width of electrode separation, with greater electrode separation resulting in greater depths of penetration. Classically, two different techniques are used to determine the electrical resistivity of earth materials. In vertical electrical sounding (VES), electrodes are expanded about the center of an array to generate a one-dimensional layered electrical section at a single point (vertical profile). The lateral profiling technique uses an array with a fixed electrode separation, which is marched along a line to image lateral variations at a constant depth. 


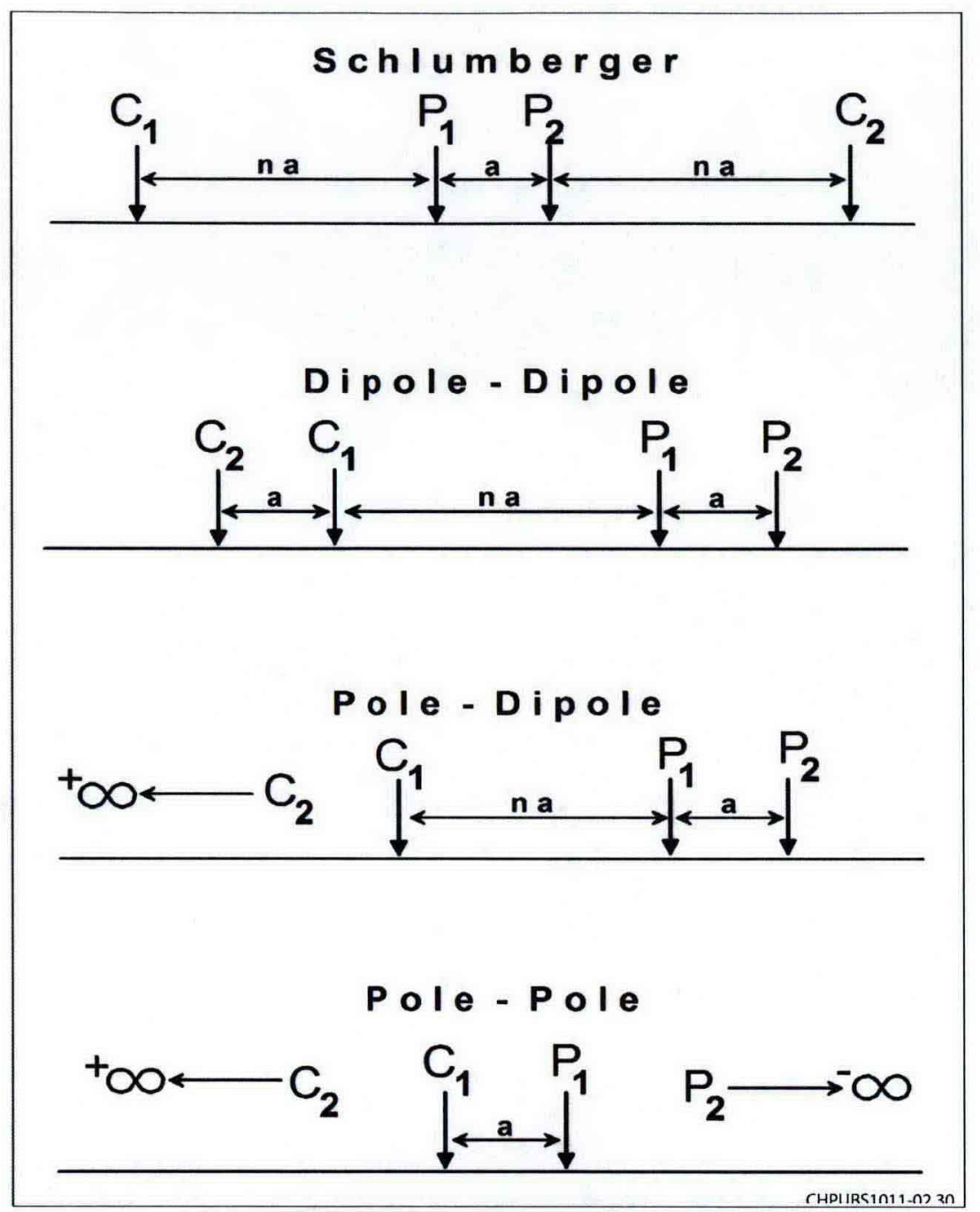

Figure A-2. 2D Resistivity Electrode Arrays

2D-ERI combines VES and lateral profiling into a single survey without the time consuming process of constantly moving electrodes and reconnecting cables. In 2D-ERI, a single cable connects a linear array of electrodes, which are turned on and off using a preprogrammed sequence via a controller box.

The raw apparent resistivity data are typically displayed as a pseudo-section where the lateral position of the measurement point is placed at the center of the corresponding electrode array, and the depth of the measurement is proportional to the electrode spacing (Figure A-3). Apparent resistivity pseudo-sections are useful for performing quality control checks and examining whether manmade objects (e.g., buried utilities) have impacted the data set.

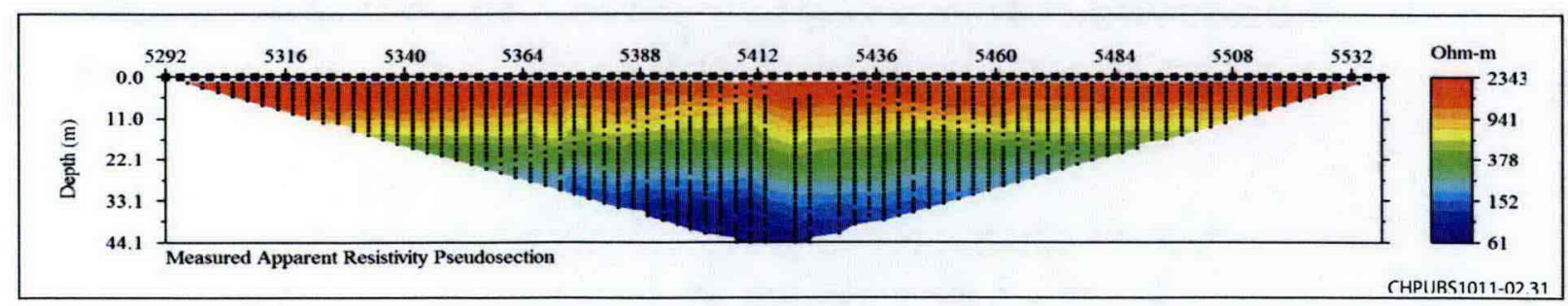

Figure A-3. Apparent Resistivity Pseudo-Section 


\section{A3.2 Two-Dimensional Resistivity Equipment}

Resistivity data were acquired using the SuperSting R8 system (Advanced Geosciences, Inc., 2001, SuperSting R8 IP 8-Channel Memory Earth Resistivity and IP Meter Instrument Manual, which allows for a maximum of eight channels of voltage information to be recorded per measurement cycle (Figure A-4). The system is DC-powered and records data on internal memory, which is later downloaded to a laptop or personal computer. Both smart electrodes (self turn on/off) and switch box configurations were used to record data along the geophysical test profile.

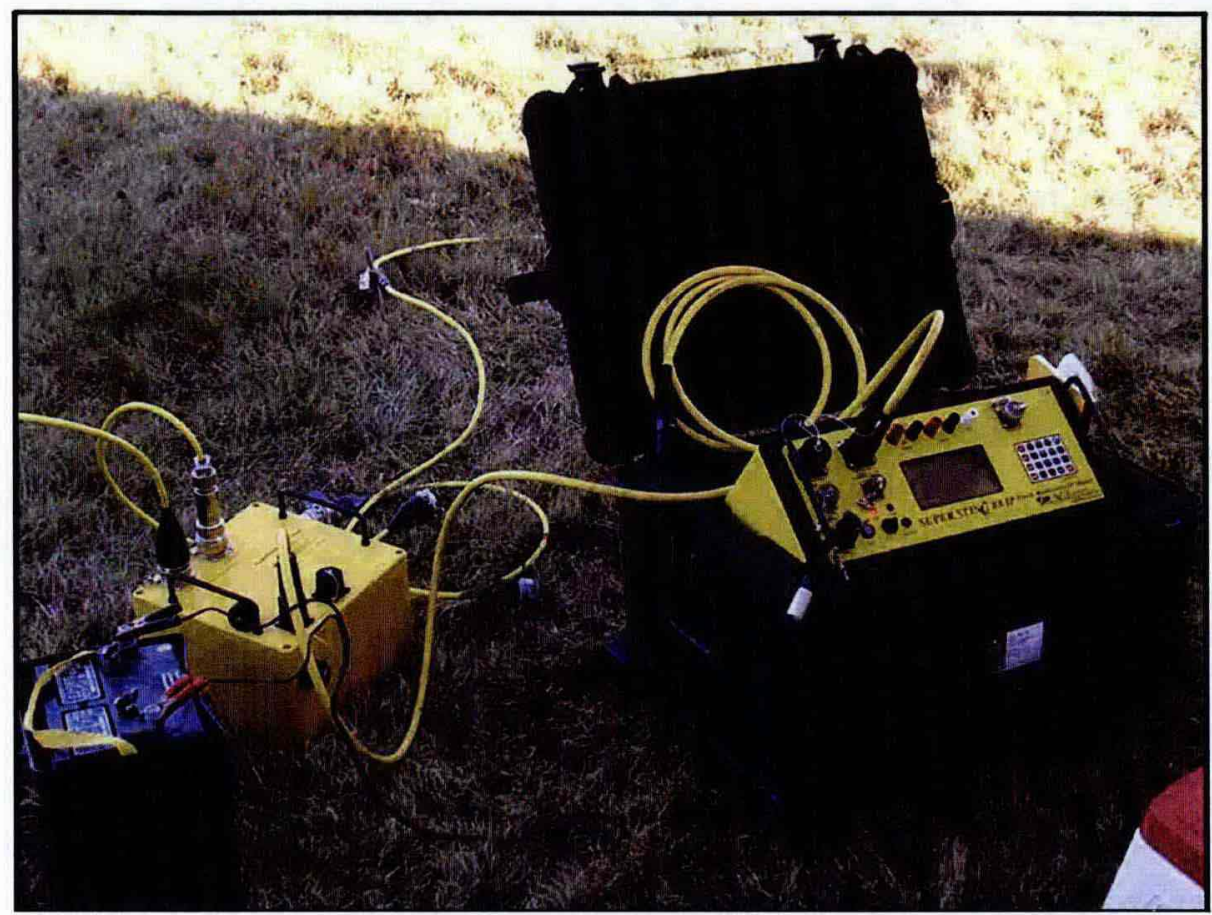

Figure A-4. Advanced Geosciences, Inc. SuperSting R8 Electrodes and Cabling

Linear arrays from 28 to 84 electrodes were acquired during the surveys using electrode spacing of $3 \mathrm{~m}$ $(9.8 \mathrm{ft})$ for testing and $6 \mathrm{~m}(19.7 \mathrm{ft})$ for production. Stainless steel electrodes of $25 \mathrm{~cm}(10$-in.) in length (Figure A-4) were used, and the ground surface around the electrode position was watered to improve soil-electrode coupling (reduce contact resistance).

Data were acquired in the resistivity mode using three measurement cycles at 1.2 second intervals.

Measurements were rejected if the repeat error during the three measurement cycles exceeds five percent. Maximum allowed injection current was $350 \mathrm{~mA}$, and the instrument was allowed to adjust the current automatically in order to improve signal-to-noise.

\section{A3.3 Processing Two-Dimensional Resistivity Data}

Apparent resistivity pseudo-sections are converted into a geo-electrical model of the subsurface (estimate of the true resistivity distribution) through a process termed inversion. Prior to performing the inversion, the raw data need to be screened in order to remove noisy data points that may negatively impact the inversion resulting in unrealistic estimates of the subsurface resistivity distribution.

Data points are screened using both automatic and manual (subjective) methods. 
Automatic screening consists of removing data points with high-repeat errors ( $>5$ percent), extremely high values of resistivity, and negative values and for abnormally low injection current. High repeat errors and points with extremely high values of resistivity are most likely caused by poor electrode-ground coupling, and negative values are likely the result from poor signal-to-noise.

Manual data removal involves examining the resulting pseudo-depth sections for obvious noise spikes or data drops that violate potential field theory (e.g., changes in measured voltages should be smoothly varying). Figure A-5 is an example of the noise spike editing. After data have been screened (edited), an initial set of trial inversions are performed and root-mean-square error statistics are generated for the misfit between the measured and modeled data. These error statistics can be used to provide further editing of the data with a high misfit (error) in order to improve the final model. The latter two steps are completed with extreme care to avoid removal of valid data points.

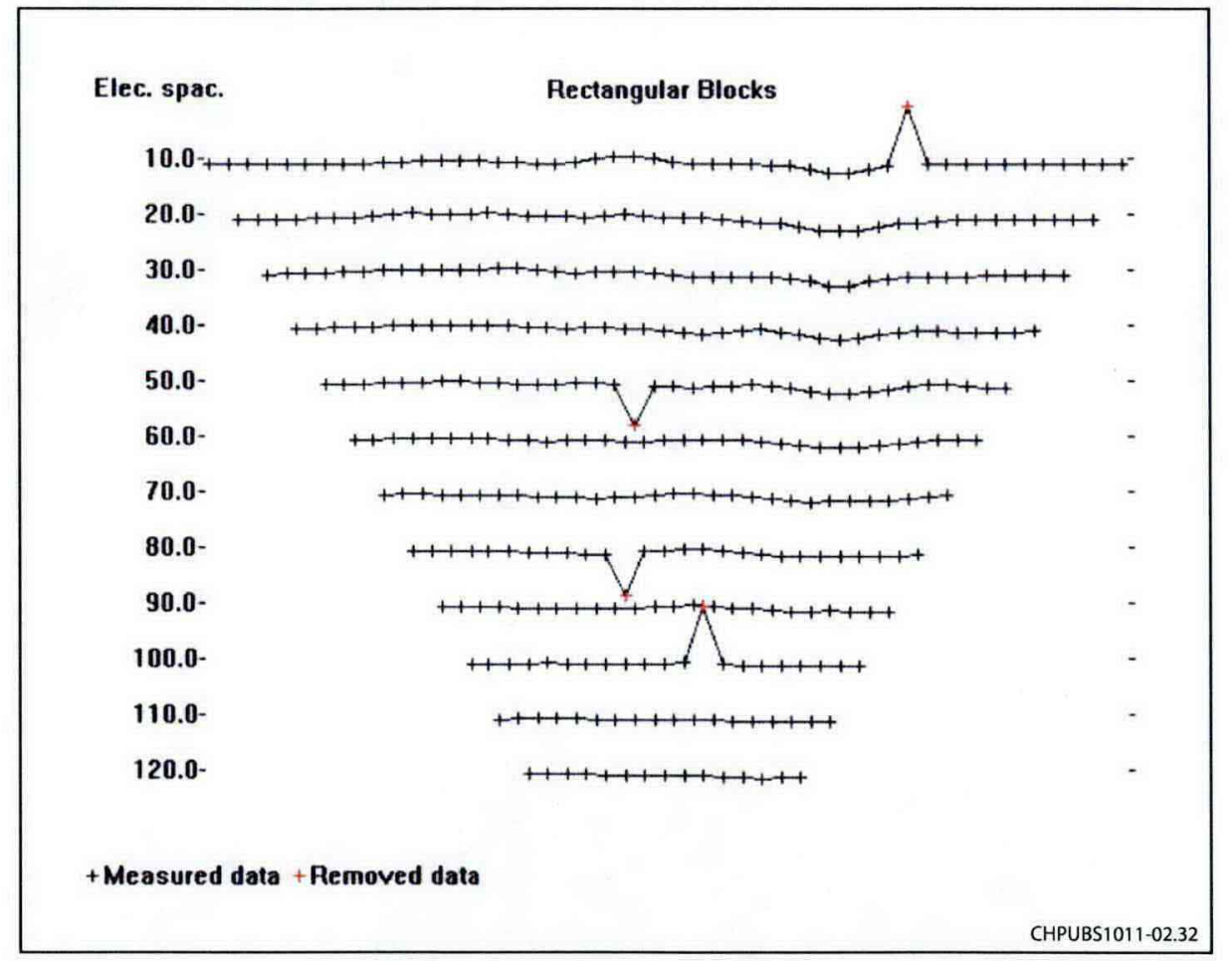

Figure A-5. Noise Spike Editing

The inversion is conducted using a smoothness-constrained least-squares inversion (Lines and Treitel, 1984, "A Review of Least-Squares Inversion and its Application to Geophysical Problems;" deGroot-Hedlin and Constable, 1990, "Occam's Inversion to Generate Smooth, Two-Dimensional Models from Magnetotelluric Data;" Sasaki, 1992, "Resolution of Resistivity Tomography Inferred from Numerical Simulation") that uses an iterative process to adjust the estimated subsurface resistivity distribution based on the misfit between the measured data and the modeled data. The inversion model is based on the subsurface being divided into a number of rectangular blocks. The general sequence is as follows:

1. Estimate an initial subsurface model (average of apparent resistivity, user assumptions, or prior knowledge).

2. Forward modeling used to compute a set of theoretical measurement data (model data). 
3. Calculate the degree of misfit between modeled and measured data.

4. Solve a linearized inverse problem using the modeled-measured misfit to develop a model perturbation vector.

5. Apply the perturbation to adjust the subsurface model.

Steps 2 through 5 are repeated until a specified set of iterations is reached or until the inversion converges. Convergence occurs when subsequent changes in the misfit between the modeled and measured data are below a user specified threshold or, in other words, subsequent model adjustments do not produce marked changes in the results of the forward model (modeled data). Maximum convergence often occurs within 3 to 5 iterations, after which misfit values do not change significantly and the model may start to become unstable (Loke, 2010, "Rapid 2D Resistivity \& IP Inversion Using the Least-Squares Method").

Two commercially available programs, RES2DINV (available at: www.geoelectrical.com) and EarthImager (available at: www.agiusa.com), can be used to perform the inversion. Although both programs employ a similar smoothness-constrained, least-squares inversion algorithm, they differ in how the parameters that constrain or control the inversion can be adjusted. For most cases, both programs produce similar results in the modeled geo-electrical section. Figure A-6 shows an output example from the RES2DINV program. The upper panel contains the measured apparent resistivity data, the middle panel is the computed (modeled) apparent resistivity data, and the lower panel is the resulting resistivity cross-section.

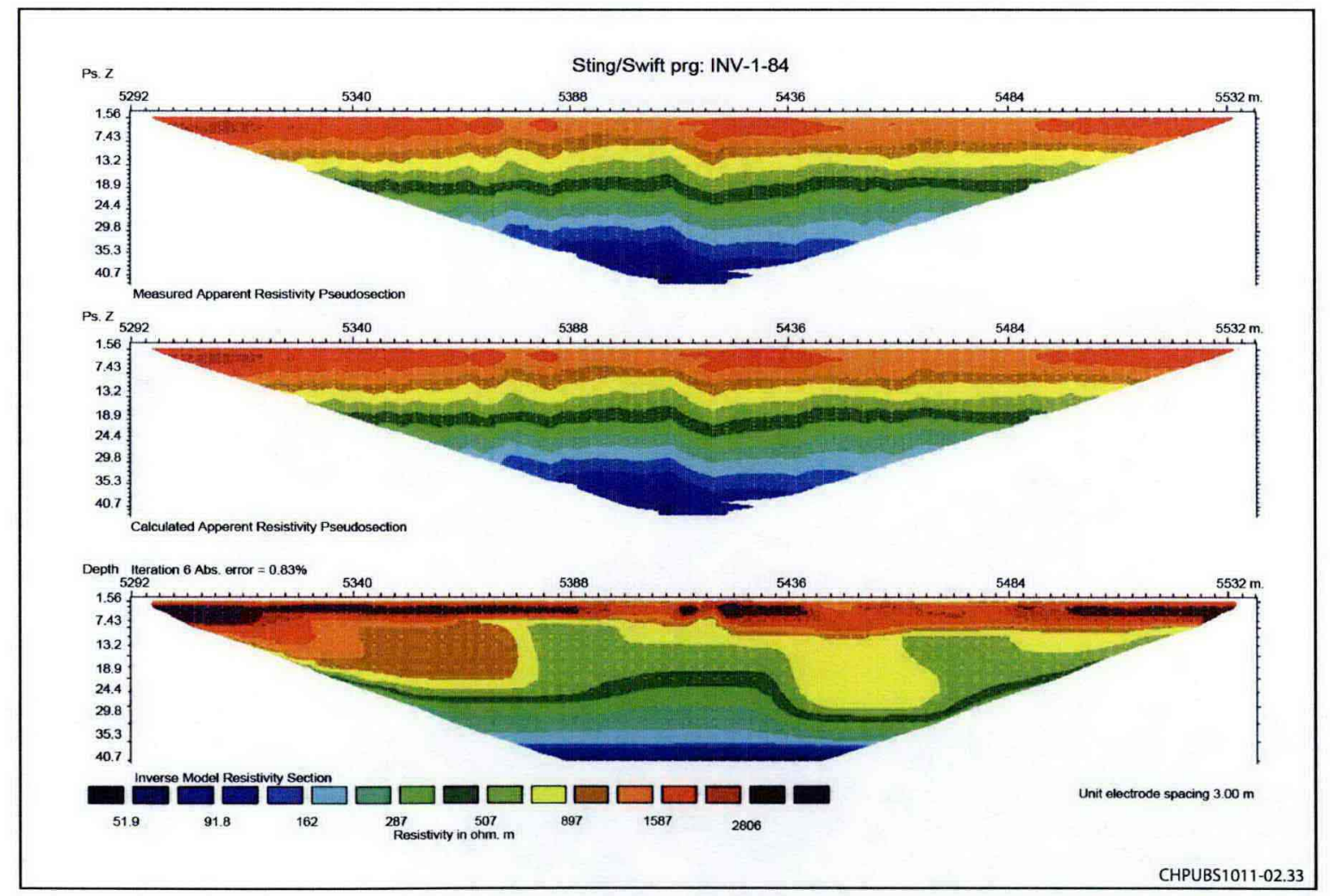

Figure A-6. RES2DINV Output Panel 


\section{A4 Electromagnetic Terrain Conductivity Surveying}

EM terrain conductivity surveying is used to measure the electrical conductivity (inverse of electrical resistivity) of the near surface and can also be used to locate buried metallic objects.

\section{A4.1 General Description}

A transmitter coil is used to induce an electrical current into the ground, and the receiver coil measures the strength of the secondary magnetic field generated by these currents. Two components of the secondary magnetic field are recorded: (1) the quadrature-phase component, which is used to measure the ground conductivity, and (2) the in-phase component, which is used for metallic detection due to its extreme sensitivity to metallic objects (Geonics, 1991, EM-34 Operating Manual). For most conditions, the electrical conductivity of the ground is nearly linearly proportional to strength of the quadrature-phase component, and instruments are calibrated to give results in units of milli-siemens per meter $(\mathrm{mS} / \mathrm{m})$ (McNeill, 1980, "Electromagnetic Terrain Conductivity Measurements at Low Induction Numbers"). The in-phase measurement is the ratio of the secondary magnetic field to the primary field and is expressed in parts per thousand.

The coils can be oriented in either a vertical dipole or horizontal dipole configuration (Figure A-7). For the vertical dipole case, the axes of the coils are oriented perpendicular to the ground surface; for the horizontal dipole case, the axes are parallel to the ground surface. For both cases, the coils are maintained in a coplanar state. The vertical dipole orientation is generally preferred over the horizontal dipole because it provides for a greater investigative depth and is less sensitive to near surface variations.

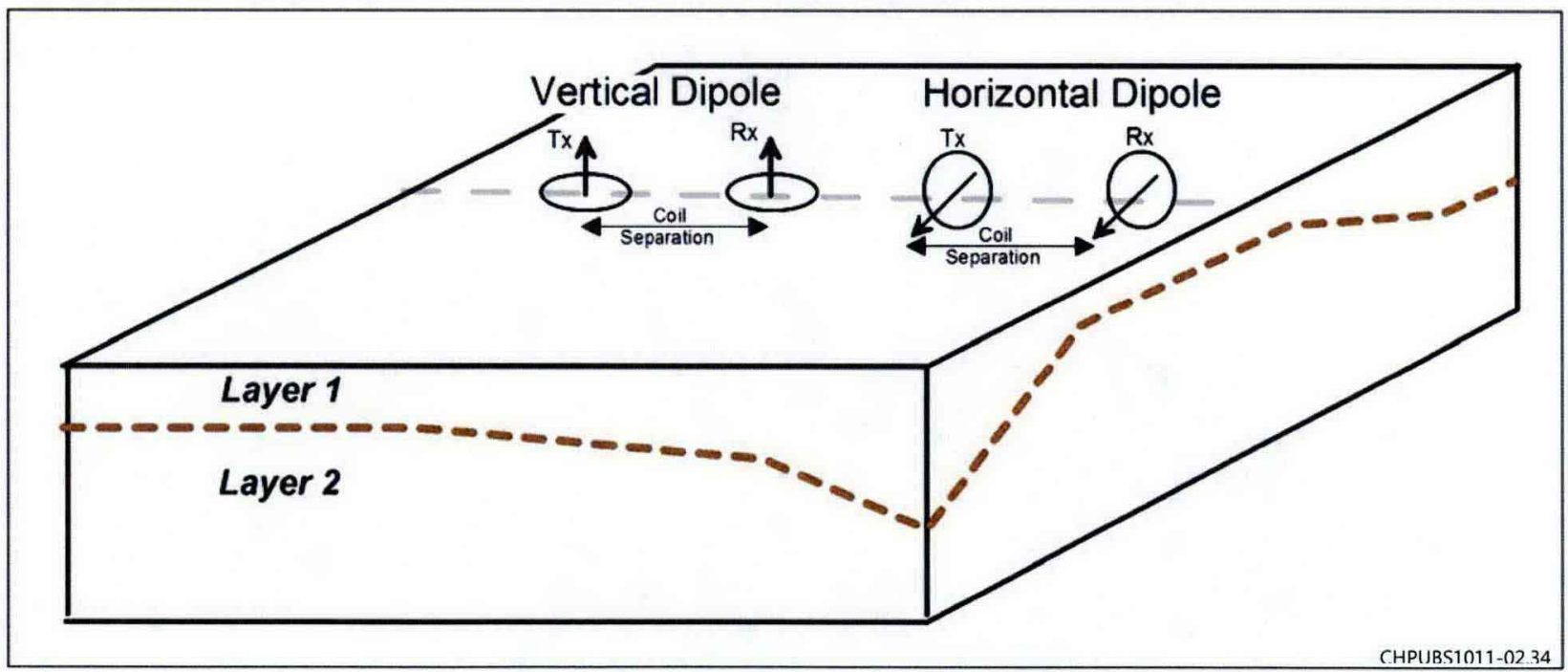

Figure A-7. Horizontal and Vertical Coil Configurations

\section{A4.2 Electromagnetic Equipment}

The Geonics EM-34 is a two-person operable instrument that can measure terrain conductivities to depths

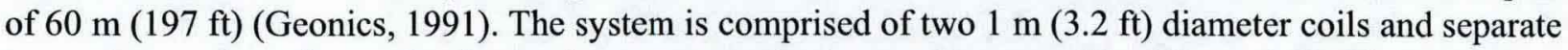
transmitter and receiver units that are interconnected using a reference cable (Figure A-8). The EM-34 operates in the frequency domain and has three pre-programmed coil separations and frequencies $(10 \mathrm{~m}[32.8 \mathrm{ft}]$ at $6,400 \mathrm{~Hz} ; 20 \mathrm{~m}[65.6 \mathrm{ft}]$ at $1,600 \mathrm{~Hz}$; and $40 \mathrm{~m}[131.2 \mathrm{ft}]$ at $400 \mathrm{~Hz})$ to allow for adjusting the depth of investigation. 


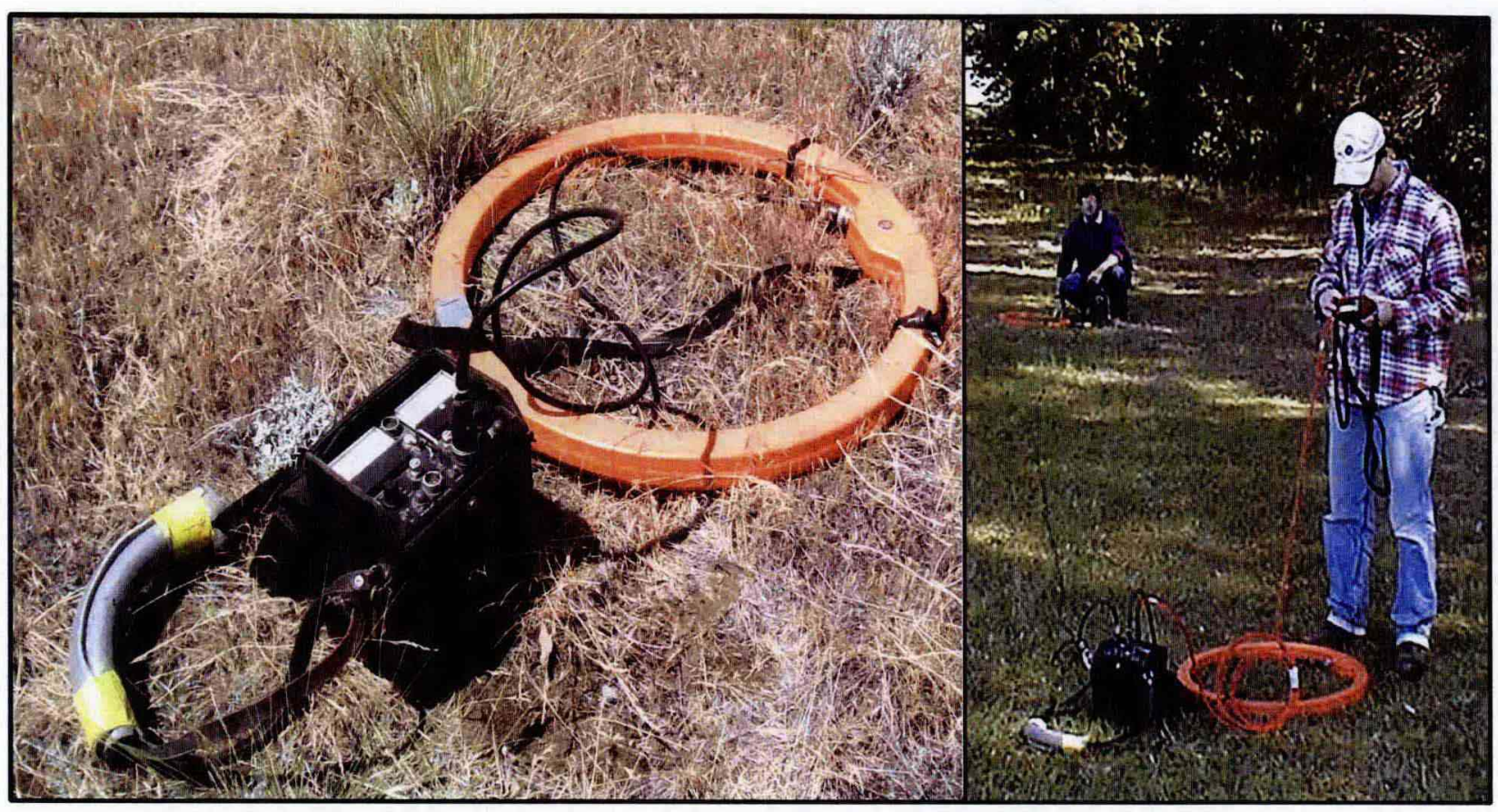

Figure A-8. Geonics EM-34 Instrument

The separation between the transmitter and receiver coils is the primary component that determines the depth of penetration. Table A-1 lists the depth of investigation for different coil orientations for the Geonics EM-34 instrument. The practical depth is roughly the depth at which 80 percent of the instrument response has occurred, and the effective depth range is the where the instrument's overall response is the greatest. Thus, layers within the effective depth range contribute most to the measured conductivity.

Table A-1. Effective Penetration Depth of the EM-34 Instrument

\begin{tabular}{cccc}
\hline Coil Separation & Coil Orientation & Investigative Depth & Effective Depth \\
\hline \multirow{2}{*}{$10 \mathrm{~m}$} & Horizontal Dipole & $7.5 \mathrm{~m}$ & $0 \mathrm{~m}$ to $6.5 \mathrm{~m}$ \\
& Vertical Dipole & $15 \mathrm{~m}$ & $1.5 \mathrm{~m}$ to $8 \mathrm{~m}$ \\
\multirow{2}{*}{$20 \mathrm{~m}$} & Horizontal Dipole & $15 \mathrm{~m}$ & $0 \mathrm{~m}$ to $13 \mathrm{~m}$ \\
& Vertical Dipole & $30 \mathrm{~m}$ & $3 \mathrm{~m}$ to $16 \mathrm{~m}$ \\
\multirow{2}{*}{$40 \mathrm{~m}$} & Horizontal Dipole & $30 \mathrm{~m}$ & $0 \mathrm{~m}$ to $26 \mathrm{~m}$ \\
& Vertical Dipole & $60 \mathrm{~m}$ & $6 \mathrm{~m}$ to $32 \mathrm{~m}$ \\
\hline
\end{tabular}

Conductivity values obtained in EM surveying represent weighted mean values of all the layer conductivities from the ground surface to the maximum depth that is sensed by the EM instrument (McNeill, 1980). If the underlying rock or sediment is uniform, the measured conductivity value will be the true conductivity. The amount of contribution to the measured conductivity from a single layer depends on its conductivity, depth, and thickness. In general, deeper layers contribute less to the final value than near-surface layers, as do layers outside the effective depth range. 


\section{A4.3 Electromagnetic Instrument Response}

Conductivity values obtained in EM surveying represent weighted mean values of all the conductivities from the ground surface to the maximum depth that is sensed by the EM instrument. The amount of contribution to the measured conductivity from a single layer depends on its conductivity, depth, and thickness. Deeper layers contribute less to the final weighted value than near-surface layers.

For a two-layer case (McNeill, 1980), the apparent conductivity measured at the surface in $\mathrm{mS} / \mathrm{m}$ by the EM instrument is:

$$
\sigma_{a}=\sigma_{1}[1-\mathrm{R}(z)]+\sigma_{2} \mathrm{R}(z)
$$

where:

$$
\begin{aligned}
& \sigma \mathrm{I}=\text { conductivity of the } \mathrm{i}^{\prime} \text { th layer (where } \mathrm{i} \text { is equal to } 1 \text { or } 2 \text { ) } \\
& \mathrm{z} \quad=\text { the depth to the second layer coil spacing }
\end{aligned}
$$

and

$$
\mathrm{R}(\mathrm{z})=\text { relative influence of the current flow for a given normalized depth }
$$

The value given by the function $\mathrm{R}(\mathrm{z})$ is dependent on the depth, coil orientation, and coil separation. For a vertical dipole $(\mathrm{v})$ orientation:

$$
R_{v}(z)=\frac{1}{\left(4 z^{2}+1\right)^{1 / 2}}
$$

and for the horizontal ${ }_{h}$ ) dipole orientation:

$$
R_{h}(z)=\left(4 z^{2}+1\right)^{1 / 2}-2 z
$$

where:

$$
\mathrm{z}=\text { layer depth/coil separation }
$$

When the terrain conductivity is measured using instrumentation with two or more coil separations (or coil orientations), the first equation can be used to estimate the conductivity contrast and approximate depth.

\section{A4.4 Processing the Electromagnetic Data}

The six measurement configurations were converted into one-dimensional layered earth models using the FREQEM program (Loke, 2006, "1-D Frequency Domain EM Modeling”). The program employs the digital filter method described by Koefoed et al., 1972, "Computation of Type Curves for Electromagnetic Depth Sounding with a Horizontal Transmitting Coil by Means of a Digital Linear Filter," and Guptasarma and Singh, 1997, "New Digital Linear Filters for Hankel J0 and J1 Transforms," to perform a damped, non-linear least-squares inversion on the EM-34 data (Lines and Treitel, 1984). An initial (or trial) model is iteratively updated (both layer thickness and electrical-conductivity) to reduce the difference between the measured and calculated data. An example of the FREQEM program output is shown in Figure A-9. Model layers are shown as green boxes, measured data as blue crosses, and modeled values as red crosses. The one-dimensional models are collated and used to construct a geo-electrical cross-section. 


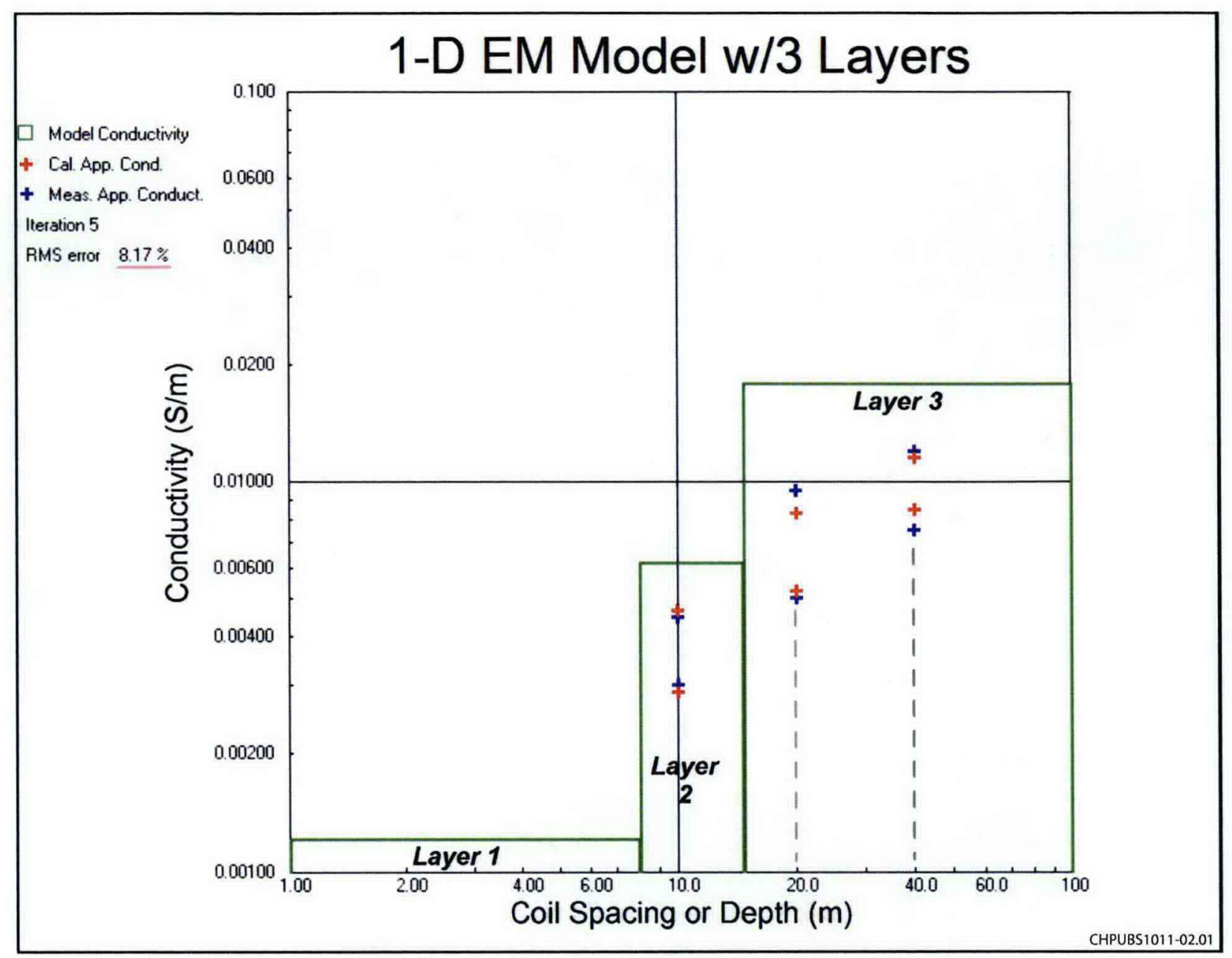

Figure A-9. One-Dimensional Frequency Domain 


\section{A5 References}

Advanced Geosciences, Inc., 2001, SuperSting R8 IP 8-Channel Memory Earth Resistivity and IP Meter Instrument Manual, Advanced Geosciences, Inc., Austin, Texas. Available at: http://www.agiusa.com/supersting.shtml.

Archie, G.E., 1942, "The Electrical Resistivity Log as an Aid in Determining Some Reservoir Characteristics," Petroleum Transactions 146:54-62.

ASTM D6431-99, 2010, Standard Guide for Using the Direct Current Resistivity Method for Subsurface Investigation, American Society for Testing and Materials, West Conshohocken, Pennsylvania.

ASTM D6639-01, 2001, Standard Guide for Using the Frequency Domain Electromagnetic Method for Subsurface Investigations, American Society for Testing and Materials, West Conshohocken, Pennsylvania.

deGroot-Hedlin, C. and S. Constable, 1990, "Occam's Inversion to Generate Smooth, Two-Dimensional Models from Magnetotelluric Data," Geophysics 55(12):1613-1624.

Geonics, 1991, EM-34 Operating Manual, Geonics Ltd., Mississauga, Ontario, Canada.

Guptasarma, D. and B. Singh, 1997, "New Digital Linear Filters for Hankel J0 and J1 Transforms," Geophysical Prospecting 45(5):745-762.

Hilchie, Douglas W., 1989, Advanced Well Log Interpretation, Society of Petroleum, Boulder, Colorado.

Koefoed, O., D.P. Ghosh, and G.J. Polman, 1972, "Computation of Type Curves for Electromagnetic Depth Sounding with a Horizontal Transmitting Coil by Means of a Digital Linear Filter," Geophysical Prospecting 20(2):406-420.

Lines, L.R. and S. Treitel, 1984, “A Review of Least-Squares Inversion and its Application to Geophysical Problems,” Geophysical Prospecting 32(2):159-186.

Loke, M.H. and R.D. Barker, 1996, "Rapid Least-Squares Inversion of Apparent Resistivity Pseudosections by a Quasi-Newton Method," Geophysical Prospecting 44(1):131-152.

Loke, M.H., 2006, “1-D Frequency Domain EM Modeling," FreqEM Software Manual, PugSoft, Inc., Penang, Malaysia.

Loke, M.H., 2010, "Rapid 2D Resistivity \& IP Inversion Using the Least-Squares Method," RES2DINV Version 3.59 Software Manual, GEOTOMO Software, Penang, Malaysia.

McNeill, J.D., 1980, "Electromagnetic Terrain Conductivity Measurements at Low Induction Numbers," Technical Note TN-6, Geonics, Ltd., Mississauga, Canada.

Sasaki, Yutaka, 1992, "Resolution of Resistivity Tomography Inferred from Numerical Simulation," Geophysical Prospecting 40(4):453-464. 
SGW-47996, REV. 0 